\title{
The Role of p21ras in Receptor Tyrosine Kinase Signaling
}

\author{
René H. Medema and Johannes L. Bos* \\ Laboratory for Physiological Chemistry, Utrecht University, Vondellaan 24A, 3521 GG Utrecht, \\ The Netherlands
}

* To whom all correspondence should be addressed.

\begin{abstract}
The notion that ras proteins are required for the stimulation of mitogenesis by different receptor tyrosine kinases (RTKs) has spurred researchers to investigate the precise role of $\mathrm{p} 21$ ras in signal transduction. A large number of stimuli can drive $\mathrm{p} 21$ ras in the active conformation, and several proteins that play an important role in regulating the GTP/GDP balance on $\mathrm{p} 21$ ras have been identified. Indeed, activation of p21ras has been demonstrated to occur by stimulation of guanine nucleotide-releasing proteins (GNRPs) or inhibition of GTPaseactivating proteins (GAPs). Moreover, a number of SH2-containing proteins have been implicated in this signaling pathway, such as shc and sem-5/grb2. On the other hand, downstream signaling from p21ras involves an important protein kinase cascade. This pathway seems to be conserved in evolution, and analogous routes have been described in organisms such as yeast, nematodes, and fruit flies. Nevertheless, the direct effector molecule of p21ras that could couple to this kinase cascade is still unknown. Some indications have been obtained that suggest that this function might be partially performed by p120GAP. This review gives an overview of the role of p21ras in signaling from diverse RTKs. Elucidation of this pathway will improve our understanding of mitogenic signaling pathways and the basis of cancer.
\end{abstract}

KEY WORDS: $\mathrm{p} 21$ ras signaling, receptor tyrosine kinases, $\mathrm{p} 21$ ras activation, SH2 domains, guanine nucleotidereleasing proteins, GTPase-activating proteins, kinase cascades, protein kinase $\mathrm{C}$, phospholipases.

\section{I. p21ras AS MOLECULAR SWITCH}

\section{A. ras Genes}

Ras genes were initially identified as the transforming genes of the Harvey and Kirsten rat sarcoma virus strains (Harvey, 1964; Kirsten and Mayer, 1967). The cellular homologs of these viral ras genes were subsequently isolated as dominant oncogenes by their ability to transform NIH3T3 cells after DNA transfection (Chang et al., 1982; Parada et al., 1982; Shih and Weinberg, 1982). In addition, a third ras oncogene, called $\mathrm{N}$-ras, was isolated from a neuroblastoma cell line (Hall et al., 1983; Shimizu et al., 1983). The transforming genes turned out to be mutated alleles of the normal cellular ras genes (protooncogenes) Reddy et al., 1982; Tabin et al., 1982). Oncogenic forms of $\mathrm{p} 21$ ras have been detected in a large variety of human tumors, and the trans- forming potential of the ras oncogenes can be attributed to a single amino acid substitution at position 12, 13, or 61 of the ras protein (reviewed by Bos, 1989).

The ras genes constitute a family of highly conserved genes that code for $21-\mathrm{kDa}$ proteins localized at the inner side of the plasma membrane (for a review, see Barbacid, 1987). The ras proteins can bind GTP and GDP with high affinity (Scolnick et al., 1979; Shih et al., 1980) and have intrinsic GTPase activity (McGrath et al., 1984; Sweet et al., 1984). By analogy with other GTP-binding proteins, such as EF-Tu (Jurnak, 1985), the ras proteins were proposed to function as molecular switches, cycling between an inactive GDP-bound state and an active GTP-bound state (reviewed by Bourne et al., 1990a). Based on radical changes in cellular growth that occur upon expression of oncogenic mutants of p21ras, the GTP-bound protein was most likely to have a

0893-9675/93/\$.50 
positive effect on cellular growth and differentiation. This hypothetical function was substantiated by a number of experimental observations. First, oncogenic p21 ras can induce morphological transformation and proliferation of NIH3T3 cells (Feramisco et al., 1984; Stacey and Kung, 1984), morphological differentiation of rat pheochromocytoma cells (PC12) (Bar-Sagi and Feramisco, 1985), and maturation of Xenopus laevis oocytes (Birchmeier et al., 1985). The GTPbound, but not the GDP-bound, form of p21ras seems to be responsible for the observed effects (Satoh et al., 1987; Trahey and McCormick, 1987). Second, oncogenic mutations in the ras protooncogenes invariably cause a loss of GTPase activity (McGrath et al., 1984; Sweet et al., 1984) or an increased GTP/GDP exchange rate (Feig and Cooper, 1988b; Sigal et al., 1986b), indicating that the transforming potential is a result of a higher steady-state level of the GTP-bound form of p21ras in the cell.

Mutational analysis of oncogenic forms of p21ras indicated that, apart from the regions essential for nucleotide binding, two other domains are indispensable for transformation: the so-called "effector region" (residues 32 to 40) (Sigal et al., 1986a; Willumsen et al., 1986) and an intact CAAX motif at the $C$ terminus of the protein, which is essential for membrane localization (Willumsen et al., 1984). Mutations in the effector region destroy the transforming ability of oncogenic ras mutants without altering the cellular localization, stability, and nucleotide-binding properties of the protein. Therefore, it has been proposed that the cellular effector of $\mathrm{p} 21$ ras binds to this region. Analysis of the crystal structures of the GDP- and GTP-bound forms of p21ras has shown that the most significant conformational differences that occur upon GTP hydrolysis are restricted to two regions of the protein that are exposed on the molecular surface (Milburn et al., 1990; Schlichting et al., 1990). One of these regions is the effector region, and it is plausible that the effector of p21ras binds specifically to GTPbound p21ras by recognition of these two regions. In addition, analysis of the crystal structure of p21ras has provided more insight in the mechanism of the GTPase reaction of p21ras. A water molecule is hydrogen-bound to the carbonyl of Thr35, which positions it directly opposite to the $\beta$-phosphate of the guanine nucleotide, ideal for a nucleophilic attack on the $\gamma$-phosphate (Pai et al., 1990). Oncogenic mutations in p21ras are thought to be unable to polarize this water molecule for attack on the $\gamma$-phosphate (Krengel et al., 1990), or thought to be less efficient at stabilizing the transition state of this reaction (Prive et al., 1992).

Membrane association of $\mathrm{p} 21$ ras requires posttranslational processing, starting with polyisoprenylation (farnesylation) of the cysteine residue of the CAAX motif (Casey et al., 1989; Hancock et al., 1989), followed by proteolytic cleavage of the last three amino acids (Gutierrez et al., 1989) and methylation of the newly formed $\alpha$-carboxyl group of the cysteine residue (Clarke et al., 1988; Gutierrez et al., 1989). These modifications are stable and allow some low-avidity membrane binding and biological activity (Hancock et al., 1989). In addition, p21ras requires palmitylation at cysteine residues located immediately upstream of the CAAX motif [H-ras, $\mathrm{N}$-ras, or K-ras(A)] (Buss and Sefton, 1986; Magee et al., 1987), or a polybasic domain [K-ras(B)] (Hancock et al., 1991a, b), for efficient membrane binding. Palmitylation increases the avidity of membrane binding, but the palmityl group has a half-life of $\sim 20 \mathrm{~min}$ (Magee et al., 1987), indicating that high-affinity membrane binding of p21ras is unstable, which suggests that the localization of p21ras is subject to some kind of control mechanism.

Because polyisoprenylation is a prerequisite for the transforming potential of oncogenic forms of 221 ras, investigators have aimed at pharmacological approaches to control the farnesylation of p21ras (reviewed by Gibbs, 1991). Drugs that inhibit the biosynthesis of mevalonate, a precursor of sterols and other isoprenes such as farnesyl pyrophosphate, were shown to block the effects of oncogenic forms of $\mathrm{p} 21$ ras in X. laevis oocytes (Schafer et al., 1989) and PC12 cells (Mendola and Backer, 1990). However, mevalonate is an important precursor for many other isoprenoid derivatives (Goldstein and Brown, 1990), and it seems unlikely that general inhibitors of mevalonate synthesis will provide fruitful anticancer reagents. Indeed, lovastatin, which can block the isoprenylation of $\mathrm{p} 21 \mathrm{ras}$, inhibits cell growth, but does so independent of the function of $\mathrm{p} 21 \mathrm{ras}$ (DeClue et al., 1991a). A more selective approach 
would be to inhibit the enzyme(s) required for farnesylation of p21ras. A protein-farnesyltransferase has been purified from rat brain (Reiss et al., 1990), and specific inhibitors have been designed (Goldstein et al., 1991; Reiss et al., 1990). Still, this approach does not distinguish active oncogenic p2lras from normal p21ras or other proteins that are farnesylated, which is a major drawback for possible drug therapy. Nevertheless, the finding that certain oncogenic forms of p21 ras that no longer have the CAAX motif can function as dominant-negative mutants (Gibbs et al., 1989; Medema et al., 1991 b; Michaeli et al., 1989 ) is reason for optimism. These dominantnegative mutants presumably couple efficiently to the effector molecule and can trap it in the cytosol, thereby blocking the formation of a functional complex at the membrane. Moreover, it has been shown that oncogenic forms of p21ras are more sensitive to this type of inhibition than normal p21 ras (Farnsworth et al., 1991; Stacey et al., 1991). In addition, nonprocessed oncogenic forms of $\mathrm{p} 21$ ras are the most potent interfering mutants inasmuch as oncogenic forms of p21ras will bind the effector more efficiently than wild-type p21 ras. Thus, (a partial) inhibition of farnesylation is expected to have a profound effect on cells that express oncogenic $\mathrm{p} 21$ ras, whereas normal cells would be less affected.

\section{B. The ras Cycle}

The balance between GTP- and GDP-bound p21ras is controlled by its GTPase activity, as well as the exchange of GDP for GTP. This is exemplified by the transforming potential of mutations that affect either one of these characteristics (Feig and Cooper, 1988b; Sigal et al., 1986b). However, the intrinsic GTPase activity of p21 ras and the dissociation rate for GDP are very slow, which activated a search for factors that could accelerate these steps to ensure rapid cycling of p21ras in the cell. Two classes of regulatory proteins have been identified: GTPase-activating proteins (GAPs), which accelerate GTP hydrolysis, and guanine nucleotide-releasing proteins (GNRPs or exchange factors), which facilitate the release of bound GDP that, under the conditions prevailing in the cytoplasm, is most likely to result in the binding of GTP (for a review, see Boume et al., 1990b). Therefore, two control mechanisms for the activation state of $\mathrm{p} 21$ ras exist, either through regulation of GAP activity or through regulation of the activity of GNRP (Figure 1). The existence of these factors enables p21ras to respond rapidly to incoming signals and at the same time makes it possible for the signal to be quickly shut off, which is a prerequisite for efficient signal transduction.

Until now, two different proteins with GAP activity for p21ras have been identified in mammalian cells: p120GAP (Gibbs et al., 1988; Trahey et al., 1988; Vogel et al., 1988) and the product of the neurofibromatosis type 1 (NF-1) gene (Ballester et al., 1990; Cawthon et al., 1990; Martin et al., 1990; Viskochil et al., 1990; Wallace et al., 1990; Xu et al., 1990a). p120GAP was first identified as an abundant cytoplasmic factor for Xenopus oocytes with the ability to stimulate the GTPase activity of p21ras (Trahey and McCormick, 1987). The p120GAP protein fails to stimulate the hydrolysis of GTP on oncogenic mutants of p21ras, although the physical interaction between the two proteins was judged to be normal on the basis of competition experiments (Vogel et al., 1988). The effect of p120GAP on p21ras suggests that it functions as a negative regulator of $\mathrm{p} 21$ ras. The finding that overexpression of p120GAP can suppress transformation of NIH3T3 cells by normal Ha-ras supports this notion (Zhang et al., 1990). Also, overexpression of p120GAP reduces the level of GTP-bound p21ras in unstimulated as well as platelet-derived growth factor (PDGF)-stimulated cells (Gibbs et al., 1990). In addition to this negative regulatory function, p120GAP also may be required for p21ras effector function because it binds to the effector region (Adari et al., 1988; Cales et al., 1988).

The NF-1 gene was cloned by different groups as the gene affected in patients suffering from von Recklinghausen neurofibromatosis (Cawthon et al., 1990; Viskochil et al., 1990; Wallace et al., 1990). The sequence showed significant similarity to p120GAP in the region known to be essential for interaction with ras proteins, and subsequent experiments with recombinant $\mathrm{NF}-1$ protein (neurofibromin) showed that it also could function as a negative regulator of $\mathrm{p} 21$ ras 


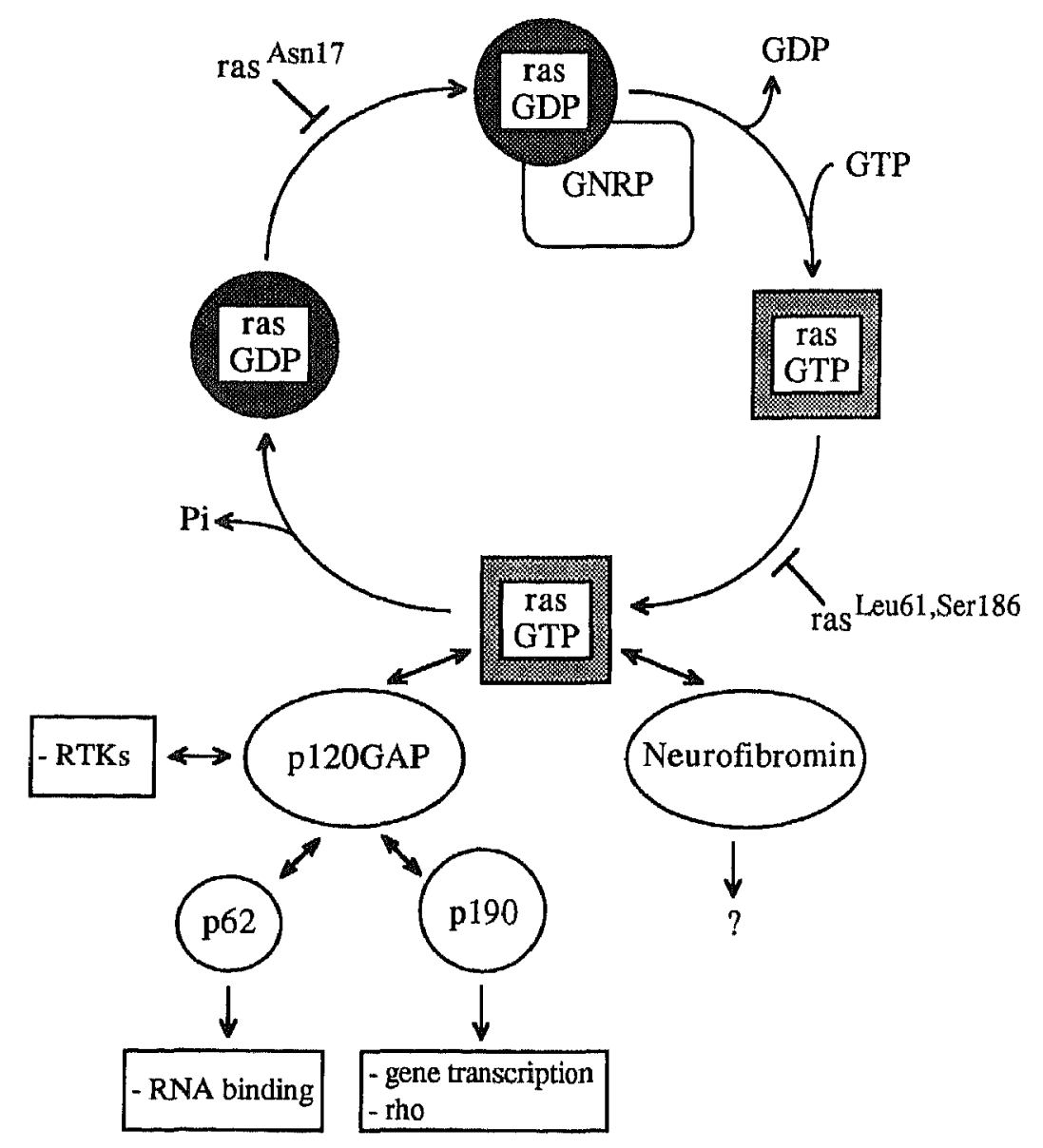

FIGURE 1. The p21ras cycle. Schematic representation of the cycling of p21 ras between the inactive GDP-bound conformation and the active GTPbound conformation. GTP/GDP exchange and GTP hydrolysis on p21 ras are relatively slow events. The exchange of GTP for GDP on p21 ras is catalyzed by a GNRP (guanine nucleotide-releasing protein), and GTP-hydrolysis by p21ras is accelerated by two different GAPs (GTPase-activating proteins): p120GAP and neurofibromin. The ratio between $\mathrm{p} 21$ ras-GDP and ras-GTP is therefore determined by the activity of the GNRPs compared to that of the GAPs. Accumulation of p21ras-GTP may be a consequence of an acceleration of the GTP/GDP exchange as a result of activation of GNRP. Alternatively, inactivation of the GAPs would result in slower GTP hydrolysis, which also would amount to an increase in p21ras-GTP. The active GTP-bound conformation of p21ras interacts with the effector molecule, which may be either p120GAP or NF-1. Potential targets of the p21ras-p120GAP complex are indicated, such as: the activated RTKs (shown to bind p120GAP), p62 (an RNA-binding protein), p190 (which has GAP activity for the rho-family of small GTP-binding proteins and homology with the glucocorticoid repressor).

(Ballester et al., 1990; Martin et al., 1990; Wallace et al., 1990; Xu et al., 1990b). Neurofibromin binds p21ras with a much higher affinity than p120GAP, indicating that it could be a more significant regulator of $\mathrm{p} 21$ ras than $\mathrm{p} 120 \mathrm{GAP}$, considering the concentration of p21ras in the cell (Bollag and McCormick, 1991). Indeed, a reduction in the level of expression of neurofibromin in
Schwannoma cells results in an elevation of the level of GTP-bound p21ras, although the expression of p120GAP is normal (Basu et al., 1992; DeClue et al., 1992). Low basal levels of p21rasGTP in these cells could be restored by overexpression of the catalytic domain of p120GAP, indicating that p120GAP also can function as a negative regulator when present in high amounts. 
Nevertheless, one could argue whether p120GAP functions as a true negative regulator of $\mathrm{p} 21$ ras in vivo. The action of p120GAP in vitro is blocked by physiological salt concentrations (Gibbs et al., 1988), and interference with p21ras signaling has only been observed when p120GAP is expressed at high levels (Bortner et al., 1991; DeClue et al., 1991b; Nori et al., 1991). At this point, a regulatory function for p120GAP should definitely not be excluded, nor should it be taken for granted.

Several groups have reported the identification and partial purification of exchange factors from mammalian cells with the ability to stimulate the release of GDP for recombinant ras proteins. First, a cytosolic protein with a molecular size between 100 and $160 \mathrm{kDa}$, which is active on ras proteins but not on other small GTP-binding proteins, was purified from rat brain (Wolfman and Macara, 1990). Second, a cytosolic protein of about $60 \mathrm{kDa}$, which also specifically stimulates the rate of guanine nucleotide exchange of several ras proteins, was purified from human placenta (Downward et al., 1990b). Third, a membraneassociated protein with similar activity was purified from bovine brain (West et al., 1990). However, this membrane-associated protein of $35 \mathrm{kDa}$ increased the exchange of guanine nucleotides on all small GTP-binding proteins that were tested (Huang et al., 1990).

More recently, several (putative) mammalian GNRPs for p21ras were cloned by homology to yeast Saccharomyces cerevisiae and Drosophila melanogaster ras GNRPs. In $S$. cerevisiae, genetic and biochemical evidence indicate that the CDC25 gene product is the major GNRP for RAS (Broek et al., 1987; Jones et al., 1991), and in D. melanogaster, the son of sevenless (SOS) gene product has been identified genetically as the potential GNRP for rasI (Bonfini et al., 1992; Rogge et al., 1991; Simon et al., 1991). The first mammalian GNRP shown to be specific for $\mathrm{p} 21$ ras (Ras-GRF) was cloned by homology to CDC25 from a rat brain library (Shou et al., 1992). Antibodies against the protein product detected a protein of $140 \mathrm{kDa}$ in brain cytosol, similar to the molecular weight of a mammalian protein that cross-reacts with anti-CDC25 polyclonal antibodies (Gross et al., 1992b). The expression of RasGRF appeared to be brain specific. Others cloned a mammalian CDC25 homolog (type I CDC25 ${ }^{\mathrm{Mm}}$ ) by functional complementation of yeast $\mathrm{CDC} 25-$ minus mutants with a mouse cDNA expression library (Martegani et al., 1992). The predicted protein encoded by this partial cDNA contains a region of 234 amino acids with $34 \%$ homology to $\mathrm{CDC} 25$, and a recombinant protein that contains this region was later shown to stimulate guanine nucleotide exchange on p21ras (Jacquet et a1., 1992). Multiple full-length cDNAs were subsequently isolated from a mouse brain cDNA (type II to IV CDC25 $\mathrm{Mm}$ ), and these CDC25-like cDNAs also seem to be expressed in a brain-specific manner, although small amounts of mRNA could be detected in other tissues, such as heart and liver (Cen et al., 1992). Analysis of the type IV CDC25 ${ }^{\mathrm{Mm}}$ cDNA revealed that it is the murine homolog of Ras-GRF from rat. Antibodies raised against a peptide encoded by all types of CDC25 $\mathrm{Mm}$ cDNAs detected proteins of 75 and $95 \mathrm{kDa}$ in NIH3T3 cells. In addition, two putative mammalian GNRPs for p21ras have been cloned by homology to SOS from a mouse eye cDNA library ( $m$ Sos 1 and $\mathrm{mSos} 2$ ) and these seem to be expressed ubiquitously (Bowtell et al., 1992). However, evidence that their gene products can specifically enhance the exchange of guanine nucleotides on p21ras has not yet been provided. Finally, smg p21 GDS (GDP dissociation stimulator), originally cloned as GNRP for two ras-related small GTP-binding proteins, smg p21 $\mathrm{A}$ and $B$ (or rap1A and rap1B), also can stimulate exchange on $\mathrm{p} 21 \mathrm{~K}$-ras $4 \mathrm{~B}$, but not $\mathrm{p} 21 \mathrm{Ha}$-ras, $\mathrm{p} 21 \mathrm{~N}$ ras, or p2 1K-ras4A (Kaibuchi et al., 1991; Mizuno et al., 1991). Thus, it appears that a class of mammalian GNRPs for $\mathrm{p} 21$ ras exists with a tissuespecific distribution.

Remarkably, in addition to the homology with $\mathrm{CDC} 25$ in the C-terminal region of the proteins encoded by Ras-GRF and type IV CDC $25^{\mathrm{Mm}}$, a 241-amino acid domain near the $\mathrm{N}$ terminus shares homology with the human breakpoint cluster region (bcr) protein (Hariharan and Adams, 1987), the vav oncogene product (Bustelo et al., 1992; Katzav et al., 1989; Margolis et al., 1992), and the dbl oncogene product (Ron et al., 1988) (Figure 2). The latter proteins are assumed to regulate raslike small GTP-binding proteins. Bcr encodes a GAP protein for p21rac (Diekmann et al., 1991) that is involved in growth factor-induced membrane ruffling (Ridley et al., 1992). The region of 




dbl-like homology
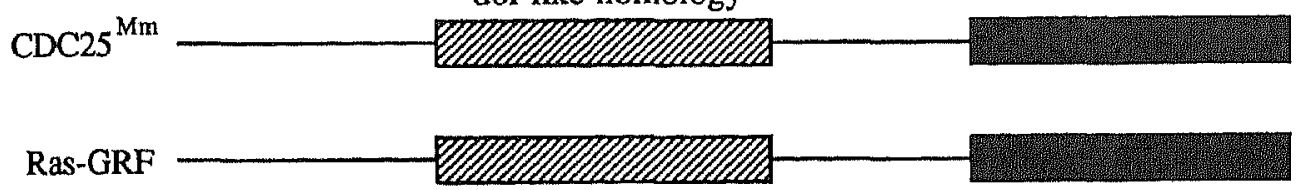

$\mathrm{dbl}$

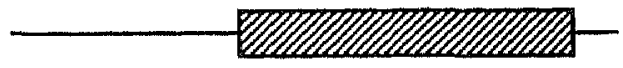

bcr

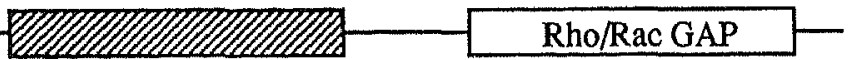

vav

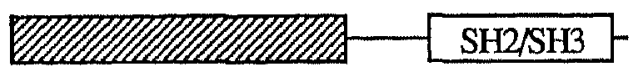

CDC24

FIGURE 2. Homologous regions in guanine nucleotide-releasing proteins (GNRPs). (Putative) GNRPs for p21ras and ras-like proteins from Saccharomyces cerevisiae (CDC25, SDC25, CDC24), Schizosaccharomyces pombe (ste6), Drosophila (SOS) and mammals (Ras-GRF, CDC25 $\mathrm{Mm}, \mathrm{dbl}, \mathrm{bcr}$, and vav), and their homologous domains. Boxes of CDC25-like homology are represented by black boxes; dbl-like homology is indicated by hatched boxes. In addition, the $\mathrm{SH} 2 / \mathrm{SH} 3$ domains in vav and the region of bor that is involved in stimulating the GTPase activity of Rho- and Rac-like proteins are indicated.

ber that is important for this activity is distinct from the region of homology shared with $\mathrm{dbl}$ and the ras GNRPs. The dbl oncogene appears to be the mammalian homolog of $\mathrm{CDC} 24$ from $S$. cerevisiae and has been shown to encode a GNRP for CDC42Hs (Hart et al., 1992), which is closely related to the rac and rho proteins (Munemitsu et al., 1990). Therefore, it is possible that Ras-GRF is active on different members of the ras superfamily, allowing cross-talk between different signaling pathways. Such cross-talk also is possible at the level of the GAP proteins inasmuch as p120GAP has been shown to associate with a protein of $190 \mathrm{kDa}$ (Ellis et al., 1990), which has a region of similarity with bcr (Settleman et al., 1992b). The 190-kDa protein has been shown to have GAP-like activity for the rho family of small GTP-binding proteins (Settleman et al., 1992a).
Therefore, the activation state of a number of small GTP-binding proteins may be tightly linked through bifunctionality, or direct interaction, of their regulatory proteins. Such a fine-tuning of small GTP-binding proteins has been observed in the case of rac and tho, where growth factorinduced activation of p21rac seems to drive activation of p21rho (Downward, 1992; Ridley and Hall, 1992; Ridley et al., 1992).

\section{C. ras-Mediated Effects}

The transforming potential of oncogenic forms of $\mathrm{p} 21$ ras and the similarity to the heterotrimeric $G$ proteins involved in signal transduction implies that ras proteins function in signal transduction pathways that control cell proliferation. This hy- 
pothesis was initially tested by microinjection of recombinant ras proteins to analyze the direct effects of p21ras on different cell types. Such an approach has the advantage that long-term and indirect effects of transformation that occur after introduction of oncogenic p21 ras by DNA transfection can be disregarded. In NIH3T3 cells, microinjection of $\mathrm{p} 21$ ras causes morphological transformation and stimulation of DNA synthesis in the absence of growth factors (Feramisco et al., 1984; Stacey and Kung, 1984). Also, a large variety of other effects have been reported, such as membrane ruffling (Bar-Sagi and Feramisco, 1986), induction of c-fos expression (Stacey et al., 1987), maturation and stimulation of diacylglycerol (DAG) production in $X$. laevis oocytes (Birchmeier et al., 1985; Lacal et al., 1987b), and differentiation of PC12 cells (Bar-Sagi and Feramisco, 1985; Noda et al., 1985). Because microinjection is rather laborious and only a limited number of cells can be studied, scrape loading of p21ras into quiescent cells was used to study the role of $\mathrm{p} 21$ ras in the activation of cellular kinases. Scrape loading of active p21ras in Swiss 3 T3 cells leads to the activation of protein kinase C (PKC) (Morris et al., 1989), induction of c-myc expression (Lloyd et al., 1989), and DNA synthesis (Morris et al., 1989). In addition, rapid activation of extracellular signal-regulated kinases (erks) was observed after scrape loading of oncogenic p21ras (Leevers and Marshall, 1992). These findings indicated that active p21ras can indeed mimic the action of growth factors, suggesting that $\mathrm{p} 21$ ras functions as a mediator of their message.

To analyze which cellular stimuli actually require the function of $\mathrm{p} 21$ ras for efficient signal transduction, a monoclonal antibody (Y13-259) that can neutralize the function of p21ras was used in microinjection experiments. Microinjection of Y13-259 has shown that the function of p21ras is required for growth factor-induced cell proliferation (Mulcahy et al., 1985) and transformation by a number of viral oncogenes (Smith et al., 1986). In X. laevis oocytes, ras proteins are required for insulin-induced maturation (Korn et al., 1987), and in PC12 cells, NGF-induced differentiation is blocked by microinjection of Y13259 (Hagag et al., 1986). An alternative approach to elucidate the involvement of p21ras in certain signaling routes was made possible by the isolation of a mutant of p21ras with the ability to inhibit cellular p21ras function in vivo (Feig and Cooper, 1988a). This dominant inhibitory mutant, p21ras(Asn 17), has a reduced affinity for GTP, and therefore is locked in the inactive state. Its inhibitory potential is thought to be a consequence of a constitutive association of the GNRP with $\mathrm{p} 21 \mathrm{ras}$, forming an inactive complex, thereby blocking the activation of normal p21ras (Farnsworth and Feig, 1991). Recently, direct proof that this mutant inhibits the activation of p21 ras by different extracellular stimuli has been obtained (Medema et al., 1993). Expression of p21ras(Asn17) inhibits proliferation of normal and v-src-transformed NIH3T3 cells (Feig and Cooper, 1988a). Also, p21ras(Asn17) has been used to show a requirement for $\mathrm{p} 21$ ras in NGF-induced differentiation of PC12 cells (Szeberényi et al., 1990), growth factor-induced stimulation of DNA synthesis (Cai et al., 1990), and growth factorinduced fos expression in NIH3T3 cells (Cai et al., 1990; Medema et al., 1991b). Furthermore, induction of interleukin (IL)-2 expression in response to protein kinase $\mathrm{C}$ and $\mathrm{T}$-cell receptor stimulation in $\mathrm{T}$ lymphoblasts is inhibited in cells expressing p21ras(Asn17) (Rayter et al., 1992). Recently, the activation of extracellular signalregulated kinases (erks), raf-1 kinase, and a ribosomal S6 kinase (pp90rsk) by a variety of growth factors was shown to require the function of $\mathrm{p} 21 \mathrm{ras}$ by making use of p21ras(Asn17) (de Vries-Smits et al., 1992; Thomas et al., 1992; Wood et al., 1992). Another dominant inhibitory mutant of p21ras, p21ras(Leu61Ser186), which apparently interferes with binding of the effector molecule to active p21ras at the cell membrane, inhibits insulin-induced maturation of $X$. laevis oocytes and insulin-induced gene expression (Gibbs et al., 1989; Medema et al., 1991b). Altogether, these observations place p21ras at a crucial point in signaling pathways that regulate proliferation and differentiation. Ras proteins apparently exert their effects through activation of cellular kinases and induction of the expression of certain early response genes. The most straightforward cascade of events would be activation of p21ras in response to these extracellular stimuli, in turn causing activation of cellular kinases. However, based on the experiments described earlier, it also is 
possible that $\mathrm{p} 21$ ras activation is not a direct consequence of these extracellular stimuli, but that manifestation of their effects requires the function of $\mathrm{p} 21$ ras in a separate pathway.

\section{II. p21ras IN RECEPTOR TYROSINE KINASE SIGNALING}

\section{A. Activation of p21ras}

Although a requirement for $\mathrm{p} 21$ ras activity in RTK signaling had been proposed as early as 1986 on the basis of experiments with neutralizing antibodies against p21 ras (Smith et al., 1986), no direct evidence for activation of $\mathrm{p} 21$ ras by these RTKs was available for some time. The first reports that external signals control the activation state of p21ras came from different groups; one group used stimulation of the antigen receptor of $\mathrm{T}$ lymphocytes to induce a rapid and dramatic activation of p21ras (Downward et al., 1990a), whereas others showed that PDGF and serum can cause a small but consistent increase in the level of p21ras-GTP (Gibbs et al., 1990; Satoh et al., 1990b). Since then, a variety of extracellular stimuli have been shown to cause an activation of p21ras. Epidermal growth factor (EGF) (Osterop et al., 1993; Satoh et al., 1990a), insulin (Burgering et al., 1991), thrombin, and lysophosphatidic acid (LPA) (van Corven et al., 1993) were shown to drive $\mathrm{p} 21$ ras into its active conformation in fibroblasts. Also, in cells carrying activated oncogenes with tyrosine kinase activity, such as v-src, v-abl, or erbB2/neu, the levels of p21ras-GTP are increased (Gibbs et al., 1990; Satoh et al., 1990a). In PC12 cells, NGF and EGF induce an accumulation of the GTP-bound conformation of p21ras (Qiu and Green, 1991). This also can be achieved by stimulation of PC12 cells with fibroblast growth factor (FGF), insulin, insulin-like growth factor (IGF)-1, and IL-6, but only in the presence of sodium vanadate (Nakafuku et al., 1992). In addition, many cytokines, including IL-2, IL-3, IL-5 (Duronio et al., 1992), granulocyte/macrophage colony-stimulating factor (GM-CSF) (Satoh et al., 1991), erythropoietin (Torti et al., 1992), and steel factor (Duronio et al., 1992), activate p21ras in hematopoietic cells. Also, stimulation of epithelial cells with transforming growth factor- $\beta$
(TGF $\beta$ ) results in activation of $\mathrm{p} 21$ ras (Mulder and Morris, 1992). Most recently, a relatively slow, but dramatic activation of p21ras was observed in response to UV irradiation (Devary et al., 1992). Activation of $\mathrm{p} 21$ ras by a specific extracellular stimulus appears to be independent of the cell type inasmuch as transfection of the IL-2 receptor into a murine myeloid progenitor cell line conferred IL-2 responsiveness to these cells with respect to p21 ras activation (Izquierdo et al., 1991). Similarly, EGF stimulation of a myeloid cell line containing a stably transfected EGF receptor resulted in activation of p21ras (Satoh et al., 1991). It is clear that activation of p21 ras can occur in response to a large variety of extracellular stimuli, which indicates that they share at least some common intracellular pathways. This is somewhat surprising because the growth regulatory receptors through which these different factors signal and the respective cellular responses they elicit are rather diverse.

\section{B. Mechanism of Activation}

Activation of $\mathrm{p} 21$ ras in response to triggering of a growth regulatory receptor could occur through two basically different mechanisms. First, by analogy with receptor-coupled $G$ proteins, agonist binding could stimulate GTP/GDP exchange. Conversely, growth factors may cause an inactivation of GAP activity. In T lymphocytes, activation of p21ras by the TCR and CD2 antigens correlates well with a decrease in GAP activity measured in cell extracts (Downward et al., 1990a; Graves et al., 1991). Also, erythropoietin treatment of human erythroleukemia cells causes inhibition of in vitro GAP activity, although the timing of this inhibition does not exactly coincide with the time course of p21ras activation (Torti et al., 1992). Remarkably, the exchange of nucleotides onto $\mathrm{p} 21$ ras in permeabilized $\mathrm{T}$ lymphocytes is very rapid, both in quiescent and stimulated cells, suggesting that a constitutively active GNRP is present in these cells (Downward et al., 1990a). In contrast, in fibroblasts, no evidence for an inactivation of GAP activity in response to different growth factors has been obtained, suggesting a different mechanism of activation. Indeed, activation of nucleotide exchange is (at least 
partially) responsible for insulin- and EGF-induced activation of p21 ras (Medema et al., 1993). Also, NGF-induced activation of p21 ras correlates with an increase in membrane-associated exchange activity, although this activity may not be ras specific and may coincide with a matching increase in GAP activity (Li et al., 1992). Indirect evidence also has suggested that activation of p21ras in response to serum or PDGF is mediated by enhanced nucleotide exchange rather than by inactivation of GAPs (Zhang et al., 1992). Therefore, the intracellular pathway that eventually leads to activation of $\mathrm{p} 21$ ras seems to be dependent on the type of receptor that is causing the effect.

Diversity in the mechanism by which activation of $\mathrm{p} 21$ ras can occur also is illustrated by the fact that PKC can regulate $\mathrm{p} 21$ ras in $\mathrm{T}$ lymphocytes, whereas a non-PKC-dependent pathway has been proposed to cause activation of p21ras in response to insulin (Medema et al., 1991a), PDGF (Molloy et al., 1992), IL-2 (Izquierdo et al., 1991), and NGF (Nakafuku et al., 1992). Moreover, PKC activation by the phorbol ester 12-O-tetradecanoylphorbol-13-acetate (TPA) in fibroblasts does not result in activation of $\mathrm{p} 21$ ras (Medema et al., 1991a). The TCR-induced activation of p21 ras is mediated only partially by PKC, and an alternative pathway independent of PKC coexists in $\mathrm{T}$ cells (Izquierdo et al., 1992). This PKC-independent pathway also causes a reduction in GAP activity and is sensitive to tyrosine kinase inhibitors.

Tyrosine phosphorylation seems to be an important event for $\mathrm{p} 21$ ras activation by all growth regulatory factors studied thus far. For example, tyrosine kinase inhibitors can block activation of p21ras by NGF, EGF (Qiu and Green, 1991), steel factor, IL-3 (Duronio et al., 1992), erythropoietin (Torti et al., 1992), phorbol esters, IL-6 (Nakafuku et al., 1992), and LPA (van Corven et al., 1993). Activation of p21ras by insulin, EGF, and LPA is inhibited by phenylarsine oxide, a putative tyrosine phosphatase inhibitor (Medema et al., 1991a; Medema and Bos, unpublished observations). Tyrosine kinase activity also seems to be one of the initial events in TCR signaling. Although the T-cell receptor (TCR) itself has no tyrosine kinase activity, a large body of evidence indicates that it is functionally coupled to nonreceptor tyrosine kinases in $\mathrm{T}$ cells (reviewed in Klausner and Samelson, 1991) (Figure 3). Among the candidates are p56lck and p59fyn, two tyrosine kinases of the src family, and ZAP70 , a tyrosine kinase of $70 \mathrm{kDa}$ that associates to the $\zeta$-subunit of the TCR in response to receptor activation (Chan et al., 1992). As already mentioned, the PKC-independent pathway that causes p21 ras activation in response to TCR activation is inhibited by a tyrosine kinase inhibitor (Izquierdo et al., 1992). Therefore, a tyrosine phosphorylation/dephosphorylation cascade could very well precede activation of $\mathrm{p} 21$ ras.

Clearly, signaling via p21ras is a common pathway for many growth regulatory factors. However, variations exist in the mechanism of ras activation, as well as the persistence and extent of activation. For instance, some growth regulatory



FIGURE 3. T-cell receptor signaling via nonreceptor tyrosine kinases. The T-cell receptor complex, composed of an $\alpha \beta$ heterodimer, associated with a number of CD3 polypeptides - a $\zeta \zeta$ homodimer ( $\zeta$-module) and a $\delta \varepsilon$ and $\gamma \varepsilon$ heterodimer ( $\varepsilon$-module) (see Abraham et al., 1992 , for a review) - is activated upon binding of the antigen-major histocompatibility complex. This binding results in activation of nonreceptor tyrosine kinases p56lck (which associates to the CD4 and CD8 molecules), p59fyn, and ZAP-70 (which associates to the $\zeta$-subunits). Efficient coupling of TCR activation to p56lck and p59fyn activation is dependent on the dephosphorylation of p56lck and p59fyn by the transmembrane tyrosine phosphatase CD45. Activation of this signaling complex results in activation of PLC- $\gamma$, PKC, p21 ras (via inhibition of GAP activity), rat-1 kinase, and erk1. 
factors seem to exert their effect on $\mathrm{p} 21$ ras through inactivation of GAP activity (Downward et al., 1990a; Torti et al., 1992), whereas others can activate exchange factors ( $\mathrm{Li}$ et al., 1992a; Medema et al., 1993), but it is possible that a combination of both is required for the full effect. Also, the increase in p21ras-GTP can be very transient, as is the case for thrombin-induced ras activation in CCL39 cells (van Corven et al., 1993), but on the other hand, insulin-induced ras activation can persist for more than $1 \mathrm{~h}$ (Osterop et al., 1993). Finally, activation of p21 ras in response to T-cell activation results in 50\% of total p21 ras complexed to GTP (Downward et al., 1990a), but PDGF stimulation of NIH3T3 cells causes only $15 \%$ of total p21 ras to bind GTP (Gibbs et al., 1990). Thus, the mechanism of activation of $\mathrm{p} 21$ ras and the ultimate effect on $\mathrm{p} 21$ rasGTP levels seem to be dependent on the stimulus and the cell type under investigation.

\section{Receptor Tyrosine Kinase}

Some of the early events that occur upon RTK activation have been studied extensively. Receptors with tyrosine kinase activity possess a glycosylated extracellular ligand-binding domain, a single hydrophobic transmembrane region, and a cytoplasmic domain that contains a tyrosine kinase catalytic domain. The IGF- and insulinreceptor tyrosine kinases are somewhat exceptional because they preexist as a disulfide-stabilized receptor dimer of two $\alpha \beta$ chains. Ligand binding to its cognate RTK triggers a large number of cellular responses, eventually leading to a stimulation of cell proliferation. Depending on the cell type and the type of receptor, these effects include stimulation of tyrosine kinase activity, stimulation of serine/threonine kinase activity, elevation of intracellular $\mathrm{Ca}^{2+}$ concentration, activation of phospholipase C- $\gamma$ (PLC- $\gamma$ ), activation of phosphatidylinositol-3'-kinase (PI3K), increased phosphatidylinositol turnover, stimulation of glucose and amino acid transport, and stimulation of $\mathrm{Na} / \mathrm{H}$ antiport activity (Yarden and Ullrich, 1988) (Figure 4). The tyrosine kinase domain of all RTKs and nonreceptor tyrosine kinases contains a consensus sequence, GlyXGlyXXGlyX(15-
20)Lys, that functions as part of the binding site for ATP, which is the phosphate donor for the kinase reaction (Hanks et al., 1988). Replacement of the lysine residue in this consensus in PDGF, EGF, and insulin receptors completely abolishes their kinase activity (Chen et al., 1987; Chou et al., 1987; Ebina et al., 1987; Escobedo et al., 1988; McClain et al., 1987). Although ligandbinding characteristics are normal, these kinaseminus mutants are not mitogenic when transfected into cells (Chen et al., 1987; Chou et al., 1987; Honegger et al., 1987; Williams, 1989). In addition, many ligand-induced effects appear to be dependent on the tyrosine kinase activity of the receptor (Escobedo et al., 1988; Glenney et al., 1988; Honegger et al., 1987; Moolenaar et al., 1988; Russell et al., 1987; Westermark et al., 1990). This indicates that the activation of tyrosine kinase activity is the first event in the signaling cascades initiated by RTKs. Activation of these cascades will eventually lead to proliferation, an event that seems to require the function of p21 ras. Other receptors that lack intrinsic tyrosine kinase activity, such as the $\mathrm{T}$-cell receptor, are thought to be linked to nonreceptor tyrosine kinases. The events that occur upon activation of members of the nonreceptor tyrosine kinases, e.g., c-src, show many similarities to those observed in response to activated RTKs (Cantley et al., 1991). However, here we limit ourselves to a discussion of signaling pathways initiated by RTKs.

The tyrosine kinase activity of RTKs is stimulated by ligand binding to the extracellular domain, which induces dimerization (except for the IGF and insulin receptors). The adjacent cytosolic domains will then cross-phosphorylate each other on tyrosine residues, causing a conformational change that presumably enhances kinase activity (Schlessinger, 1988). In the case of the IGF and insulin receptor, ligand binding is thought to cause a conformational change in the extracellular domain and, consequently, a conformational change in the cytosolic domain could result in kinase activation (Ullrich and Schlessinger, 1990). Upon agonist binding, RTKs will autophosphorylate on specific tyrosine residues and phosphorylate a panel of cellular substrates that control distinct signaling pathways, including activation of p21ras. 


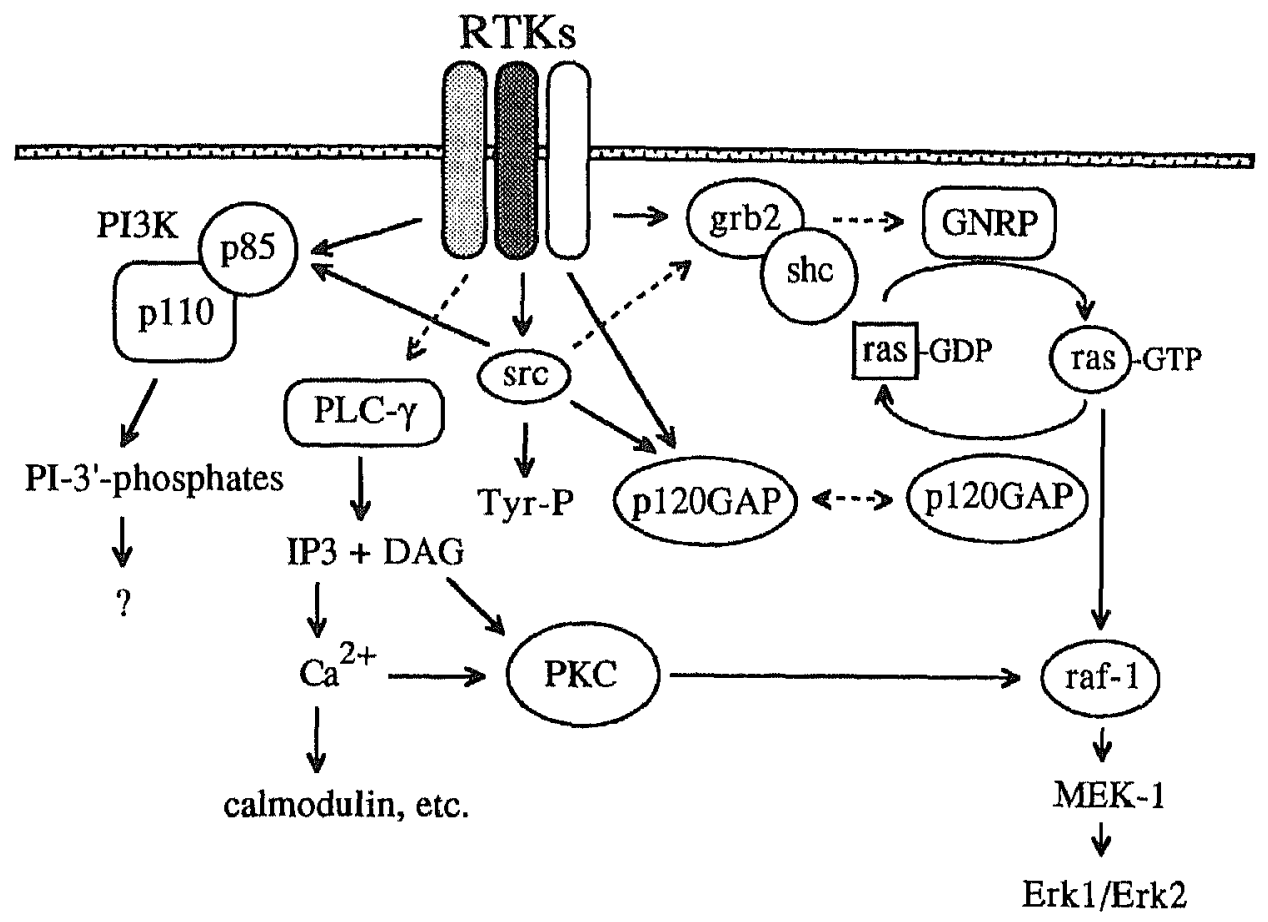

FIGURE 4. RTK-signaling pathways. Signaling pathways that are activated upon agonist binding to its cognate RTK. (1) Pl3K associates to and becomes phosphorylated by the activated RTKs and catalyzes the phosphorylation of phosphatidylinositols at the 3 ' position of the inositol rings. (2) Phospholipase $\mathrm{C}-\gamma$, associates to and is phosphorylated by the active RTKs and produces DAG and IP3, which in turn cause activation of PKC and release of $\mathrm{Ca}^{2+}$ from intracellular stores. (3) $\mathrm{c}$-src is activated in response to various growth factors, and results in increased tyrosine phosphorylation of a number of proteins. (4) p120GAP associates to a number of activated RTKs and also is involved in the regulation of p21ras, although a clear link between both phenomena is unclear at this moment. (5) Grb2 and shc associate to activated RTKs and are most likely involved in the pathway toward p21ras, presumably via the GNRP for p21ras. Activation of p21ras results in activation of raf-1, which in turn causes activation of MEK-1 and erk1 and erk2.

\section{RTK Signaling Complex}

Signaling proteins that physically associate to various activated RTKs include PLC- $\gamma$ (Margolis et al., 1989; Meisenhelder et al., 1989; Rottapel et al., 1991), p120GAP (Kaplan et al., 1990; Kazlauskas et al., 1990; Margolis et al., 1990a; Pronk et al., 1992; Reedijk et al., 1990), PI3K (Bjorge and Kudlow, 1987; Coughlin et al., 1989; Kazlauskas and Cooper, 1989; Reedijk et al., 1990; Rottapel et al., 1991; Varticovski et al., 1989), pp60src (Kypta et al., 1990), and raf-1 kinase (App et al., 1991; Morrison et al., 1988, 1989) (Figure 4). In the case of the insulin receptor, PI3K associates to the docking protein IRS-1 (Sun et al., 1991). Therefore, ligand binding may result in the formation of a signaling complex, consist- ing of the active RTK and a number of associated proteins, which triggers the activation of cellular signal transduction molecules. The fact that these RTKs seem to require the function of p21ras for stimulation of mitogenicity raises the question of which components of this signaling complex are involved in the activation of $\mathrm{p} 21$ ras.

The association of p120GAP to various activated RTKs and its subsequent tyrosine phosphorylation provides the most obvious possible link between RTK signaling and p21ras signal transduction pathways (Ellis et al., 1990; Kaplan et al., 1990; Kazlauskas et al., 1990; Molloy et al., 1989; Pronk et al., 1992; Reedijk et al., 1990). However, growth factors that drive p2lras into the active conformation and simultaneously stimulate tyrosine phosphorylation of p120GAP have 
no obvious effect on the overall GAP activity as measured in an in vitro assay (Bollag and McCormick, unpublished results; Burgering, unpublished observations). Moreover, for insulininduced activation of p21ras in NIH3T3-L1 fibroblasts, p120GAP phosphorylation is not required (Porras et al., 1992) and PDGF receptor mutants that will no longer bind and phosphorylate p120GAP on tyrosine can still signal through p21 ras (Burgering et al., 1993b). In response to various activated TRKs, p120GAP tightly associates to two tyrosine-phosphorylated proteins of 62 and $190 \mathrm{kDa}$ (Ellis et al., 1990). Although a reduction in the in vitro GAP activity toward p21ras has been observed upon association with the 190-kDa protein (Moran et al., 1991) and the activated EGF receptor (Serth et al., 1992), no correlation has been established between these associations and the activation state of p21ras. Thus, even if these modifications of p120GAP would affect its activity toward p21ras, they are not the only determinants of the activation state of p21 ras. These findings do not necessarily mean that regulation of p120GAP cannot contribute to the activation of p21ras, but they do indicate that mechanisms different from tyrosine phosphorylation and receptor association must exist. For example, a reduction in GAP activity could be caused by activation of an inhibitor protein (or lipid), and this inhibition could be lost upon lysis of the cells and would therefore remain undetected in an in vitro assay. Tyrosine phosphorylation of p120GAP could, of course, have important consequences for its function as an effector molecule (as is discussed later). Whatever the effect of RTKs on the enzymatic activity of p120GAP, some RTKs have been shown to stimulate nucleotide exchange on p21ras, which indicates that other pathways exist.

Raf-1 kinase is a serine/threonine kinase that is phosphorylated on serine residues in response to many growth factors, concomitant with an increase in kinase activity (Morrison et al., 1988). The raf- 1 kinase has been proposed to participate in the RTK signaling complex because receptor association has been observed with the PDGF and EGF receptors (App et al., 1991; Morrison et al., 1989). However, receptor association to the PDGF receptor could not be reproduced by others (Baccarini et al., 1990) and no data regarding the requirement of this association for mitogenesis have been obtained, nor has the site of association for raf- 1 kinase been mapped. Also, unlike the other RTK substrates discussed here, raf-1 kinase does not contain an $\mathrm{SH} 2$ domain (discussed in detail later). Therefore, a definite conclusion about the significance of the association of raf- 1 kinase to the PDGF- and EGF-receptor signaling complexes awaits further study. Regarding a possible role for raf- 1 kinase as intermediate between the RTKs and $\mathrm{p} 21$ ras, data have been obtained that place raf-1 kinase downstream of p21 ras in RTK signaling (as is discussed later).

PLC- $\gamma$ converts phosphatidylinositol(PI)-4,5biphosphate $\left(\mathrm{PIP}_{2}\right)$ into DAG and inositol triphosphate $\left(\mathrm{IP}_{3}\right)$, both representing second messengers (Berridge, 1987; Nishizuka, 1984). DAG is the natural activator of $\mathrm{PKC}$, which in turn may phosphorylate a variety of proteins on serine and threonine, and $\mathrm{IP}_{3}$ is released into the cytosol where it binds to a specific intracellular receptor, leading to a release of $\mathrm{Ca}^{2+}$ from intracellular stores. $\mathrm{Ca}^{2+}$ can act as a cofactor for many enzymes, including PKC and calmodulin (Berridge, 1987). PLC- $\gamma_{1}$ and $-\gamma_{2}$ couple PDGF stimulation to PI turnover, whereas the $\beta$-isoforms appear to mediate the classical $G$ protein-coupled PI response (Margolis et al., 1990b; Sultzman et al., 1991). PLC- $\gamma$ seems to require tyrosine phosphorylation for its activity in vivo (Kim et al., 1991). The activity of PLC- $\gamma$ is negatively regulated by profilin, which binds the major substrate of PLC- $\gamma$, PIP $_{2}$, with high affinity (Goldschmidt-Clermont et al., 1990). Phosphorylation of PLC- $\gamma$ is necessary to hydrolyze $\mathrm{PIP}_{2}$, which is bound to profilin (GoldschmidtClermont et al., 1991). Hydrolysis of $\mathrm{PIP}_{2}$ is assumed to relieve the inhibition of $\mathrm{PIP}_{2}$ on the function of profilin as a cofactor in actin polymerization and cytoskeletal reorganization (Goldschmidt-Clermont and Janmey, 1991). This indicates that PLC- $\gamma$ may control growth factorinduced actin rearrangement, although activation of PLC- $\gamma$ per se is not sufficient for this effect (Severinsson et al., 1990). Also, activation of PLC- $\gamma$ by different RTKs does not seem to mediate the effects on DNA synthesis. For instance, a mutant of the PDGF receptor that lacks the kinase-insert domain $(\Delta \mathrm{Ki})$, can induce PI turnover, but is no longer mitogenic (Escobedo and Williams, 1988). Furthermore, insulin and CSF-1 re- 
ceptors can stimulate mitogenesis, although no effect on PLC- $\gamma$ activity has been observed (Downing et al., 1989) and mutants of the FGF receptor that do not stimulate PI turnover are still mitogenic (Mohammadi et al., 1992; Peters et al., 1992). These findings make it unlikely that PLC- $\gamma$ could in some way mediate activation of $\mathrm{p} 21$ ras since this seems to be required for the mitogenic effect of RTKs.

PI3K catalyzes the phosphorylation of PI at the 3 ' position of the inositol ring (Whitman et al., 1988). This leads to formation of phosphatidylinositides that are resistant to the action of known PLCs (Lips et al., 1989; Serunian et al., 1989). PI3K was first identified as an associating protein of v-src and v-ros (Macara et al., 1984; Sugimoto et al., 1984). This association was subsequently observed with polyoma middle $\mathrm{T}$, where a strong correlation between PI3K association and transforming potential could be demonstrated (Whitman et al., 1985). The activity of PI3K can be stimulated by a number of mitogenic growth factors, such as PDGF (Auger et al., 1989), CSF-1 (Reedijk et al., 1990), EGF (Bjorge and Kudlow, 1987), and insulin (Endemann et al., 1990; Ruderman et al., 1990). The presence of PI3K activity complexed to pp60src, middle $T$, and the PDGF receptor has been correlated with an $85-$ $\mathrm{kDa}$ phosphoprotein (Courtneidge and Heber, 1987; Kaplan et al., 1987), and partial purification of PI3K has shown that the active fraction consists of a tightly associated heterodimer of the $85-\mathrm{kDa}$ protein and a 110-kDa protein (Carpenter et al., 1990). Both subunits of PI3K were recently cloned and the $85-\mathrm{kDa}$ protein appears to be a regulatory subunit of the enzyme (Escobedo et al., 1991b; Otsu et al., 1991; Skolnik et al., 1991), whereas the $110-\mathrm{kDa}$ subunit carries the catalytic activity (Hiles et al., 1992). Apparently, tyrosine phosphorylation is not required for activation of PI3K inasmuch as binding to IRS-1 alone results in activation (Backer et al., 1992). Conflicting results have been obtained with mutations within the PDGF receptor that abrogate PI3K association. In some cases, a loss of mitogenicity was observed (Coughlin et al., 1989; Escobedo and Williams, 1988; Fantl et al., 1992), whereas other groups report loss of PI3K association without an effect on the mitogenic response (Heideran et al., 1991; Kazlauskas et al., 1992; Yu et al., 1991).
Therefore, no straightforward conclusions as to the role of PI3K in RTK-stimulated mitogenesis can be drawn from these experiments. However, PI3K also has been found associated to oncogenic ras proteins, which suggested a direct involvement of PI3K in p21ras signaling (Sjölander et al., 1991). Neverthless, the fact that the $\triangle K$ Ki PDGF receptor mutant can no longer activate PI $3 K$, but can still signal through p21ras toward erkl and erk2, makes it unlikely that PI3K functions up- or downstream of p21ras (Burgering et al., 1993b).

\section{E. SH2 Domains and Tyrosine Kinase Signaling}

The association of substrates of RTKs to the activated receptors occurs between specific autophosphorylation sites in the RTKs and conserved domains in the substrates. These domains are known as SH2 domains and were originally identified in members of the src family of nonreceptor tyrosine kinases, such as v-src and v-fps (Sadowski et al., 1986). SH2 domains have since been identified in a large variety of proteins, such as p120GAP, PLC- $\gamma$, the $85-\mathrm{kDa}$ PI3K subunit, PTP1C (a phosphotyrosine phosphatase [Shen et al., 1991]) and a number of novel transforming genes, including v-crk, nck, grb2, shc, and vav (discussed later) (Figure 5). An SH2 domain consists of about 100 amino acids, and mutations within this domain often reduce the transforming potential of $\mathrm{v}$-src (Koch et al., 1991). This finding suggested that these SH2 domains may direct the interaction of STC with several cellular proteins that are necessary for transformation. This interaction was shown to be mediated by the binding of src-SH2 domains to phosphorylated tyrosine residues of target proteins (Anderson et al, 1990a). In addition, the SH2 domains can negatively regulate the tyrosine kinase activity of $c$-src through interaction with phosphorylated Tyr-527 (Cantley et al., 1991). This is supported by the finding that certain mutations in the SH2 domains can enhance the catalytic and transforming potential of c-src (Hirai and Varmus, 1990; SeidelDugan et al., 1992). Most proteins with SH2 domains also contain one or more copies of another conserved src homology domain of about 50 amino acids, the SH3 domain (Koch et al., 1991). Muta- 


\section{ENZYMES:}



\section{ADAPTORS:}



FIGURE 5. Proteins containing $\mathrm{SH} 2 / \mathrm{SH} 3$ domains. $\mathrm{SH} 2$ domains are depicted as black boxes (approximately 100 amino acids) and the hatched boxes represent the $\mathrm{SH} 3$ domains (approximately 50 amino acids). The SH2/SH3-containing proteins can be grouped into two groups, those that have a known enzymatic activity and those that presumably function as adaptor proteins for other proteins.

tional analysis of SH3 domains suggests a role for this domain in regulation of the tyrosine kinase activity of c-src and c-abl (Franz et al., 1989; Hirai and Varmus, 1990; Jackson and Baltimore, 1989; Kato et al., 1986; Seidel-Dugan et al., 1992). SH3 domains also have been identified in several proteins without $\mathrm{SH} 2$ domains that associate with the cytoskeleton or cellular membranes (Chenevert et al., 1992; Drubin et al., 1990; Koch et al., 1991; Rodaway et al., 1989), which indicates that this region may be involved in the targeting of proteins to specific subcellular locations.
A first indication that $\mathrm{SH} 2$ domains are involved in the binding of phosphorylated tyrosine residues came from the analysis of the p47gagcrk oncoprotein. This protein activates tyrosine kinase activity, although it has no apparent enzymatic activity by itself (Mayer et al., 1988). $\mathrm{p} 47 \mathrm{gag}$-crk associates with a large number of tyrosine-phosphorylated proteins, including pp60v-src (Matsuda et al., 1990; Mayer and Hanafusa, 1990). The region of $\mathrm{p} 47 \mathrm{gag}$-crk that is important for association with tyrosine-phosphorylated proteins appeared to be its SH2 domain. This finding 
was followed by the observation that the isolated SH2 domains of different RTK substrates could bind to the activated RTKs (Anderson et al., 1990a; Hu et al., 1992; Mayer et al., 1991; McGlade et al., 1992; Mohammadi et al., 1991; Moran et al., 1990; Reedijk et al., 1992). This suggests that the autophosphorylation of the RTKs triggered by ligand binding results in a panel of phosphotyrosine residues that function as recognition sites for different substrates. The insulin receptor is somewhat exceptional in this respect because it seems to require a separate $\mathrm{SH} 2$-docking protein to bind certain SH2-containing proteins, such as PI3K (Lavan et al., 1992; Sun et al., 1991). This function is fulfilled by the most prominent substrate of the insulin receptor, insulin receptor substrate-1 (IRS-1), a protein of approximately 185 $\mathrm{kDa}$, which contains several potential tyrosine phosphorylation sites that could serve as recognition sites for SH2 domains (Sun et al., 1991).

The amino acids adjacent to the phosphorylated tyrosine appear to determine the affinity of different SH2-containing proteins for that specific site (Cantley et al., 1991). Thus, the binding specificity of a given $\mathrm{SH}$-containing protein is dictated by the amino acid sequence surrounding each phosphorylated tyrosine. This is exemplified by the fact that small phosphopeptides (as small as five amino acids), identical to the proposed binding sites, can specifically inhibit the binding of SH2-containing proteins that normally bind at this position (Escobedo et al., 1991a; Fantl et al., 1992; Kashishian et al., 1992). With these peptides, and by making use of mutants of the PDGF receptor that lack specific tyrosine residues, it has been demonstrated that the PDGF receptor has different binding sites for PLC- $\gamma$, p120GAP, and PI3K (Fantl et al., 1992; Kashishian et al., 1992; Kazlauskas et al, 1992). This suggests that a given receptor can mediate its signal through a receptor-specific panel of SH2-containing proteins for which it contains high-affinity binding sites. However, the fact that each substrate will bind to the PDGF receptor at a different position does not necessarily mean that one receptor molecule can bind all of these substrates at the same time.

The identification of $\mathrm{SH} 2$ domains as specific binding sites for tyrosine-phosphorylated proteins sheds more light on the possible mechanism of signaling from activated RTKs to p21 ras. Re- cently, candidate proteins containing $\mathrm{SH} 2 / \mathrm{SH} 3$ domains that could link activated RTKs to signaling pathways involving ras proteins have been identified. First, in Caenorhabditis elegans, the sem-5 gene encodes a small protein with two SH3 domains flanking a SH2 domain, and this protein plays an important role in vulval development (Clark et al., 1992). Genetic evidence places sem5 between the let-23 gene and the let- 60 gene, also involved in correct vulva formation. The let23 gene shows similarity to the EGF receptor, and let-60 is homologous to mammalian ras genes. This suggests that in C. elegans, sem-5 is required for signaling from the RTK to p21ras. Interestingly, grb2, the human homolog of the sem-5 gene, has been identified and cloned by virtue of its association to the EGF receptor (Lowenstein et al., 1992). Microinjection of grb2 protein together with normal p21ras, at concentrations where neither protein alone has any effects, results in an induction of DNA synthesis (Lowenstein et al., 1992). This strongly suggests that the function of grb2 and that of p21ras is somehow linked, although they are not necessarily involved in the same pathway. Each could function in a separate pathway and act synergistically in the induction of DNA synthesis. Second, a gene was cloned by screening cDNA libraries with DNA probes of SH2 domains (Pelicci et al., 1992). The resulting cDNA, which encodes a protein with a single $\mathrm{SH} 2$ domain and a region homologous to the $\alpha 1$ chain of collagen, was termed shc. The shc protein associates to the activated EGF receptor (McGlade et al., 1992; Pelicci et al., 1992). In addition, this protein is phosphorylated on tyrosine upon activation of the EGF receptor and in v-src- or v-fps-transformed cells (McGlade et al., 1992; Pelicci et al., 1992; Pronk et al., 1993). Overexpression of the shc gene transforms NIH3T3 cells, which indicates the importance of the gene product in the regulation of cellular proliferation. A link between shc and p21ras signaling was recently provided by the finding that the shc protein will bind to the grb2 protein upon RTK activation, and overexpression of shc induces ras-dependent neurite outgrowth in $\mathrm{PC} 12$ cells (Rozakis-Adcock et al., 1992). Third, the nck protein, which consists of three SH 3 domains and one SH2 domain (Lehman et al., 1990), is phosphorylated on serine and tyrosine in response 
to stimulation with EGF, PDGF, and NGF in A431 cells, NIH3T3 cells, and PC12 cells, respectively (Li et al., 1992b; Meisenhelder and Hunter, 1992; Park and Rhee, 1992). In addition, increased phosphorylation of nck is also observed in src-transformed NIH3T3 cells (Meisenhelder and Hunter, 1992) and in T lymphocytes upon activation of the T-cell receptor (Park and Rhee, 1992). Nck binds to the activated EGF and PDGF receptors, and this association is mediated by the SH2 domain of nck ( $\mathrm{Li}$ et al., 1992b; Park and Rhee, 1992). At present, no data have been obtained that place nck in one signaling pathway with p21 ras, but overexpression of nck in NIH3T3 cells and $3 \mathrm{Y} 1$ rat fibroblasts causes oncogenic transformation (Chou et al., 1992; Li et al., 1992b), suggesting that nck plays an important role in the mitogenic signaling of RTKs. Taken together, this suggests that a cascade of SH2/phosphotyrosine interactions may link the RTKs to the eventual activation of p21ras. However, one should bear in mind that some of the experiments rely on overexpression of the $\mathrm{SH} 2$-containing proteins. High levels of the SH2-containing proteins could result in interaction with proteins for which they have a relatively low affinity. Under physiological conditions, these interactions may not occur.

Similarly, other regulatory proteins of small G-proteins that contain $\mathrm{SH} 2 / \mathrm{SH} 3$ domains or interact with $\mathrm{SH} 2 / \mathrm{SH} 3$-containing proteins have been identified. For example, 3BP-1, a protein that associates with the SH3 domain of c-abl, shows similarity to the bcr protein and n-chimaerin, suggesting it might have GAP activity for the rho family of small GTP-binding proteins (Cicchetti et al., 1992). The SH3 binding site of 3BP-1 was recently localized to a ten-amino acid stretch very rich in proline (Ren et al., 1993). Also, the vav protein, which contains an $\mathrm{SH} 2$ domain flanked by two SH3 domains (Margolis et al., 1992), has a region of homology to the $\mathrm{dbl}$ oncogene, a possible exchange factor for rho- or rac-like GTPbinding proteins (Hart et al., 1991). Moreover, BUD5, a putative GTP-GDP exchange factor cloned from $S$. cerevisiae, interacts with BEM1, which contains two SH3 domains (Chant et al., 1991; Chenevert et al., 1992; Powers et al., 1991). Therefore, the SH2/SH3 domains may perform important functions in the regulation of small GTP-binding proteins.

\section{F. Lipids as Activators of p21ras}

The activation state of p21ras can be controlled by lipids. For instance, activation of PKC, in response to phorbol esters, causes activation of p21ras in T lymphocytes (Downward et al., 1990a), indicating that $\mathrm{DAG}$, the physiological activator of $\mathrm{PKC}$, is involved in the regulation of $\mathrm{p} 21$ ras. However, such activation of p21ras by PKC has been observed only in $\mathrm{T}$ cells, which shows that the RTKs, most of which will activate PKC, do not signal to p21ras via PKC. Also, the phospholipid LPA can induce a transient activation of p21ras in rat-1 fibroblasts (van Corven et al., 1993). The effect of LPA, however, is probably mediated by a protein tyrosine kinase (van Corven et al., 1993).

In addition to these more or less indirect effects of lipids on the activation state of p21ras, a more direct role for lipids in the regulation of p21ras by GAPs has been proposed. Initially, it was found that the mitogenicity of certain lipids is virtually completely inhibited by microinjection of the neutralizing anti-ras antibody $\mathrm{Y} 13-259$ (Yu et al., 1988), suggesting that their mitogenic signals are mediated exclusively by p21ras. Subsequent studies have shown that the ability of the purified GAPs to stimulate the GTPase activity of p21ras in vitro is inhibited by several lipids (Tsai et al., 1989). Interestingly, the metabolism of the lipids with inhibitory potential, such as phosphatidic acid, arachidonic acid, and PI monophosphate, changes upon mitogenic stimulation. Lipids with the ability to inhibit GAP activity in vitro are produced within 1 to 5 min of serum stimulation of NIH3T3 cells (Yu et al., 1990). These findings have led to the proposal that certain growth factors may regulate the activation state of p21ras by regulating lipid metabolism, resulting in the inhibition of GAP activity. The inhibition appears to be a consequence of a direct interaction of p120GAP with the mitogenically active lipids, and this interaction is dependent on divalent ions (Tsai et al., 1991). However, the concentration dependence of the inhibition suggests that formation of micelles may be the prerequisite of this effect, especially since the lipids with low critical micellar concentration (CMC) values are the most potent inhibitors (Serth et al., 1991). Nevertheless, the local concentration of certain 
lipids at the cellular membrane could reach the values required for inhibition, and certain lipids can inhibit the activity of both p120GAP and neurofibromin at concentrations well below their CMC (Golubic et al., 1991). Mitogenically active phospholipids also may regulate $\mathrm{p} 21$ ras via activation of a putative GTPase inhibitory protein. Such a protein, which binds phospholipids, was partially purified from mouse brain (Tsai et al., 1990), although no further evidence for the identity and physiological importance of the protein has been provided.

Neurofibromin and p120GAP are affected differently by certain lipids. For instance, neurofibromin is very sensitive to $\mathrm{PIP}_{2}$, arachidonic acid, and phosphatidic acid, whereas p120GAP is much less sensitive to these compounds (Bollag and McCormick, 1991). These lipids do not prevent the interaction of p120GAP or neurofibromin with p21ras, suggesting that lipids could stabilize the interaction of p21ras-GTP with a specific GAP. This could have important implications for the interaction of $\mathrm{p} 21$ ras with its downstream target, as is discussed later. However, regulation of the activation state of p21ras requires more than production of mitogenically responsive lipids because serum, which efficiently stimulates formation of these lipids, is a poor activator of p21ras. Of course, it remains to be determined if inhibition of lipid production can block activation of p21ras. It could be that these lipids potentiate the effect of a growth factor that has an effect on nucleotide exchange on $\mathrm{p} 21 \mathrm{ras}$, a possibility that requires further study.

\section{DOWNSTREAM SIGNALING OF p21ras}

\section{A. p120GAP as Effector}

A number of experimental observations have indicated that p120GAP, in addition to negatively regulating p21ras, may play a role in the downstream signaling from $\mathrm{p} 21$ ras as well (reviewed in McCormick, 1989). Initial data showed that p120GAP interacts with p21ras at a site denoted as the effector region. Antibodies directed against the effector region of p21ras can block the interaction with p120GAP (Rey et al., 1989), and most mutations in the effector region that reduce the transforming potential of ras oncoproteins also impair the interaction with p120GAP (Adari et al., 1988; Cales et al., 1988). Moreover, mutants of $\mathrm{p} 21$ ras, which have a high affinity for p120GAP but lack the consensus membrane localization site, inhibit signaling from active p21ras (Gibbs et al., 1989; Medema et al., 1991b; Michaeli et al., 1989). Also, K-rev (rap1A), a member of the ras family that can revert ras-transformed cells, has been suggested to do so through competition for p120GAP, on the basis of its identical effector region (Frech et al., 1990; Kitayama et al., 1989). However, all these observations may be a consequence of an effector molecule different from p120GAP, which has a binding site on p21ras that (partially) overlaps the binding site for p120GAP.

Further evidence for an effector function for p120GAP came from experiments with isolated atrial cell membranes, where $\mathrm{p} 120 \mathrm{GAP}$ can cause inhibition of potassium channel opening induced by the activated muscarinic receptor (Yatani et al., 1990). This effect requires interaction of p120GAP with p21ras because the addition of Y13-259 blocked the p120GAP-induced inhibition (Yatani et al., 1990). In X. laevis oocytes, a similar situation has been observed for activation of the maturation-promoting factor (Dominguez et al., 1991). Here an induction of H1-kinase activity was measured upon microinjection of p120GAP or oncogenic p21 ras, and this effect was blocked by Y13-259 or a neutralizing antip120GAP antibody (Dominguez et al., 1991). In addition, antibodies against phosphocholine (PC)specific PLC (PC-PLC) also blocked the effect of oncogenic p21ras and p120GAP, suggesting that PC-PLC is somehow activated by the active p21ras/p120GAP complex and mediates oocyte maturation (as is discussed later). However, in contrast to microinjection of oncogenic p21ras, microinjection of p120GAP did not stimulate germinal vesicle breakdown (GVBD), which is a good parameter of oocyte maturation. This was explained by the fact that only a minor fraction of endogenous p21ras (required for interaction with p120GAP) will be in the active conformation in resting oocytes (Dominguez et al., 1991). Nevertheless, insulin-induced maturation of oocytes was inhibited by microinjection of p120GAP in the same study. Because insulin-induced maturation 
is mediated by $\mathrm{p} 21$ ras, one would expect that this effect would be enhanced, rather than inhibited, by $\mathrm{p} 120 \mathrm{GAP}$. Thus, the interaction of $\mathrm{p} 21$ ras and p120GAP alone appears to be insufficient for induction of oocyte maturation.

In the isolated atrial cell membranes, it was shown that p120GAP deletion mutants encoding only the $\mathrm{SH} 2 / \mathrm{SH} 3$ domains can establish inhibition of potassium channel opening independently of p21 ras (Martin et al., 1992). This suggests that the effector function of $\mathrm{p} 120 \mathrm{GAP}$ resides in the SH2/SH3 domains, and that interaction of p120GAP with p21ras causes a conformational change in the GAP protein that enables the SH2/SH3 domains to interact with their downstream target. The same deletion mutants of p120GAP can induce expression from the fos promoter in a transient expression system (Medema et al., 1992). However, in this case, the induction is dependent on ras activity because coexpression of $\mathrm{p} 21$ ras (Asn 17) blocks the effect. Therefore, it is unlikely that p120GAP alone is the target of $\mathrm{p} 21$ ras in this particular signaling pathway, but other signals that stem from p21 ras are required to induce various effects (Figure 1). This notion is supported by the finding that p21ras(Glu38), has a normal affinity for p120GAP (Krengel et al., 1990), although the transforming ability of normal p21ras is destroyed by this mutation (Cales et al., 1988), thus indicating that interaction between p21ras and p120GAP per se is not sufficient for transformation. Deletion mutants of p120GAP that encode only the catalytic domain involved in interaction with p21ras (Marshall et al., 1989) can inhibit induction of gene expression by activated forms of p21ras, an effect that can be reverted by coexpression of full-length p120GAP (Schweighoffer et al., 1992). This suggests that the catalytic domain of p120GAP competes with full-length p120GAP for binding to p21ras, but that the catalytic domain of p120GAP alone cannot perform the effector function, in agreement with the finding that this function is localized in the $\mathrm{SH} 2 / \mathrm{SH} 3$ domains.

The targets of other $G$ proteins have been shown to contain GAP activity. For instance, in the control of protein synthesis, the ribosomes act as both effector and GAP for the bacterial elongation factor EF-Tu (Bourne et al., 1990a). Interaction of the photoreceptor heterotrimeric $\mathrm{G}$ pro- tein, transducin, with its effector, cGMP phosphodiesterase, accelerates GTP hydrolysis on transducin (Arshavsky and Bownds, 1992). Similarly, phospholipase C- $\beta 1$, which is an effector for the heterotrimeric $G_{\mathrm{c} / 11}$ protein, has GTPase stimulatory activity toward $G_{q / 11}$ (Berstein et al., 1992). These observations point to the possibility that a general theme exists in which the effector molecule for GTP-binding proteins could control their upstream regulators (Bourne and Stryer, 1992). This raises the question whether neurofibromin, the other GTPase-activating protein for p21ras, also can function as an effector. In that way, multiple signals could stem from $\mathrm{p} 21$ ras by selection of different effector proteins, a decision that could be controlled by mitogenic lipids (Bollag and McCormick, 1991). It should be noted however, that deletion of neurofibromin results in increased levels of the GTP-bound form of $\mathrm{p} 21 \mathrm{ras}$, which is thought to cause the transformed phenotype of the Schwannoma cell lines (Basu et al., 1992; DeClue et al., 1992). If so, then the effector function of neurofibromin, if such exists, seems dispensable for transformation by p21ras. Introduction of oncogenic p21 ras in normal Schwann cells causes a block in cell proliferation (Ridley et al,, 1988), indicating that active p21ras in the presence of neurofibromin leads to growth arrest in these cells. This has led to the proposal that neurofibromin could be an effector for p21ras, which mediates growth-inhibitory effects (Bollag and McCormick, 1992) (also see Figure 1).

Proteins that bind to p120GAP are potential targets of the p21ras-p120GAP effector complex. First, two p120GAP-associated proteins, p62 and p190, that were cloned recently could participate in p21ras signaling (Figure 1). The p62 protein has significant homology to a putative hnRNP protein and binds RNA, suggesting a role in RNA processing, but the relevance of this with respect to 21 ras signal transduction is still obscure (Wong et al., 1992). The p190 protein can function as a GAP for p21rac and p21rho, and interaction of p120GAP and p190 may allow coupling of signaling pathways involving p21 ras and rho family members (Settleman et al., 1992a). Second, the protein appears to be identical to the transcriptional repressor of the glucocorticoid receptor, which raises the possibility that $\mathrm{p} 21$ ras can signal directly to the nucleus through the p120GAPp190 complex (Settleman et al., 1992b). 


\section{B. Kinases Downstream of p21ras}

Raf-1 kinase is a 70- to 75-kDa phosphoprotein with intrinsic kinase activity toward serine and threonine residues (Rapp, 1991). Several lines of evidence suggested that p21ras and raf-1 kinase function in the same signaling pathway. First, expression of oncogenic forms of $\mathrm{p} 21$ ras leads to enhanced phosphorylation of raf-1 kinase in NIH3T3 and PC12 cells (Morrison et al., 1988; Wood et al., 1992). Second, a dominant-negative mutant of raf- 1 kinase or antisense raf-1 RNA can suppress transformation of NIH3T3 and normal rat kidney (NRK) cells by oncogenic forms of p21ras (Kizaka-Kondoh et al., 1992; Kolch et al., 1991). Third, transformation by v-raf does not require the function of $\mathrm{p} 21$ ras (Feig and Cooper, 1988a; Smith et al., 1986). In addition, both raf1 kinase and $\mathrm{p} 21$ ras appear to be essential components of a signaling pathway shared by EGF and PDGF (Kizaka-Kondoh et al,, 1992). This notion is supported by the fact that raf- 1 kinase activity is stimulated in response to many different ligands, a situation that is remarkably similar to activation of p21ras (App et al., 1991; Baccarini et al., 1990; Blackshear et al., 1990; Carroll et al., 1990; Kovacina et al., 1990; Morrison et al., 1988; Siegel et al., 1990; Turner et al., 1991). In addition, activation of raf-1 kinase by different growth factors is blocked in the presence of p21ras(Asn17) (Troppmair et al., 1992; Wood et al., 1992), demonstrating that activation of raf- 1 kinase by RTKs is mediated by $\mathrm{p} 21 \mathrm{ras}$. Such a mechanism is somewhat contradictory to the direct activation of raf1 kinase, which is assumed to occur upon stimulation of the PDGF receptors (Morrison et al., 1989). However, PDGF stimulation of tyrosine phosphorylation of raf- 1 kinase was not observed by other investigators (Baccarini et al., 1990), and other growth factors, such as EGF, insulin, and CSF-1, elicit only serine phosphorylation of raf1 kinase (App et al., 1991; Baccarini et al., 1990; Blackshear et al., 1990; Kovacina et al., 1990). Thus, activation of raf-1 kinase in general appears to be a more indirect effect of RTK activation.

In addition to raf- 1 kinase, the activation of erks, or mitogen-activated protein (MAP) kinases (erk1 or p44mapk and erk2 or p42mapk), by a number of growth factors requires the activity of p21ras (de Vries-Smits et al., 1992; Thomas et al., 1992; Wood et al., 1992). In some ras-transformed cells, these kinases are constitutively activated, and oncogenic p21 ras can cause activation of erk 1 and erk2 when introduced into quiescent cells (Leevers and Marshall, 1992). Erks are serine/ threonine kinases, and activation requires phosphorylation of erk 1 and erk2 at a threonine and a tyrosine residue separated by one amino acid (Anderson et al., 1990b; Boulton et al., 1991; Payne et al., 1991). The activation of a serine/ threonine kinase by phosphorylation at tyrosine residues was initially thought to provide the link between RTK activation and the observed increase in serine/threonine phosphorylation of cellular proteins (Anderson et al., 1990b). However, the kinase responsible for activation of erk 1 and erk2 (MAP kinase kinase or mapkk) has characteristics of a kinase that is activated by serine/ threonine phosphorylation (Alessandrini et al., 1992; Crews and Erikson, 1992; Gómez and Cohen, 1991; Kosako et al., 1992; L'Allemain et al., 1992; Matsuda et al., 1992; Nakielny et al., 1992a, b). Mapkk is a "dual kinase" because it can phosphorylate erks on both tyrosine and threonine residues (Nakielny et al., 1992b; Posada and Cooper, 1992; Rossomando et al., 1992). Recently, mapkk was cloned from a murine pre-B cell cDNA library (and named MEK) (Crews et al., 1992). It should be noted that activation of erks also can occur in a ras-independent manner. For example, TPA-induced activation of erks in rat- 1 cells is not dependent on the activity of p21ras (de VriesSmits et al., 1992). Moreover, activation of erk2 by EGF in rat-1 cells is only partially inhibited by expression of p21ras(Asn17), and full inhibition is accomplished when the calcium chelator EGTA is added in combination with expression of p21ras(Asn17) (Burgering et al., 1993a). This suggests that EGF stimulates both a ras- and a $\mathrm{Ca}^{2+}$-dependent route, each of which can mediate erk2 activation.

The findings that activation of both raf- $1 \mathrm{ki}$ nase and erk1/erk 2 requires the function of $\mathrm{p} 21$ ras suggested a relationship between these protein kinses. Initially, two groups reported that erks could phosphorylate raf-1 kinase in vitro (Anderson et al., 1991; Lee et al., 1992), suggesting that raf- 1 kinase is downstream of erk. However, raf1 kinase, which is phosphorylated by erk $1 /$ erk 2 in vitro, is only slightly activated. More recently, different groups have shown that immunoprecipitated raf-1 kinase can reactivate dephosphory- 
lated mapkk (Dent et al., 1992; Howe et al., 1992; Kyriakis et al., 1992) and that erks are constitutively activated in raf-transformed cells (Dent et al., 1992; Howe et al., 1992). This suggests that raf-1 kinase is the mapkk kinase or activates this kinase through another kinase present in the preparations used for in vitro phosphorylation. This places raf- 1 kinase upstream of erk 1 and erk 2 and downstream of $\mathrm{p} 21$ ras. Thus, an important signal transduction pathway is emerging in which $\mathrm{p} 21$ ras controls raf- 1 kinase, which can activate erk 1 and erk2 via mapkk (Figure 6). The fact that erk1/erk2 also can phosphorylate raf-1 kinase suggests that some feedback mechanism may exist by which erks regulates raf-1 kinase activity. Nevertheless, some data, which are apparently in conflict with this straightforward pathway, have been obtained. For example, mutants of the EGF receptor that lack kinase activity can no longer activate raf-1 kinase (Baccarini et al., 1991), whereas activation of erk 1 and erk2 is still observed (although the response is sharply reduced) (Campos-González and Glenney, 1992), suggesting that other (redundant) routes may exist. However, a small residual kinase activity of the mutant EGF receptor also could explain this result. In addition, optimal activation of raf- 1 kinase in insect cells requires coexpression of oncogenic p21ras and pp60src, suggesting that the mechanism of activation is more complex (Williams et al., 1992). Also, v-raf

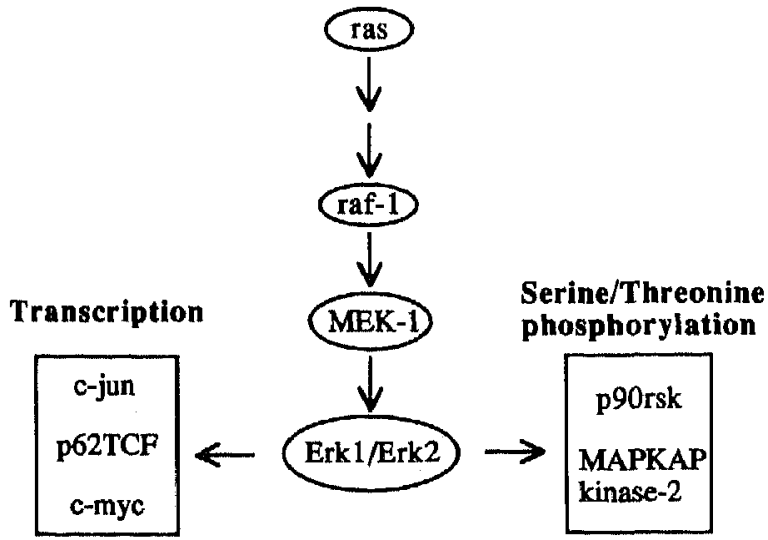

FIGURE 6. A kinase cascade that is initiated by p21ras. Activation of p21ras results in activation of raf1, which in turn can activate mapkk (MEK-1). MEK-1 can activate erk1 and erk2. These latter kinases are thought to be involved in the activation of a variety of transcription factors and other serine/threonine kinases. Therefore, this pathway may mediate many ras-induced effects, such as an altered gene expression. expression in $\mathrm{PC} 12$ cells fails to activate erk2 (Wood et al., 1992), although immunoprecipitates of raf from PC12 cells are able to reactivate dephosphorylated mapkk (Howe et al., 1992). The reason for this difference is unclear, but suggests that for the activation of erk2 in vivo, the presence of active raf-1 kinase is not sufficient.

Activation of erk1 and erk2 has important consequences for transcriptional and translational activity in the cell. Erk2 can activate other kinases, such as p90rsk (S6 kinase II) (Erikson, 1991; Sturgill et al., 1988) and a newly identified kinase, termed MAP kinase-activated protein kinase-2 (MAPKAP kinase-2), whose the substrates are still unknown (Stokoe et al., 1992) (Figure 6). Also, the relevant substrates of p90rsk are still elusive inasmuch as phosphorylation of $\mathrm{S} 6$ by p90rsk in vitro results only in a partial reactivation (Ahn et al., 1990), and another kinase, p70 S6 kinase, is held responsible for the activation of S6 in vivo (Ahn et al., 1990; Ballou et al., 1991; Chung et al., 1992). The latter kinase is not activated by erk1 or erk2 and is part of a distinct signaling pathway (Ballou et al., 1991; Chung et al., 1992), for which the involvement of p21ras has not yet been addressed. In addition, purified erks can directly phosphorylate a number of transcription factors in vitro, such as c-myc (Alvarez et al., 1991; Seth et al., 1991), c-jun (Alvarez et al., 1991; Pulverer et al., 1991), and p62TCF (Gille et al., 1992) (Figure 6). Thus, activation of erks may be responsible for the induction of gene expression observed in response to different growth factors. However, one should bear in mind that phosphorylation of these transcription factors is observed with purified kinases in an in vitro kinase assay. Therefore, kinases that copurify with erk1/erk2 or associate to them may be responsible for the observed phosphorylations.

Several possibilities exist by which p21ras could cause activation of raf- 1 kinase. The raf- 1 protein has its kinase domain in the carboxyterminal half of the protein, whereas the aminoterminal region of the protein negatively regulates kinase activity ( $\mathrm{Li}$ et al., 1991). The aminoterminal domain of raf-1 kinase has been implicated to function like the regulatory lipid-binding domain of PKC, and activation of raf- 1 kinase may take place by an allosteric regulatory mechanism (Stanton et al., 1989). On the other hand, 
activation of the kinase activity of raf-1 kinase correlates with increased phosphorylation of raf1 kinase, suggesting that activation also may be a consequence of phosphorylation. Therefore, p21ras should either activate the allosteric activator of raf-1 kinase or activate (directly or indirectely) the raf- 1 kinase. The fact that phorbol esters can cause activation of raf- 1 kinase in all cells suggests that $\mathrm{PKC}$ is a common intermediate (Li et al., 1991), which would argue against allosteric regulation of raf-1 kinase by $\mathrm{p} 21$ ras. Nevertheless, TPA-sensitive PKC is not involved in ras-dependent activation of erk 1 and erk 2 by PDGF or insulin in fibroblasts. Possibly p120GAP could affect the activity of a kinase through binding of a tyrosine-phosphorylated residue by means of its SH2 domains. A positive regulatory function for the SH2 domains of p120GAP in p21 ras signaling has indeed been demonstrated (Martin et al., 1992; Medema et al., 1992; Schweighoffer et al., 1992). Whether these domains can cause activation of a protein kinase remains to be shown.

\section{Phospholipases}

RTK stimulation frequently results in the generation of DGA, which is a potent activator of PKC (Nishizuka, 1988). The initial formation of DAG is a consequence of a rapid and transient hydrolysis of PI by PI-specific PLC, which also produces $\mathrm{IP}_{3}$, causing a transient $\mathrm{Ca}^{2+}$ release from intracellular stores (Berridge, 1987). This PLCmediated degradation of inositol phospholipids is an important step in the signal transduction cascades triggered by different growth factors (Berridge, 1987; Williams, 1989). This transient DAG production is often followed by a more sustained elevation of DAG, which is thought to be a consequence of phosphatidylcholine (PC) hydrolysis (Exton, 1990). Also, cells transformed with ras oncogenes display increased steady-state levels of DAG (Fleischman et al., 1986; Wolfman and Macara, 1987), and microinjection of oncogenic $\mathrm{p} 21$ ras in $X$. laevis oocytes causes a rapid production of DAG (Lacal et al., 1987a). The increased level of DAG is most likely responsible for the sustained activation of PKC observed in ras-transformed cells (Diaz-Laviada et al., 1990). Sustained activation of $\mathrm{PKC}$ is a prerequisite for long-term physiological responses, such as proliferation and differentiation (Asaoka et al., 1991; Berry et al., 1990; William et al., 1990), and cells that stably overexpress PKC show disturbed growth control and enhanced tumorigenicity (Cuadrado et al., 1990; Housey et al., 1988; Krauss et al., 1989; Megidish and Mazurek, 1989; Persons et al., 1988; Watanabe et al., 1992). This suggests that formation of DAG may be an important event in ras transformation, although the mechanism by which p21ras can stimulate DAG formation is not fully understood.

The elevated levels of DAG in ras-transformed cells may be a consequence of an induction of PIspecific PLC (PI-PLC) inasmuch as microinjection of neutralizing anti-PI-PLC antibodies can block ras-induced DNA synthesis (Smith et al., 1990). However, ras-transformed cells do not contain elevated levels of inositol phosphates (Lacal et al., 1987d), nor do they show enhanced basal PI-PLC activity (Seuwen et al., 1988), and scrape loading of p21ras into Swiss 3T3 cells causes a rapid activation of $\mathrm{PKC}$ in the absence of any measurable effect on PI turnover (Morris et al., 1989). Also, microinjection of oncogenic p21 ras in oocytes does cause a dramatic increase in DAG, but only minor differences in the levels of other products of PI turnover are observed (Lacal et al., 1987a). Therefore, PI-PLC-catalyzed hydrolysis of PI is an unlikely source for DAG in ras-transformed cells.

An alternative source for DAG is hydrolysis of PC. Indeed, analysis of the molecular species of 1,2-diacylglycerides produced upon EGF and PDGF treatment demonstrates that DAG formation is due primarily to PC hydrolysis, and hydrolysis of other phospholipids contributes only to a very minor extent (Pessin et al., 1990). In addition, ras-transformed cells exhibit increased levels of phosphocholine (PCho), the other product of PC-PLC-catalyzed hydrolysis of PC (Lacal, 1990). A similar elevation of PCho has been observed in PDGF-stimulated fibroblasts (Besterman et al., 1986; Pessin et al., 1990). However, it should be noted that the increased levels of PCho in ras-transformed cells, as well as in response to various mitogens, may be caused in part by elevated choline-kinase activity (Besterman et al., 1986; Lacal, 1990; Macara, 1989, Warden and Friedkin, 1985). Also, the increase in PCho pre- 
cedes the observed increase in DAG in the oocytes microinjected with active $\mathrm{p} 21$ ras, suggesting that PC is not the only source of DAG (Lacal et al., 1987b). Nevertheless, sufficient data indicate that part of the DAG produced in ras-transformed cells is a result of PC-PLC-catalyzed hydrolysis of PC.

Indeed, PC-PLC plays an important role in ras- and growth factor-induced mitogenesis. For instance, addition of PC-PLC from Bacillus cereus to the medium of Swiss 3T3 fibroblasts stimulates DNA synthesis (Larrodera et al., 1990) and can induce gene expression (Diaz-Meco et al., 1991). Remarkably, maximal induction of DNA synthesis by addition of PC-PLC to the medium is detected $\sim 9 \mathrm{~h}$ before the maximal stimulation triggered by PDGF. This is the same time lag required for PDGF to stimulate formation of PCho, suggesting that activation of PC-PLC is a relatively late event (Larrodera et al., 1990). Similarly, microinjection of PC-PLC in X. laevis oocytes induces maturation, and neutralizing antibodies against PC-PLC can block maturation induced by insulin or microinjected p21 ras (Garcia de Herreros et al., 1991). Again, induction of maturation by PC-PLC is faster than insulin-induced maturation and the time lag correlates with the time required to stimulate PCho production. The time course of induction of oocyte maturation by microinjection of p21ras closely resembles that generated by microinjection of PC-PLC, indicating that activation of p21ras and PC-PLC are both late events. Interestingly, expression of PC-PLC can overcome inhibition of proliferation of $\mathrm{NIH} 3 \mathrm{~T} 3$ cells by a dominant inhibitory p21ras mutant [p21ras(Asn17)] (Cai et al., 1992), suggesting that PC hydrolysis is the target of p21ras, which mediates mitogenic signaling. In addition, stimulation of PC-PLC-catalyzed hydrolysis of PC induced by EGF or serum is inhibited by expression of $\mathrm{p} 21$ ras(Asn17), indicating that $\mathrm{p} 21$ ras mediates growth factor-induced activation of $\mathrm{PC}$ PLC (Cai et al., 1992). Altogether, these data suggest the existence of a mitogenic signaling pathway in which p21ras would, as a late but crucial event in mitogenesis, activate PC-PLC.

However, some questions remain, for example, the timing of this mitogenic signaling pathway. For PDGF-stimulated mitogenesis, activation of PC-PLC seems to occur around $8 \mathrm{~h}$ after addition of PDGF (Larrodera et al., 1990). Also, serum-stimulated DNA synthesis is sensitive to inhibition by the anti-ras neutralizing antibody Y13-259 up to around $8 \mathrm{~h}$ after addition of serum (Mulcahy et al., 1985). This suggests that activation of PC-PLC by p21ras occurs at a very late stage in mitogenic signaling. However, we know that p21ras is activated rapidly in response to different growth factors, and from experiments with $X$. laevis oocytes, it is suggested that PC-PLC is activated rapidly upon microinjection of oncogenic p21ras (Lacal et al., 1987a). Why, then, would activation of PC-PLC occur as a late event in mitogenic signaling by these growth factors? One could argue that the levels of p21 ras-GTP after growth factor stimulation are not comparable with those as a result of microinjection, but this would lead to the conclusion that activation of PC-PLC cannot occur in response to physiological levels of $\mathrm{p} 21$ ras-GTP. To add to this confusion, PDGF stimulation was initially reported to give rise to a very rapid release in PCho (Besterman et al., 1986; Pessin et al., 1990), but these early time points were not studied in later studies, where a delayed response was observed. Because addition of PC-PLC seems sufficient to overcome inhibition of p21ras, this would suggest that activation of PC-PLC is the only crucial event in mitogenic signaling downstream of p21ras. If this is so, then one would come to the remarkable conclusion that all early events occurring within minutes of growth factor stimulation (such as activation of $\mathrm{p} 21$ ras, erks, induction of fos expression, etc.) are required only for the eventual induction of PC-PLC, which occurs $8 \mathrm{~h}$ later. It should be noted that a discrepancy exists as to the kinetics of PCho release upon microinjection of oncogenic p21ras in X. laevis. In one study, PCho release was detected $2 \mathrm{~h}$ after microinjection of oncogenic p21 ras (Diaz-Meco et al., 1992), whereas others detected increased levels of PCho at $30 \mathrm{~min}$ after microinjection (Garcia de Herreros et al., 1991; Lacal et al., 1987a). Therefore, activation of $\mathrm{p} 21$ ras could be very closely linked to activation of PC-PLC, but these events might just as well be separated by more than $1 \mathrm{~h}$ in mitogenic signaling.

Confusion also exists as to the signals produced by PC-PLC. At first sight, the production of DAG would provide an adequate second messenger, causing activation of PKC. However, PC-PLC- 
induced DNA synthesis in Swiss 3T3 fibroblasts (Larrodera et al., 1990), as well as induction of stromelysin expression (Diaz-Meco et al., 1991), is independent of phorbol ester-sensitive PKC. In contrast, maturation of $X$. laevis oocytes by PC-PLC requires the function of PKC- $\zeta$ (Dominguez et al., 1992). It could be that this isoform also is responsible for the induction of DNA synthesis in Swiss 3T3 fibroblasts because it is insensitive to TPA downregulation (Ono et al., 1989). In addition, activation of $\mathrm{PC}$ hydrolysis by oncogenic $\mathrm{p} 21$ ras in Swiss 3T3 cells seems to require a phorbol ester PKC (Price et al., 1989). This would place PKC both up- and downstream of PC-PLC in Swiss 3T3 cells, the PKC, with the isoform upstream being sensitive to phorbol esters, and the PKC isoform downstream being insensitive to phorbol esters. Other metabolites that are produced as a result of increased levels of DAG, such as arachidonic acid, phosphatidic acid (PA), and LPA, also could function as "second" messengers. Indeed, PA and LPA are very good mitogens when added to A431 and rat-1 cells (Moolenaar et al., 1986; van Corven et al., 1989), and mitogenic signaling by EGF in $\mathrm{Balb} / \mathrm{c} 3 \mathrm{~T} 3$ cells requires arachidonic acid metabolism, although the sole addition of arachidonic acid metabolites is not sufficient for mitogenesis (Handler et al., 1990). Taken together, a function for PC-PLC somewhere downstream of p21ras in mitogenic signal transduction is a serious possibility, although many questions are still unanswered concerning the timing of this effect and the character of the signal that is generated.

\section{Role of Protein Kinase}

As already mentioned, PKC appears to play an important role in the transformation of cells by oncogenic forms of p21ras. However, the exact position and role of $\mathrm{PKC}$ in signal transduction by p21ras is a matter of debate. Most of this controversy stems from the fact that no experimental approaches are available at present that can inhbiit or distinguish all of the different isoforms of PKC. A present, ten different isoforms of PKC have been identified, with distinct enzymological characteristics and tissue-specific distribution. The four classical isoforms, or cPKC isoforms $\left(\alpha, \beta_{1}, \beta_{2}\right.$, and $\gamma$ ) are activated by $\mathrm{Ca}^{2+}$ and DAG (Nishizuka,
1988), whereas the isoforms of the nPKC (novel PKC) subspecies $(\delta, \varepsilon, \eta(\mathrm{L})$, and $\theta)$ are activated by DAG in the absence of $\mathrm{Ca}^{2+}$ (Koide et al., 1992; Ogita et al., 1992). All these isoforms respond well to phorbol esters (Koide et al., 1992; Nishizuka, 1988; Ogita et al., 1992). The two isoforms of the most recently discovered PKC subspecies, the atypical PKC isoforms (aPKC) $(\zeta$ and $\lambda$ ) apparently do not respond to DAG or $\mathrm{Ca}^{2+}$, nor to phorbol esters (Ono et al., 1989; Ways et al., 1992). This indicates that retention of PKC activity is possible after prolonged treatment with phorbol esters, an approach that is widely used to investigate the involvement of $\mathrm{PKC}$ in signaling pathways. Indeed, examples show that not all PKC activity is downregulated after prolonged treatment with phorbol esters (Cooper et al., 1989; Isakov et al., 1990; Ways et al., 1992). Moreover, even isoforms that are sensitive to phorbol esters can be retained (Borner et al., 1992; Strulovici et al., 1991). Therefore, conclusions based on depletion of PKC activity by prolonged exposure to phorbol esters need to be viewed with caution. Even more frustrating is the fact that some isoforms of PKC, which are downregulated in a specific cell type, may not behave as such in another cellular background. For instance, PKC- $\zeta$ is not downregulated by phorbol esters in a variety of cell lines (Ways et al., 1992), but can be downregulated in R6 rat embryo fibroblasts (Borner et al., 1992). Specific phosphorylation of PKC substrates, such as the $80-\mathrm{kDa}$ MARCKS protein, is often used as a measure for the state of total PKC activity in the cell. Since the MARCKS protein itself was recently found to be downregulated by prolonged treatment with TPA, this measurement may not be a good readout for total PKC activity (Brooks et al., 1991). The use of PKC inhibitors, such as staurosporine, sphingosine, and $\mathrm{H} 7$, would be more appropriate, but the specificity of these compounds also is questionable. More specific inhibition can be accomplished by making use of the pseudosubstrates of PKC isoforms, but these compounds do not easily enter the cell, so that permeabilization or transfection of expression plasmids is required. It seems that with the current knowledge of PKC, it would be more appropriate to draw conclusions about the involvement of specific isoforms and not to address PKC as one enzymatic entity. 
Nevertheless, some conclusions can be drawn from the vast amount of data that is available on the role of $P K C$ in p21ras signaling. For instance, TPA-induced DNA synthesis in NIH3T3 cells can be inhibited by microinjection of $\mathrm{Y} 13$ 259 or expression of p21ras(Asn 17) (Cai et al., 1990; Yu et al., 1988). Also overexpression of p120GAP can block c-fos expression, activation of erk2, and DNA synthesis induced by TPA in Swiss 3 T3 cells (Nori et al., 1991), suggesting that $\mathrm{p} 21$ ras mediates TPA-induced PKC signal transduction. In PC12 cells, TPA-induced activation of raf-1 kinase, erks, and p90rsk is blocked by the expression of $\mathrm{p} 21 \mathrm{ras}(\mathrm{Asn} 17$ ) (Thomas et al., 1992; Wood et al., 1992). In contrast, TPAinduced activation of erk2 in COS-1 cells (Howe et al., 1992) or rat-1 cells (de Vries-Smits et al., 1992) and induction of fos expression by TPA also are not blocked by the expression of p21ras(Asn17) (Cai et al., 1990). It is possible that these conflicting results are a consequence of the difference in cell type. Alternatively, as mentioned previously, inhibition through interference with the function of p21ras does not necessarily point to a common pathway, but could just as well plead for cooperating routes.

Direct proof that PKC can function as upstream activator of $\mathrm{p} 21$ ras comes from $\mathrm{T}$ cells, where a rapid and profound increase in the level of p21ras-GTP could be observed after TPA treatment (Downward et al., 1990a). Also, in PC12 cells, the combination of TPA and the tyrosine phosphatase inhibitor vanadate can cause activation of p21ras through the TPA-sensitive PKC (Satoh et al., 1991). However, functional PKC does not seem to be required for activation of p21ras in T cells inasmuch as pseudosubstrates of PKC could not prevent activation of p21ras by stimulation of the T-cell receptor in permeabilized cells (Izquierdo et al., 1992), demonstrating that the TCR-signaling pathway does not necessarily signal via PKC. Also, in fibroblasts, no evidence has been found that activation of PKC can drive p21ras in the active conformation. Indeed, phorbol ester-sensitive isoforms of PKC are not required for activation of $\mathrm{p} 21 \mathrm{ras}$ by different growth factors in fibroblasts (Medema et al., 1991a; Satoh et al., 1991), which shows that activation of p21ras by (phorbol ester-sensitive) PKC is limited to certain cell types.
PKC also plays an important role downstream of p21ras. For instance, scrape loading of p21ras into Swiss 3T3 cells rapidly activates $\mathrm{PKC} \mathrm{(Morris}$ et al., 1989). Moreover, microinjection or scrape loading of oncogenic p21ras fails to induce DNA synthesis in cells where PKC has been downregulated by prolonged treatment with phorbol esters (Lacal et al., 1987c; Morris et al., 1989). In ras-transformed cells, the sustained activation of PKC is observed, without a concomitant downregulation of the enzyme (Diaz-Laviada et al., 1990). Furthermore, PKC- $\zeta$ functions downstream of p21 ras in insulin-induced oocyte maturation (Dominguez et al., 1992). As mentioned previously, different isoforms of PKC mediate signaling to and from PC-PLC in ras signaling (Diaz-Laviada et al., 1990; Price et al., 1989). These data suggest that PKC could be required at multiple stages during p21ras signal transduction. Most likely, separate isoforms are responsible for signal transduction at each stage. However, a reliable determination of the position of PKC isoforms in this pathway will await the development of good reagents that can specifically inhibit each of the different isoforms.

\section{E. Transcription Factors}

In ras-transformed cells, many genes are differently expressed, but initially it was unclear whether the altered expression of these genes was a direct consequence of the presence of active p21ras or an indirect consequence of transformation. Therefore, investigators analyzed the expression of certain genes in cells where oncogenic p21ras could be conditionally expressed or introduced by microinjection. Using these methods, a number of genes were shown to be upregulated upon the appearance of oncogenic p21 ras, such as the stromelysin gene (Matrisian et al., 1986), the collagenase gene (Schönthal, 1988), the c-fos gene (Schönthal, 1988; Stacey et al., 1987), VL30driven constructs (Owen et al., 1990), and the TGF- $\beta$ gene (Owen and Ostrowski, 1990). Transcriptional activation of these genes by oncogenic p21ras is mediated by a number of binding sites: the TRE (TPA-responsive element) (Gutman and Wasylyk, 1990; Imler et al., 1988), the PEA3binding site (Wasylyk et al., 1989), or the RRE 
(ras-responsive element) (Owen and Ostrowski, 1990). This indicated that 221 ras can specifically regulate the activity of the transcription factors that bind to these sites. The AP-1 transcription factor (which binds to the TRE) is composed of heterodimers of c-jun and c-fos family members, which are themselves oncoproteins (reviewed in Vogt and Bos, 1990). The products of the ets-1 and ets- 2 oncogenes can activate transcription by binding to the PEA3 binding site (Wasylyk et al., 1990), and the RRE binds AP-1, ets-2, and a protein of $120 \mathrm{kDa}$ functionally related to known ets-coded proteins (Langer et al., 1992; Owen and Ostrowski, 1990; Wasylyk et al,, 1990). The ets-1 protein cooperates with c-jun and c-fos for activation of transcription from the polyoma enhancer (Gutman and Wasylyk, 1990). The AP-1 binding site in the collagenase promoter is sufficient to confer ras responsiveness, but when the PEA3binding site is present, this response is enhanced (Imler et al., 1988). This indicates that p21ras can activate transcription through c-jun or c-fos and that ets can enhance this effect (for a review, see Bortner et al., 1993). Several mechanisms by which p21ras can stimulate AP-1-dependent transcription have evolved. First, the c-jun protein is posttranslationally modified upon the appearance of active p21ras, resulting in a stimulation of its transactivating potential (Binétruy et al., 1991; Pulverer et al., 1991; Smeal et al., 1991, 1992). In addition, the expression of c-fos is transiently induced by active p21ras, resulting in increased AP-1 binding activity (Schönthal, 1988; Stacey et al., 1987). The transient nature of this induction is a consequence of repression of fos-promoter activity by elevated levels of $c$-fos (Schönthal, 1988). Finally, this initial stimulation of AP-1 activity gives rise to a more sustained increase in c-jun expression mediated by a TRE in the c-jun promoter (Angel et al., 1988).

Activation of the $c$-jun protein is associated with phosphorylation of its activation domain, as well as dephosphorylation of at least one of three inhibitory phosphorylation sites next to its DNAbinding domain (Boyle et al., 1991). In unstimulated cells, c-jun is phosphorylated on the inhibitory sites (Boyle et al., 1991). Initially, glycogen synthase kinase 3 (GSK3) was held responsible for this phosphorylation (Woodgett, 1991), but recently evidence has been obtained that casein kinase II (CKII) phosphorylates c-jun at these sites (Lin et al., 1992). This finding suggests that CKII negatively regulates the expression of genes that are transactivated by c-jun. This is in apparent contradiction with the finding that several growth factors that stimulate expression of AP-1inducible genes also enhance CKII activity (Ackermann et al., 1990; Klarlund and Czech, 1988; Sommercorn et al,, 1987). In addition, CKII can stimulate $\mathrm{c}$-fos expression through activation/ phosphorylation of the serum-response factor (SRF), suggesting that CKII has a positive effect on gene expression (Gauthier-Rouvière et al., 1991; Manak et al., 1990). At present, no data are available concerning the effect of $\mathrm{p} 21$ ras on the activity of CKII.

Phosphorylation of the sites in the activation domain of c-jun can be established by erk 2 in vitro, suggesting that erk2 is the connection between p21ras and c-jun (Pulverer et al., 1991). However, a c-jun protein kinase has been isolated by association to recombinant jun protein, but does not appear to be erk1 or erk2 (Adler et al,, 1992). Jun activity is required for ras transformation, indicating that $\mathrm{c}$-jun is a mediator of $\mathrm{p} 21 \mathrm{ras}$ action (Lloyd et al., 1991). Moreover, ras-induced expression from promoters containing AP-1- and PEA3-binding sites requires raf-1 kinase, suggesting that this route is likely to involve erk2 (Bruder et al., 1992). Other possible candidates for phosphorylation by erk2 are p62TCF and myc (Gille et al., 1992; Seth et al., 1991), but not much is known about the involvement of $\mathrm{p} 21$ ras in the regulation of the transcriptional activity of these factors.

\section{IV. p21ras IN DEVELOPMENT}

\section{A. Proliferation vs. Differentiation}

The identification of ras genes as transforming oncogenes made researchers initially focus on the positive role of p21ras in the proliferative signals of various growth factors. Clearly, as discussed herein, p21ras activation plays a decisive role in the onset of proliferation in fibroblasts. However, not long after the discovery of $\mathrm{p} 21$ ras as an oncoprotein, it became apparent that ras proteins also play a crucial role in differentiation. 
For instance, microinjection of oncogenic forms of p21ras into PC12 cells causes an induction of neurite outgrowth and a block of cellular proliferation (Bar-Sagi and Feramisco, 1985; Noda et al., 1985). Expression of oncogenic p21 ras leads to proliferation arrest in Schwann cells (Ridley et al, 1988) and causes differentiation in F9 embryonal carcinoma cells (Yamaguchi-Iwai et al., 1990). Also, introduction of v-H-ras in cultured human medullary thyroid carcinomas (MTC) induces differentiation, a process that actually opposes the normal tumor progression of these carcinomas (Nakagawa et al., 1987). Again, introduction of oncogenic p21ras causes a reduced cellular proliferation. Furthermore, differentiation of 3T3-L1 into adipocytes can be induced by expression of oncogenic $\mathrm{p} 21 \mathrm{ras}$, a process that normally requires insulin or IGF-1 (Benito et al., 1991). In contrast, oncogenic p21ras seems to have a negative effect on myogenic differentiation (Olson et al., 1987) and $\mathrm{Ca}^{2+}$-induced differentiation of keratinocytes (Weissman and Aaronson, 1983). Thus, it seems that the cellular context determines whether $\mathrm{p} 21$ ras controls differentiation or proliferation.

This explanation was challenged, however, by the finding that both NGF and EGF can cause an activation of endogenous p21 ras in PC12 cells (Qiu and Green, 1991). Remarkably, only NGF induces differentiation of PC12 cells, whereas EGF will induce proliferation. Using neutralizing antibodies and dominant inhibitory mutants, it was shown that induction of differentiation depends on the activity of $\mathrm{p} 21$ ras, whereas normal cellular proliferation is not affected (Hagag et al., 1986; Szeberényi et al., 1990). Moreover, microinjection of oncogenic p21ras alone is sufficient for neuronal differentiation (Bar-Sagi and Feramisco, 1985; Noda et al., 1985). This raises an intriguing question: why does EGF not induce differentiation of $\mathrm{PC} 12$ cells? Of course, one could argue that microinjection of oncogenic p21ras overrules the requirement of synergizing pathways that are normally activated by NGF, but not by EGF, which function independently of p21ras. Also, EGF could activate additional routes that may cause the cell to proliferate. Alternatively, quantitative differences in the activation of $\mathrm{p} 21$ ras may exist that can explain the difference in response. As a matter of fact, the activation of p21ras by EGF is transient, whereas the activation by NGF is a more lasting response (Qiu and Green, 1992). This might seem a minor difference at first sight, but one that may have major consequences for the downstream signaling from p21ras. It turns out that translocation of erk2 to the nucleus occurs only in response to NGF. EGF causes activation of erk2, but no erk2 can be detected in the nucleus after stimulation with EGF (Traverse et al., 1992), possibly a consequence of the transient nature of the erk 2 activation. Active erk2 in the nucleus may phosphorylate various transcription factors that cannot serve as substrates of cytoplasmic erk2. These transcription factors could then regulate the transcription of genes involved in the differentiation of PC12 cells. However, it remains to be established whether this translocation is the decisive factor for the cell to differentiate.

Although these data suggest that in $\mathrm{PC12}$ cells the time course of p21ras activation is crucial for it to function in the induction of proliferation or differentiation, such criteria may not apply to other cell types. For instance, insulin stimulation of A14 cells (NIH3T3 cells overexpressing the human insulin receptor) results in a durable activation of $\mathrm{p} 21$ ras, concomitant with increased DNA synthesis (Osterop et al., 1993). In contrast, EGF-induced activation of p21ras in rat-1 cells is transient, but also induces a marked stimulation of DNA synthesis. Moreover, the hypothesis that translocation of erk2 is required for it to activate transcription factors remains to be tested. Clearly, the different effects of EGF and NGF in PC12 cells plus the fact that they utilize common pathways make these cells an ideal model system to study the events required to trigger either differentiation or proliferation.

\section{B. Development}

So far, we have mainly discussed the involvement of p21ras in signal transduction in mammalian cells. Nevertheless, elegant studies concerning the role of p21ras in signal transduction have been performed in a number of different organisms, in particular S. cerevisiae, Schizosaccharomyces pombe, $C$. elegans, and D. melanogaster. These studies show not only a remarkable conser- 
vation of the signaling pathways in which p21ras is involved, but also that certain conceptual differences exist. It is not within the scope of this review to give a complete description of the developmental processes controlled by $\mathrm{p} 21$ ras in the various organisms; excellent reviews have appeared on these issues (Broach, 1991; Greenwald and Rubin, 1992; Rubin, 1989, 1991; Sternberg and Horvitz, 1991). Here, we limit ourselves to an overview of the more recent findings and discuss their relevance with respect to the function of p21ras in mammalian cells.

In budding yeast (Saccharomyces cerevisiae), two genes, RAS1 and RAS2, have been identified that are structurally and functionally homologus to mammalian ras genes (Broek et al., 1985; DeFeo-Jones et al., 1983; Powers et al., 1984). However, despite the functional conservation, in budding yeast, RAS proteins function (exclusively) as upstream activators of adenylate cyclase (CYR1) (Kataoka et al., 1985; Toda et al., 1985), an enzyme that is not directly regulated by $\mathrm{p} 21$ ras in mammalian cells (Beckner et al., 1985). This RAS/cAMP system in budding yeast controls initiation of the cell cycle (reviewed in Broach, 1991). When nutrient levels are sufficiently high, cells enter the mitotic cycle. On the other hand, starvation causes an inactivation of this pathway, and consequently cells will enter $G_{0}$ and sporulate. Therefore, the activation state of RAS 1 and RAS2 is in some way linked to the nutrient status. Several regulatory proteins of RAS in budding yeast have been cloned, such as two different GNRPs, CDC25 and SDC25 (Broek et al., 1987; Camonis et al., 1986; Créchet et al., 1990; Jones et al,. 1991), and two different GAPs, IRA1 and IRA2 (Tanaka et al., 1989, 1990). These proteins show significant homology with their respective mammalian counterparts, and in fact, one mammalian GNRP has been cloned by functional complementation of a CDC25- strain (Martegani et al., 1992). Interestingly, both IRA 1 and IRA2 are not believed to function as effectors for RAS proteins, but solely downmodulate RAS activity, since the loss of function of both IRA1 and IRA2 suppresses the lethality of $\mathrm{CDC} 25$-null mutations (Tanaka et al., 1989). Finally, SRV2 (or CAP) seems to be required for efficient coupling of RAS to adenylate cyclase (Fedor-Chaiken et al., 1990; Field et al., 1990), which raises the ques- tion of whether similar proteins exist in mammalian cells. Despite the clear linkage of RAS and adenylate cyclase in budding yeast, it is unclear how the nutrient status can control the RAS/cAMP pathway. Recently, it was reported that in response to glucose, the CDC25 protein dissociates from RAS upon phosphorylation by cAMP-dependent protein kinase (Gross et al., 1992a). This indicates that activation of the CAMP/RAS pathway results in a reduced interaction of RAS with its upstream activator, $\mathrm{CDC} 25$, which could serve as a feedback mechanism. It has been proposed that allosteric (in)activation of regulatory proteins of RAS by certain metabolites of glucose could trigger the activation of RAS (Broach, 1991). If so, this provides us with interesting options for the regulation of $\mathrm{p} 21 \mathrm{ras}$ in mammalian cells. This situation would be somewhat similar to the regulation of p21ras by lipid metabolites discussed previously.

The fission yeast (Schizosaccharomyces pombe) contains a single ras gene, ras1 (Fukui and Kaziro, 1985). This ras gene is not required for growth control, as in budding yeast, but functions in the sexual differentiation pathways (Fukui et al., 1986; Nadin-Davis et al., 1986). Loss of function of ras1 results in a loss of pheromone response and sterile yeast strains. In fission yeast, no effector for ras1 has been identified, and the ste6 gene is the only regulatory gene for ras 1 identified thus far. The ste6 gene encodes a CDC25 homology and is therefore believed to be the GNRP for ras1 (Fukui et al., 1986; Hughes et al., 1990; Nadin-Davis et al., 1986). However, activation of ras1 alone does not seem to be sufficient for entry into meiosis, indicating that other pathways must be activated that synergize with ras 1 (Nielsen et al., 1992).

Recently, kinase cascades showing homology to the erk-kinase cascades in mammalian cells have been partially elucidated in both budding and fission yeast (Figure 7). In budding yeast, FUS3 and KSS1 encode erk homologs. Analogous to erks, FUS3 is phosphorylated on both tyrosine and threonine residues (separated by one amino acid) upon pheromone treatment (Gartner et al., 1922). Genetic evidence places the protein kinases STE7 and STE11 upstream of FUS3 and $\mathrm{KSS} 1$, in a pathway in which activation of STE11 would precede activation of STE7 (Cairns et al., 
mammals

S. pombe

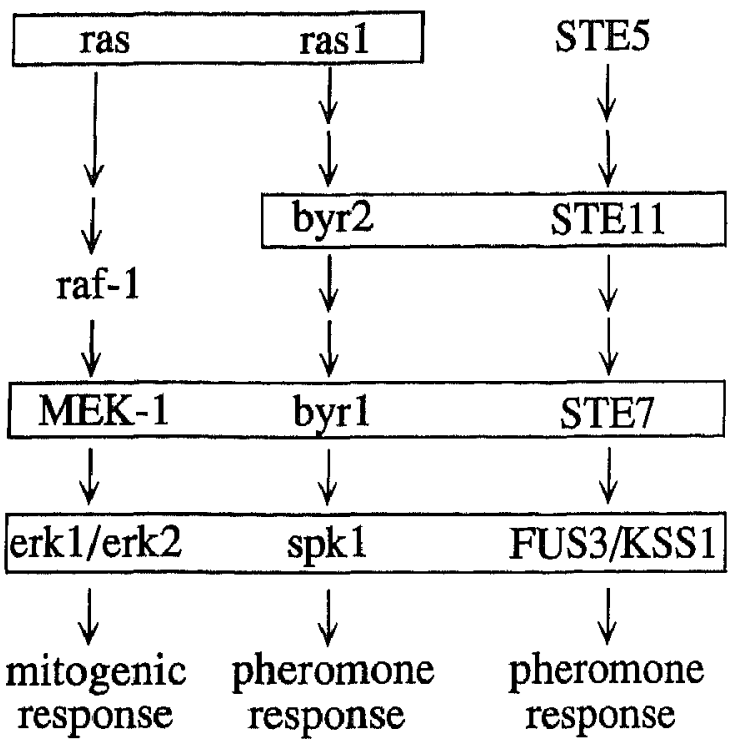

FIGURE 7. Conservation of a kinase cascade in yeast and mammals. Known intermediates of the kinase cascade initiated by p21 ras in mammalian cells, eventually leading to activation of erk1 and erk2 are depicted for Saccharomyces cerevisiae, Schizosaccharomyces pombe, and mammals. Intermediates that show homology throughout these species are boxed. At places where two arrows are shown between two intermediates, one or more proteins may be required for transduction of the signal.

1992; Stevenson et al., 1992). Similarly, in fission yeast, the protein kinase spk 1 represents an erk homolog (Toda et al., 1991), whereas byr1 (Nadin-Davis and Nasim, 1988, 1990) and byr2 (Wang et al., 1991) represent protein kinases that are both believed to function downstream of ras 1 . Sequence comparison shows that byr 1 and STE7 resemble mapkk (Crews et al., 1992; Howe et al., 1992), suggesting that the signal transduction pathway has been conserved. However, the mammalian raf-1 kinase, which has been proposed to be the kinase that activates mapkk (Dent et al., 1992; Howe et al., 1992; Kyriakis et al., 1992), shows no apparent homology to STE11 or byr2 (Howe et al., 1992). These kinases have been proposed to play a role upstream of STE7 and byr1, respectively, but are not necessarily immediately upstream of STE7 and byr1, and could just as well represent the yeast raf-kinase kinases. Altogether, the signal transduction pathway of fission yeast, more than that in budding yeast, shows a remarkable resemblance to the pathway that has recently become apparent in mammals, i.e., p21ras activates a kinase cascade that includes mapkk (STE11, byr2), which phosphorylates and activates erk (STE7, byr1). Further genetic analysis of this pathway in yeast will provide us with novel intermediates and targets of this pathway. Because the pathway is apparently so well conserved, homologs in mammals are likely to exist, although the RAS/cAMP system in Saccharomyces cerevisiae has clearly demonstrated that such extrapolations do not always hold.

C. elegans is the only multicellular organism for which a complete cell lineage map is available. The induction of vulva formation in this nematode is believed to be initiated by an inductive signal produced by a gonadal anchor cell that triggers the vulva precursor cells to divide and produce the vulva. Correct development of the vulva depends on the strength of the inductive signal. The inductive signal produced by the anchor cells will override an inhibitory signal and cause the cells close to the anchor cell to have the vulval fate. Interest for this organism from the ras field boomed when a gene was identified in C. elegans (let-60), that was shown to encode a protein homologous to mammalian p21 ras (Han and Sternberg, 1990) (Figure 8). This gene was originally isolated as a gene involved in vulva induction (Ferguson et al., 1987). Dominant mutations in let-60, which are similar to the oncogenic mutations in mammalian ras genes, lead to formation of the multivulva phenotype, whereas loss-of-function mutations invariably result in a vulvaless phenotype (Beital et al., 1990). By genetics, many other genes involved in vulva induction have been identified (Ferguson et al., 1987). Let-23, the first to be characterized, encodes a RTK with similarities to the EGF receptor (Aroian et al., 1990). More recently, a protein containing $\mathrm{SH} 2 / \mathrm{SH} 3$ domains was cloned from $C$. elegans (sem-5), and is involved in vulva induction (Clark et al., 1992). Genetic evidence places this protein downstream of let-23 and upstream of let- 60 , suggesting that $\mathrm{SH} 2 / \mathrm{SH} 3$ domains perform important functions in this pathway. An homologous protein from humans was tested for its function in p21ras signaling, based on the genetic linkage in nematodes. Remarkably, the human homolog, grb2, could cause DNA synthesis in 


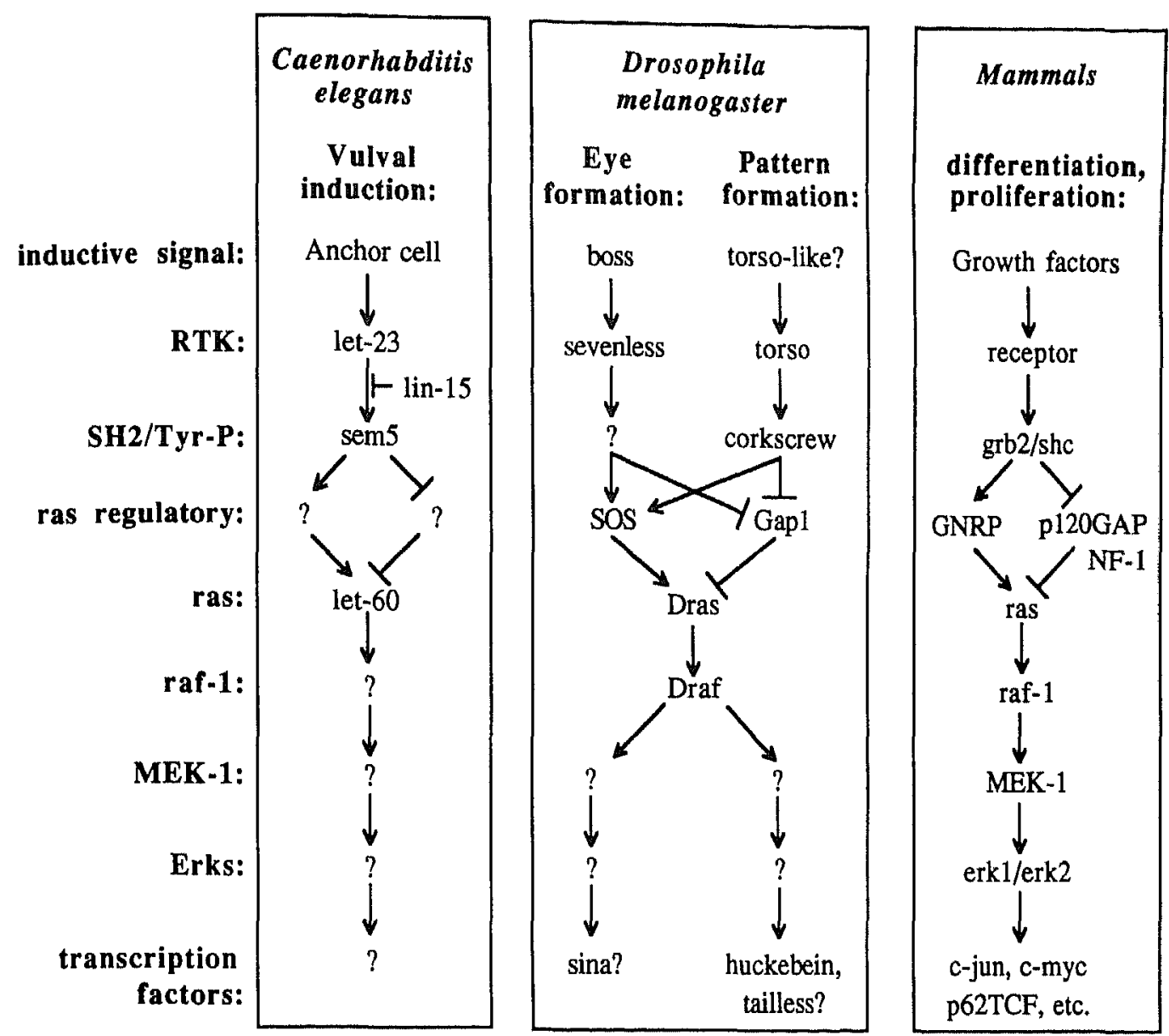

FIGURE 8. Ras signal transduction pathways in C. elegans, D. melanogaster, and mammals. RTK signaling via p21ras is initiated by an inductive signal, resulting in activation of the RTK. The next step most likely involves a network of tyrosine phosphorylations/dephosphorylations and SH2-mediated interactions, of which a few components have just recently become clear. This network must somehow result in activation of p21ras by means of activation of a GNRP or inactivation of a GAP, the level indicated as ras regulatory proteins. Ras activation then can activate the raf-1 kinase, although many intermediates could precede this particular activation. Raf- 1 kinase initiates a kinase cascade, which will eventually result in the transduction of the signal to the nucleus by phosphorylation of a number of transcription factors. The simple schemes presented here are partially based on speculations and serve to indicate the conservation in this particular signaling pathway, but it is likely that many other intermediates are critical to this pathway.

cells when coinjected with normal p21ras (see above). This clearly illustrates that the biological approach benefits from the groundwork layed by the genetic approach to 21 ras signaling.

In D. melanogaster, ras proteins regulate cell fate in the developing eye (Figure 8). The signaling pathway is somewhat reminiscent of that in C. elegans. Development of the R7 photoreceptor cell requires the interaction of the sevenless receptor ( $\mathrm{sev}$ ) with its ligand bride-on-sevenless (boss), which is expressed on the surface of an adjacent R8 cell (Krämer et al., 1991). The sevenless receptor encodes a transmembrane re- ceptor with tyrosine kinase activity (Hafen et al., 1987). Several mutant flies were subsequently isolated with aberrant R7 development. Analysis of these mutants revealed that the Drosophila ras1 gene was involved in this signal transduction pathway in control of R7 cell fate (Fortini et al., 1992; Simon et al., 1991). Moreover, a CDC25 homolog, son-of-sevenless (SOS), was identified as another gene involved in this pathway (Bonfini et al., 1992; Fortini et al., 1992; Simon et al., 1991). Therefore, it seems acceptable that the interaction of boss with the sevenless receptor causes activation of rasl. The activation of rasl, 
as in mammalian cells, requires the action of a guanine nucleotide release factor, a function that is most likely fulfilled by the sos protein. Also, a gene encoding a Drosophila homolog of the mammalian GAPs has been identified, called Gap1 (Gaul et al., 1992). Deletion of the Gapl gene leads to formation of supernumerary R7 cells, similar to what is seen in flies expressing ras 1 (Val12). This suggests that, at least for R7 induction, the Gapl protein does not function as an effector for rasl. Most interestingly, a Drosophila homolog of human rap1A (roughened) has been identified that apparently antagonizes the function of rasl (Hariharan et al., 1991). This is very similar to the finding that overexpression of rap $1 \mathrm{~A}$ can revert ras-transformed cells (Kitayama et al., 1989). The gain of function mutations of roughened affect a phenylalanine at position 157 that is conserved in raplA and H-ras, but no functional role has been ascribed to this amino acid. It will be of great interest to see whether a similar mutation in rap $1 A$ could also potentiate its role as a suppressor of ras transformation. Finally, the Drosophila homolog of raf-1 kinase, lethal(a)polehole or Draf (Mark et al., 1987), plays a crucial role in the $\mathrm{R} 7$ pathway (Dickson et al., 1992). Therefore, also in Drosophila, the p21 ras signaling pathway seems to be similar to what has been proposed in mammalian cells.

In addition to the function in eye development, functional Draf is required for head and tail formation in the developing Drosophila embryo (Ambrosio et al., 1989; St Johnston and NüssleinVolhard, 1992). This developmental process requires the protein products of torso and corkscrew (csw) (Casanova and Struhl, 1989; Klingler et al., 1988; Perkins et al., 1992; Sprenger et al., 1989), as well as two transcription factors, tailless and huckebein (reviewed in St. Johnston and NuissleinVolhard, 1992) (Figure 8). Torso appears to encode a RTK and corkscrew encodes a putative tyrosine phosphatase with two $\mathrm{SH} 2$ domains, similar to mammalian PTP1C (Shen et al, 1991). The involvement of Draf in this pathway suggests a function for rasl as well, based on the proposed signaling pathway in mammalian cells. Indeed, it seems that rasl also is required for torso signaling (cited in Roberts, 1992). Therefore, as in mammalian cells, p21ras and raf-1 kinase are important intermediates in signaling by different RTKs in
Drosophila and SH2-containing proteins perform important functions. The finding that a tyrosine phosphatase with $\mathrm{SH} 2$ domains plays a role in a RTK signaling route that also requires $\mathrm{p} 21$ ras opens up new perspectives. The importance of phosphatases in p21ras signaling in mammalian cells has indeed been implicated (Medema et al., 1991a) and therefore it will be of great interest to identify the mammalian homolog of corkscrew. This protein may prove to be an important mediator of RTK signaling toward p2lras.

Clearly, the conserved function of ras genes in different organisms enables us to take a genetic approach to tackling dilemmas such as the identification of the effector of p21ras, intermediates required for activation by RTKs, etc. Genetic and biochemical approaches to signal transduction have benefited from the progress shown in the separate fields, and it seems that future research will depend on a combination of both.

\section{CONCLUDING REMARKS}

The last few years have provided us with many new insights into the role of p21 ras in signal transduction, although important topics, such as the effector molecule of $\mathrm{p} 21 \mathrm{ras}$, mechanism of p21ras activation, and the role of $\mathrm{PKC}$ in the p21 ras pathway, remain to be covered. Most importantly, the ras protein seems to couple RTKs to kinase cascades, involving raf-1 kinase and erks, making signal transduction toward the nucleus possible. Clearly, SH2-containing proteins play an important adaptor function in this signaling pathway, possibly by altering the enzymatic activity of certain proteins by an allosteric activation. These functions as well as many components of the $\mathrm{p} 21$ ras signaling pathway, are apparently conserved through evolution. The available model systems in genetically well-defined organisms will certainly speed up the identification of regulatory proteins, as well as the downstream targets of p21ras. As usual, some questions have been answered, but many more have been created. Most importantly, a general scheme for signal transduction from RTKs via p21ras has evolved, which will direct future research to fill in many of the missing links. Ultimately, combined research efforts will elucidate the versatile role of 
p21ras in many key processes in development, i.e., cellular proliferation and differentiation. That our understanding of disease processes like cancer will benefit from this knowledge needs no explanation.

\section{ACKNOWLEDGMENTS}

The authors thank Boudewijn Burgering, Loesje van der Voorn, Bert Pronk, and JanPaul Medema for helpful discussions and critically reading the manuscript. We also thank Boudewijn Burgering, Gideon Bollag, and Frank McCormick for sharing unpublished observations. The work performed in the Laboratory for Physiological Chemistry at the University of Utrecht was sponsored in part by grants from the Dutch Cancer Foundation.

\section{REFERENCES}

Abraham, R. T., L. M. Karnitz, J. P. Secrist, and P. J. Leibson: Signal transduction through the T-cell antigen receptor. Trends Biochem. Sci., 17:434-438, (1992).

Ackermann, P., C. Glover, and N. Osherhoff: Stimulation of casein kinase II by EGF: relationship between the physiological activity of the kinase and the phosphorylation state of its beta subunit. Proc. Nall. Acad. Sci. U.S.A., 87:821-825 (1990).

Adari, H., D. R. Lowy, B. M. Willumsen, C. J. Der, and F. McCormick: Guanosine triphosphatase activating protein (GAP) interacts with the $\mathrm{p} 21$ ras effector binding domain. Science, 240:518-521 (1988).

Adler, V., A. Polotskaya, F. Wagner, and A. S. Kraft: Affinity-purified c-Jun amino-terminal protein kinase requires serine/threonine phosphorylation for activity. J. Biol. Chem., 267:17,001-17,005 (1992).

Ahn, N. G., J. E. Weiel, C. P. Chan, and E. G. Krebs: Identification of multiple epidermal growth factorstimulated protein serine/threonine kinases from Swiss 3T3 cells. J. Biol. Chem., 265:11487-1 1494 (1990).

Allessandrini, A., C. M. Crews, and R. L. Erikson: Phorbol ester stimulates a protein-tyrosine/threonine kinase that phosphorylates and activates the Erk-I gene product. Proc. Natl. Acad. Sci. U.S.A., 89:8200-8204 (1992).

Alvarez, E., I. C. Northwood, F. A. Gonzalez, D. A. Latour, A. Seth, C. Abate, T. Curran, and R. J. Davis: ProLeu-Ser/Thr-Pro is a consensus primary sequence for substrate protein phosphorylation. J. Biol. Chem., 266:15,277-15,285 (1991).
Ambrosio, L., A. P. Mahowald, and N. Perrimon: Requirement of the Drosophila raf homologue for torso function. Nature, 342:288-291 (1989).

Anderson, D., C. A. Koch, L. Grey, C. Ellis, M. F. Moran, and T. Pawson: Binding of SH2 domains of phospholipase $\mathrm{C} \gamma \mathrm{l}, \mathrm{GAP}$, and src to activated growth factor receptors. Science, 250:979-982 (1990a).

Anderson, N. G., P. Li, L. A. Marsden, N. Williams, T. M. Roberts, and T. W. Sturgill: Raf-1 is a potential substrate for mitogen-activated protein kinase in vivo. Biochem. J., 277:573-576 (1991).

Anderson, N. G., J. L. Maller, N. K. Tonks, and T. W. Sturgill: Requirement for integration of signals from two distinct phosphorylation pathways for activation of MAP kinase. Nature, 343:651-653 (1990b).

Angel, P., E. Allegretto, S. Okino, K. Hattori, W. Boyle, T. Hunter, and M. Karin: Oncogene jun encodes a sequence specific transactivator similar to AP-1. $\mathrm{Na}$ ture, 332:166-171 (1988).

App, H., R. Hazan, A. Zilberstein, A. Ullrich, J. Schlessinger, and U.R. Rapp: Epidermal growth factor (EGF) stimulates association and kinase activity of raf- 1 with the EGF receptor. Mol. Cell Biol., 11:913-919 (1991).

Aroian, R. V., M. Koga, J. E. Mendel, Y. Ohshima, and P. W. Sternberg: The let-23 gene necessary for Caenorhabditis elegans vulval induction encodes a tyrosine kinase of the EGF receptor subfamily. Nature, 348:693-698 (1990).

Arshavsky, V. Y. and M. D. Bownds: Regulation of deactivation of photoreceptor $G$ protein by its target enzyme and cGMP. Nature, 357:416-417 (1992).

Asaoka, Y., M. Oka, K. Yoshida, and Y. Nishizuka: Metabolic rate of membrane-permeant diacylglycerol and its relation to human resting $T$-lymphocyte activation. Proc. Natl. Acad. Sci. U.S.A., 88:8681-8685 (1991).

Auger, K. R., L. A. Serunian, S. P. Soltoff, P. Libby, and L. C. Cantley: PDGF-dependent tyrosine phosphorylation stimulates production of noval polyphosphoinositides in intact cells. Cell, 57:167-175 (1989).

Baccarini, M., G. N. Gill, and E. R. Stanley: Epidermal growth factor stimulates phosphorylation of RAF-1 independently of receptor autophosphorylation and internalization. J. Biol. Chem., 266:10,941-10,945 (1991).

Baccarini, M., D. M. Sabatini, H. App, U. R. Rapp, and E. R. Stanley: Colony stimulating factor-1 (CSF-1) stimulates temperature dependent phosphorylation and activation of the RAF-1 proto-oncogene product. $E M B O$ $J$, 9:3649-3657 (1990).

Backer, J. M., M. G. Myers, Jr., S. E. Shoelson, D. J. Chin, X.-J. Sun, M. P. Miralpeix, P. Hu, B. Margolis, E. Y. Skolnik, J. Schlessinger, and M. F. White: Phosphatidylinositol $3^{\prime}$-kinase is activated by association with IRS-1 during insulin stimulation. EMBO J., 11:3469 3479 (1992).

Ballester, R., D. Marchuk, M. Boguski, A. Saulino, R. Letcher, M. Wigler, and F. Collins: The NFI locus encodes a protein functionally related to mammalian GAP and yeast IRA proteins, Cell, 63:851-859 (1990). 
Ballou, L. M., H. Luther, and G. Thomas: MAP2 kinase and $70 \mathrm{~K}$ S6 kinase lie on distinct signalling pathways. Nature, 349:348-350 (1991).

Bar-Sagi, D. and J. R. Feramisco: Microinjection of the ras oncogene protein into $\mathrm{PCl} 2$ cells induces morphological differentiation. Cell, 42:841-848 (1985).

Bar-Sagi, D. and J. R. Feramisco: Induction of membrane ruffling and fluid phase pinocytosis in quiescent fibroblasts by ras proteins. Science, 233:1061-1068 (1986).

Barbacid, M.: ras genes. Annu. Rev. Biochem., 56:779-827 (1987).

Basu, T. N., D. H. Gutmann, J. A. Fletcher, T. W. Glover, F. S. Collins, and J. Downward: Aberrant regulation of ras proteins in malignant tumor cells from type 1 neurofibromatosis patients. Nature, 356:713-715 (1992).

Beckner, S. K., S. Hattori, and T. Y. Shih: The ras oncogene product p21 is not a regulatory component of adenylate cyclase. Nature, 317:71-72 (1985).

Beitel, G. J., S. G. Clark, and H. R. Horvitz: Caenorhabditis elegans ras gene let-60 acts as a switch in the pathway of vulval induction. Nature, 348:503-509 (1990).

Benito, M., A. Porras, A. R. Nebreda, and E. Santos: Differentiation of 3T3-L1 fibroblasts to adipocytes induced by transfection of ras oncogenes. Science, 253:565568 (1991).

Berridge, M. J.: Inositol triphosphate and diacylglycerol: two interacting second messengers. Annu. Rev. Biochem., 56:159-193 (1987).

Berry, N., K. Ase, A. Kishimoto, and Y. Nishizuka: Activation of resting human $T$ cells requires prolonged stimulation of protein kianse C. Proc. Natl. Acad. Sci. U.S.A., 87:2294-2298 (1990).

Berstein, G., J. L. Blank, D.-Y. Jhon, J. H. Exton, S. G. Rhee, and E. M. Ross: Phospholipase C- $\beta 1$ is a GTPaseactivating protein of $G_{q / 11}$, its physiologic regulator. Cell, 70:411-418 (1992).

Besterman, J. M., V. Duronio, and P. Cuatrecasas: Rapid formation of diacylglycerol from phosphatidylcholine: a pathway for generation of a second messenger. Proc. Natl. Acad. Sci. U.S.A., 83:6758-6789 (1986).

Binétruy, B., T. Smeal, and M. Karin: Ha-Ras augments c-Jun activity and stimulates phosphorylation of its activation domain. Nature, 351:122-127 (1991).

Birchmeier, C., D. Broek, and M. Wigler: RAS proteins can induce meiosis in Xenopus oocytes. Cell, 43:615-621 (1985).

Bjorge, J. D. and J. E. Kudlow: Epidermal growth factor receptor synthesis is stimulated by phorbol ester and epidermal growth factor: evidence for a common mechanism. J. Biol, Chem., 262:6615-6622 (1987).

Blackshear, P. J., D. McNeill Haupt, H. App, and U. R. Rapp: Insulin activates the raf-1 protein kinase. $J$. Biol. Chem, 265:12,131-12,134 (1990).

Bollag, G. and F. McCormick: Differential regulation of rasGAP and neurofibromatosis gene product activities, Nature, 351:576-579 (1991).

Bollag, G. and F. McCormick: NF is enough of GAP. $\mathrm{Na}$ ture, 356:663-664 (1992).
Bonfini, L., C. A. Karlovich, C. Dasgupta, and U. Banerjee: The Son of sevenless gene product: a putative activator of Ras. Science, 255:603-606 (1992).

Borner, C., S. N. Guadagno, D. Fabbro, and I. B. Weinstein: Expression of four protein kinase $\mathrm{C}$ isoforms in rat fibroblasts. J. Biol. Chem., 267:12,892-12,899 (1992).

Bortner, D. M., M. Ulivi, M. F. Roussel, M. C. Ostrowski: The carboxy-terminal catalytic domain of the GTPaseactivating protein inhibits nuclear signal transduction and morphological transformation mediated by the CSF-1 receptor. Genes Dev., 5:1777-1785 (1991).

Bortner, D. M., S. J. Langer, and M. C. Ostrowski: Nonnuclear oncogenes and the regulation of gene expression in transformed cells, CRC Crit. Rev. Oncogene., 4:137-160 (1993).

Bos, J. L.: ras oncogenes in human cancer: a review. Cancer Res., 49:4682-4689 (1989).

Bourne, H. R., D. A. Sanders, and F. McCormick: The GTPase superfamily: a conserved switch for diverse cell functions. Nature, 348:125-132 (1990a).

Bourne, H. R., D. A. Sanders, and F. McCormick: The GTPase superfamily: conserved structure and molecular mechanism. Nature, 349:1 17-127 (1990b).

Bourne, H. R, and L. Stryer: The target sets the tempo. Nature, 358:54l-543 (1992).

Bowlell, D., P. Fu, M. Simon, and P. Senior: Identification of murine homologues of the Drosophila Son of sevenless gene: potential activators of ras. Proc. Natl. Acad. Sci. U.S.A., 89:6511-6515 (1992).

Boyle, W. J., T. Smeal, L. H. K. Defize, P. Angel, J. R. Woodgett, $M$. Karin, and T. Hunter: Activation of protein kinase $\mathrm{C}$ decreases phosphorylation of $\mathrm{c}$-Jun at sites that negatively regulate its DNA-binding activity, Cell, 64:573-584 (1991).

Broach, J. R.: Ras genes in Saccharomyces cerevisiae signal transduction in search of a pathway. Trends Genet., 7:28-33 (1991)

Broek, D., N. Simiy, O. Fasano, A. Fujiyama, F. Tamanoi, $J$. Northup, and M. Wigler: Differential activation of yeast adenylate cyclase by wild-type and mutant ras proteins. Cell, 41:763-769 (1985).

Broek, D., T. Toda, T. Michaeli, L. Levin, C. Birchmeier, M. Zoller, S. Powers, and M. Wigler: The S. cerevisiae $C D C 25$ gene product regulates the $R A S /$ adenylate cyclase pathway. Cell, 48:789-799 (1987).

Brooks, S. F., T. Herget, J. D. Erusalimsky, and E. Rozengurl; Protein kinase $\mathrm{C}$ activation potentially down-regulates the expression of its major substrate, $80 \mathrm{~K}$, in Swiss 3T3 cells. EMBO J., 10:2497--2505 (1991).

Bruder, J. T., G. Heidecker, U. R. Rapp: Serum-, TPA-, and Ras-induced expression from Ap-1/Ets-driven promoters requires Raf-1 kinase. Genes Dev., 6:545-556 (1992).

Burgering, B. M. T., A. M. M. de Vries-Smits, R. H. Medema, P. van Weeren, and J. L. Bos: Epidermal growth factor activates extracellular signal-regulated kinase 2 via p21 ras-dependent and independent pathways. Mol. Cell. Biol., in press (1993a).

Burgering, B. M. T., E. Freed, L. van der Voorn, F. McCormick, and J. L. Bos: PDGF-induced p21 ras- 
mediated signalling is independent of PDGF receptor interaction with GAP or Pl-3 kinase. EMBO $J_{.}$, in press (1993b).

Burgering, B. M. T., R. H. Medema, J. A. Maassen, M. L. Van de Wetering, A. J. Van der Eb, F. McCormick, and J. L. Bos: Insulin stimulation of gene expression mediated by p21ras activation. EMBO J., 10:11031109 (1991)

Buss, J. E. and B. M. Sefton: Direct identification of palmitic acid as the lipid attached to $221^{\text {ras }}$. Mol. Cell. Biol, 6:116-122 (1986).

Bustelo, X. R., J. A. Ledbetter, and M. Barbacid: Product of vav proto-oncogene defines a new class of tyrosine protein kinase substrates. Nature, 356:68-74 (1992).

Cai, H., P. Erhardt, J. Szeberényi, M. T. Diaz-Meco, T. Johansen, J. Moscat, and G. M. Cooper: Hydrolysis of phosphatidylcholine is stimulated by ras proteins during mitogenic signal transduction. Mol. Cell. Biol., 12:5329-5335 (1992).

Cai, H., J. Szeberényi, and G. M. Cooper: Effect of a dominant inhibitory Ha-ras mutation on mitotic signal transduction in NIH 3T3 cells. Mol. Cell. Biol., 10:5314 5323 (1990).

Cairns, B. R., S. W. Ramer, and R. D. Kornberg: Order of action of components in the yeast pheromone response pathway revealed with a dominant allele of the STE11 kinase and the multiple phosphorylation of the STE7 kinase. Genes Dev., 6:1305-1318 (1992).

Cales, C., J. F. Hancock, C. J. Marshall, and A. Hall: The cytoplasmic protein GAP is implicated as the target for regulation by the ras gene product. Nature, 332:548-551 (1988).

Camonis, J. H., M. Kalékine, B. Gondré, H. Garreau, E. Boy-Marcotte, and M. Jacquet: Characterization, cloning and sequence analysis of the $C D C 25$ gene which controls the cyclic AMP level of Saccharomyces cerevisiae. EMBO J., 5:375-380 (1986).

Campos-González, R. and J. R. Glenney: Tyrosine phosphorylation of mitogen-activated protein kinase in cells with tyrosine kinase-negative epidermal growth factor receptors. J. Biol. Chem., 267:14,535-14,538 (1992).

Cantley, L. C., K. R. Auger, C. Carpenter, B. Duckworth, A. Graziani, R. Kapeller, and S. Soltoff: Oncogenes and signal transduction. Cell, 64:281-302 (1991).

Carpenter, C. L., B. C. Duckworth, K. R. Auger, B. Cohen, B. S. Schaffhausen, and L. C. Cantley: Purification and characterization of phosphoinositide 3-kinase from rat liver. J. Biol. Chem., 265:19,704-19,711 (1990).

Carroll, M. P., I. Clark-Lewis, U. R. Rapp, and W. S. May: Interleukin-3 and granulocyte-macrophage colonystimulating factor mediate rapid phosphorylation and activation of cytosolic c-raf. J. Biol. Chem., 265:19,812-19,817 (1990).

Casanova, J. and G. Struhl: Localized surface activity of torso, a receptor tyrosine kinase, specifies terminal body pattern in Drosophila. Genes Dev., 3:2025-2038 (1989).

Casey, P. J., P. A. Solski, C. J. Der, and J. E. Buss; p21ras is modified by a farnesyl isoprenoid. Proc. Natl. Acad. Sci. U.S.A., 86:8323-8327 (1989).
Cawthon, R. M., R. Weiss, G. Xu, D. Viskochil, M. Culver, J. Stevens, M, Robertson, D. Dunn, R. Gesteland, P. O'Connell, and $\mathbf{R}$. White: A major segment of the neurofibromatosis type 1 gene: cDNA sequence, genomic structure, and point mutations. Cell, 62:193201 (1990).

Cen, H., A. G. Papageorge, R. Zippel, D. R. Lowy, and K. Zhang: Isolation of multiple mouse cDNAs with coding homology to Saccharomyces cerevisiae CDC25: identification of a region related to $\mathrm{Bcr}, \mathrm{Vav}, \mathrm{Dbl}$ and CDC24. EMBO J., 11:4007-4015 (1992).

Chan, A. C., M. Iwashima, C. W. Turck, and A. Weiss: ZAP. 70: a $70 \mathrm{kd}$ protein-tyrosine kinase that associates with the TCR $\zeta$ chain. Cell, 71:649-662 (1992).

Chang, E. H., M. E. Furth, E. M. Scolnick, and D. R. Lowy: Tumorigenic transformation of mammalian cells induced by a normal human gene homologous to the oncogene of Harvey murine sarcoma virus. Nature, 297:479-483 (1982).

Chant, J., K. Corrado, J. R. Pringle, and I. Herskowitz: Yeast $B U D 5$, encoding a putative GDP-GTP exchange factor, is necessary for bud site selection and interacts with bud formation gene BEMI. Cell, 65:1213-1224 (1991).

Chen, W. S., C. S. Lazar, M. Poenie, R. Y. Tsien, G. N. Gill, and M. G. Rosenfeld: Requirement for intrinsic protein tyrosine kinase in the immediate and late actions of the EGF receptor. Nature, 328:820-823 (1987).

Chenevert, J., K. Cotrado, A. Bender, J. Pringle, and I. Herskowitz: A yeast gene (BEMI) necessary for cell polarization whose product contains two SH3 domains. Nature, 356:77-79 (1992).

Chou, C. K., T. J. Dull, D. S. Russell, R. Gherzi, D. Lebwohl, A. Ullrich, and O. M. Rosen: Human insulin receptors mutated at the ATP-binding site lack protein tyrosine kinase activity and fail to mediate postreceptor events of insulin. $J$. Biol. Chem., 262:1842-1847 (1987).

Chou, M. M. J. E. Fajardo, and H. Hanafusa: The SH2- and SH3-containing Nck protein transforms mammalian fibroblasts in the absence of elevated phosphotyrosine levels. Mol. Cell. Biol., 12:5834-5842 (1992).

Chung, J., C. J. Kuo, G. R. Crabtree, and J. Blenis: RapamycinFKBP specifically blocks growth-dependent activation of and signaling by the $70 \mathrm{kd}$ S6 protein kinases. Cell, 69:1227-1236 (1992).

Cicchetti, P., B. J. Mayer, G. Thiel, and D. Baltimore: Identification of a protein that binds to the $\mathrm{SH} 3$ region of Abl and is similar to Bcr and GAP-rho. Science, 257:803-806 (1992).

Clark, S. G., M. J. Stern, and H. R. Horvitz: C. elegans cellsignalling gene sem-5 encodes a protein with $\mathrm{SH} 2$ and SH3 domains. Nature, 356:340-344 (1992).

Clarke, S., J. P. Vogel, R. J. Deschenes, and J. Stock: Posttranslational modification of the Ha-ras oncogene protein: evidence for a third class of protein carboxyl methyltransferases. Proc. Natl. Acad. Sci. U.S.A., 85:4643-4647 (1988).

Cooper, D. R., J. E. Watson, M. Acedevo-Duncan, R. J. Pollet, M.L. Standaert, and R. V. Farese: Retention of 
specific protein kinase $C$ isozymes following chronic phorbol ester treatment in BC3H-1 myocytes. Biochem. Biophys. Res. Commun., 161:327-334 (1989).

Coughlin, S. R., J. A. Escobedo, and L. T. Williams: Role of phosphatidylinositol kinase in PDGF receptor signal transduction. Science, 243:1191-1194 (1989).

Courtneidge, S. A. and A. Heber: An $81 \mathrm{kd}$ protein complexed with middle $T$ antigen and $p p 60^{r . s r}:$ a possible phosphatidylinositol kinase. Cell, 50:1031-1037 (1987).

Créchet, J.-B., P. Poullet, M.-Y. Mistou, A. Parmeggiani, J. Camonis, E. Boy-Marcotte, F. Damak, and M. Jacquet: Enhancement of the GDP-GTP exchange of RAS proteins by the carboxyl-terminal domain of SCD25. Science, 248:866-868 (1990).

Crews, C. and R. L. Erikson: Purification of a murine protein-tyrosine/threonine kinase that phosphorylates and activates the Erk-I gene product: relationship to the fission yeast byrl gene product. Proc. Natl. Acad. Sci. U.S.A., 89:8205-8209 (1992).

Crews, C. M., A. Allesandrini, and R. L. Erikson: The primary structure of MEK, a protein kinase that phosphorylates the ERK gene product. Science, 258:478480 (1992).

Cuadrado, A., C. J. Molloy, and M. Pech: Expression of protein kinase $\mathrm{C} \mathrm{I}$ in NIH 3T3 cells increases its growth response to specific activators. FEBS Lett., 260:281-284 (1990).

de Vries-Smits, A. M. M., B. M. T. Burgering, S. J. Leevers, C. J. Marshall, and J. L. Bos: Involvement of p2 1 ras in activation of extracellular signal-regulated kinase 2. Nature, 357:602-604 (1992).

DeClue, J. E., A. G. Papageorge, J, A. Fletcher, S. R. Diehl, N. Ratner, W. C. Vass, and D. R. Lowy: Abnormal regulation of mammalian $\mathrm{p} 21^{\text {ras }}$ contributes to malignant tumor growth in von Recklinghausen (type 1) neurofibromatosis. Cell, 69:265-273 (1992).

DeClue, J. E., W. C. Vass, A. G. Papageorge, D. R. Lowy, and $B . M$. Willumsen: Inhibition of cell growth by lovastatin is independent of ras function. Cancer Res., 51:712-717 (1991a).

DeClue, J. E., K. Zhang, P. Redford, W. C. Vass, and D. R. Lowy: Suppression of $s r c$ transformation by overexpression of full length GTPase-activating protein (GAP) or of the GAP C-terminus. Mol. Cell. Biol., 11:2819-2825 (1991b).

DeFeo-Jones, D., E. M. Scolnick, R. Koller, and R. Dhar: ras-related gene sequences identified and isolated from Saccharomyces cerevisiae. Nature, 306:707-709 (1983).

Dent, P., W. Haser, T. A. J. Haystead, L. A. Vincent, T. M. Roberts, and T. W. Sturgill: Activation of mitogenactivated protein kinase kinase by v-raf in NIH 3T3 cells and in vitro. Science, 257:1404-1407 (1992).

Devary, Y., R. A. Gottlieb, T. Smeal, and M. Karin: The mammalian ultraviolet response is triggered by activation of src tyrosine kinases. Cell, 71:1081-1091 (1992).

Diaz-Laviada, I., P. Larrodera, M. T. Diaz-Meco, M. E. Cornet, P. H. Guddal, T. Johansen, and J. Moscat; Evidence for a role of phosphatidylcholine-hydrolysing phospholipase $\mathrm{C}$ in the regulation of protein kinase $\mathrm{C}$ by ras and $\operatorname{src}$ oncogenes. EMBO J,, 9: 3907-3912 (1990).

Diaz-Meco, M. T., I. Dominguez, L. Sanz, M. M. Municio, E. Berra, M. E. Cornet, A. Garcia de Herreros, T. Johansen, and J. Moscat: Phospholipase C-mediated hydrolysis of phosphatidylcholine is a target of transforming growth factor $\beta 1$ inhibitory signals. Mol. Cell. Biol, 12:302-308 (1992).

Diaz-Meco, M. T., S. Quiñones, M. M. Municio, L. Sanz, D. Bernal, E. Cabrero, J. Saus, and J. Moscat: Protein kinase $\mathrm{C}$-independent expression of stromelysin by platelet-derived growth factor, ras oncogene and phosphatidylcholine-hydrolyzing phospholipase C. J. Biol. Chem., 266:22,597-22,602 (1991).

Dickson, B., F. Sprenger, D. Morrison, and E. Hafen: Raf functions downstream of Ras 1 in the sevenless signal transduction pathway. Nature, 360:600-603 (1992).

Diekmann, D., S. Brill, M. D. Garrett, N. Totty, J. Hsuan, C. Monfries, C. Hall, L. Lim, and A. Hall: $B c r$ encodes a GTPase-activating protein for $\mathrm{p} 21^{\text {rac }}$. Nature, 351:400-402 (1991).

Dominguez, I., M. T. Diaz-Meco, M. M. Municio, E. Berra, A. Garcia de Herreros, M. E. Cornet, L. Sanz, and J. Moscat: Evidence for a role of protein kinase $\mathrm{C} \zeta$ subspecies in maturation of Xenopus laevis oocytes. Mol. Cell. Biol., 12:3776-3783 (1992).

Dominguez, I., M. S. Marshall, J. B. Gibbs, A. Garcia de Herreros, M. E. Cornet, G. Graziani, M. T. DiazMeco, T. Johansen, F. McCormick, and J. Moscat: Role of GTPase activating protein in mitogenic signalling through phosphatidylcholine-hydrolysing phospholipase C. EMBO J., 10:3215-3220 (1991).

Downing, J. R., B. L. Margolis, A. Zilberstein, R. A. Ashmun, A. Ullrich, C. J. Sherr, and J. Schlessinger: Phospholipase C- $\gamma$, a substrate for PDGF receptor kinase, is not phosphorylated on tyrosine during the mitogenic response to CSF-1. EMBO J., 11:33453350 (1989).

Downward, J.: Rac and Rho in tune. Nature, 359:273-274 (1992).

Downward, J., J. D. Graves, P. H. Warne, S. Rayter, and D. A. Cantrell: Stimulation of p $21^{\text {ras }}$ upon T-cell activation. Nature, 346:719-723 (1990a).

Downward, J., R. Riehl, L. Wu, and R. A. Weinberg; Identification of a nucleotide exchange-promoting activity for p21 ras. Proc. Natl. Acad. Sci. U.S.A., 87:5998$6002(1990 \mathrm{~b})$.

Drubin, D. G., J. Mulholland, Z. Zhu, and D. Botstein: Homology of a yeast actin-binding protein to signal transduction proteins and myosin-I. Nature, 343:288-290 (1990).

Duronio, V., M. J. Welham, S. Abraham, P. Dryden, and J. W. Schrader: p21 ras activation via hemopoictin receptors and c-kit requires tyrosine kinase activity but not tyrosine phosphorylation of $\mathrm{p} 21^{\text {ras }}$ GTP-ase-activating protein. Proc. Natl.Acad. Sci. U.S.A., 89:15871591 (1992).

Ebina, Y., E. Araki, M. Taira, F. Shimida, M. Mori, C. S. Craik, K. Siddle, S. B. Pierce, R. A. Roth, and W. J. Rutter: Replacement of lysine residue 1030 in the 
putative ATP-binding region of the insulin receptor abolishes insulin- and antibody-stimulated glucose uptake and receptor kinase activity. Proc. Natl. Acad. Sci. U.S.A., 84:704-708 (1987).

Ellis, C., M. Moran, F. McCormick, and T. Pawson: Phosphorylation of GAP and GAP-associated proteins by transforming and mitogenic tyrosine kinases. Nature. 343:377-381 (1990).

Endemann, G., K. Yonezama, and R. A. Roth: Phosphatidylinositol kinase or an associated protein is a substrate for the insulin receptor tyrosine kinase. $J$. Biol. Chem., 265:396-400 (1990).

Erikson, R. L.: Structure, expression, and regulation of protein kinases involved in the phosphorylation of ribosomal protein S6. J. Biol. Chem., 266:6007-6010 (1991).

Escobedo, J. A., P. J. Barr, and L. T. Williams: Role of tyrosine kinase and membrane-spanning domains in signal transduction by the platelet-derived growth factor receptor. Mol. Cell. Biol., 8:5126-5131 (1988).

Escobedo, J. A., D. R. Kaplan, W. M. Kavanaugh, C. W. Turck, and L. T. Williams: A phosphatidylinositol-3 kinase binds to platelet-derived growth factor receptors through a specific receptor sequence containing phosphotyrosine. Mol. Cell. Biol., 11:1125-1132 (1991a).

Escobedo, J. A., S. Navankasattusas, W. M. Kavanaugh, D. Milfay, V. A. Fried, and L. T. Williams, cDNA cloning of a novel $85 \mathrm{kd}$ protein that has $\mathrm{SH} 2$ domains and regulates binding of PI3-kinase to the PDGF $\beta$-receptor. Cell, 65:75-82 (1991b).

Escobedo, J. A. and L. T. Williams: A PDGF receptor domain essential for mitogenesis but not for many other responses to PDGF. Nature, 335:85-87 (1988).

Exton, J. H.: Signaling through phosphatidyl choline breakdown. J. Biol. Chem., 265:1-4 (1990).

Fantl, W. J., J. A. Escobedo, G. A. Martin, C. W. Turck, M. del Rosario, F. McCormick, and L. T. Williams: Distinct phosphotyrosines on a growth factor receptor bind to specific molecules that mediate different signaling pathways. Cell, 69:413-423 (1992).

Farnsworth, C. L. and Feig, L. A.: Dominant inhibitory mutations in the $\mathrm{Mg}^{2+}$-binding site of ras ${ }^{\mathrm{H}}$ prevent its activation by GTP. Mol. Cell. Biol., 11:4822-4829 (1991).

Farnsworth, C. L., M. S. Marshall, J. B. Gibbs, D. W. Stacey, and L. A. Feig: Preferential inhibition of the oncogenic form of ras $^{\mathrm{H}}$ by mutations in the GAP binding/ "effector" domain. Cell, 64:625-633 (1991).

Fedor-Chaiken, M., R. J. Deschenes, and J. R. Broach: SRV2, a gene required for $R A S$ activation of adenylate cyclase in yeast. Cell, 61:329-340 (1990).

Feig, L. A. and G. M. Cooper: Inhibition of NIH 3T3 cell proliferation by a mutant ras protein with preferential affinity for GDP. Mol. Cell. Biol., 8: 3235-3243 (1988a).

Feig, L. A. and L. A. Cooper: Relationship among guanine nucleotide exchange, GTP hydrolysis, and transforming potential of mutated ras proteins. Mol. Cell. Biol., 8:2472-2478 (1988b).
Feramisco, J. R., M. Gross, T. Kamata, M. Rosenberg, and R. W. Sweet: Microinjection of the oncogenic form of the human H-ras (T24) protein results in rapid proliferation of quiescent cells. Cell, 38:109-117 (1984).

Ferguson, E. L., P. W. Sternberg, and H. R. Horvitz: A genetic pathway for the specification of the vulval cell lineages of Caenorhabditis elegans. Nature, 326:259267 (1987),

Field, J., A. Vojtek, R. Ballester, G. Bolger, J. Colicelli, K. Ferguson, J. Gerst, T. Kataoka, T. Michaeli, S. Powers, M. Riggs, L. Rodgers, I. Wieland, B. Wheland, and $M$. Wigler: Cloning and characterization of $C A P$, The $S$. cercvisiae gene encoding the $70 \mathrm{kd}$ adenylyl cyclase-associated protein. Cell, 61:319-327 (1990).

Fleischman, L. F., S. B. Chahwala, and L. Cantley: Rastransformed cells: altered levels of phosphatidylinositol-4,5-bisphosphate and catabolites. Science, 231:407-410 (1986).

Fortini, M. E., M. A. Simon, and G. M. Rubin: Signalling by the sevenless protein tyrosine kinase is mimicked by Rasl activation. Nature, 355:559-561 (1992).

Franz, W. M., P. Berger, and J. Y. J. Wang: Deletion of an $\mathrm{N}$-terminal regulatory domain of the c-abl tyrosine kinase activates its oncogenic potential. EMBO J., 8:137-147 (1989).

Frech, M., J. John, V. Pizon, P. Chardin, A. Tavitian, R. Clark, F. McCormick, and A. Wittinghofer: Inhibition of GTPase activating protein stimulation of ras-p21 GTPase by the Krev-1 gene product. Science, 29:169$171(1990)$.

Fukui, Y. and Y. Kaziro: Molecular cloning and sequence analysis of a ras gene from Schizosaccharomyces pombe. EMBO J., 4:687-692 (1985).

Fukui, Y., T. Kozasa, Y. Kaziro, T. Takeda, and M. Yamamoto: Role of a ras homolog in the life cycle of Schizosaccharomyce pombe. Cell, 44:329-336 (1986).

Garcia de Herreros, A., I. Dominguez, M. T. Diaz-Meco, G. Graziani, M. E. Cornet, P. H. Guddal, T. Johansen, and J. Moscat: Requirement of phospholipase C-catalyzed hydrolysis of phosphatidylcholine for maturation of Xenopus laevis oocytes in response to insulin and ras p21.J. Biol. Chem., 266;6825-6829 (1991).

Gartner, A., K. Nasmyth, and G. Ammerer: Signal transduction in Saccharomyces cerevisiae requires tyrosine and threonine phosphorylation of FUS3 and KSS1. Genes Dev., 6:1280-1292 (1992).

Gaul, U., G. Mardon, and G. M. Rubin: A putative ras GTPase activating protein acts as a negative regulator of signaling by the sevenless receptor tyrosine kinase. Cell, 68: 1007-1019 (1992).

Gauthier-Rouvière, C., M. Basset, J,-M. Blanchard, J.-C. Cavadore, A. Fernandez, and N. J. C. Lamb: Casein kinase II induces c-fos expression via the serum response element pathway and $\mathrm{p} 67^{\mathrm{SRF}}$ phosphorylation in living fibroblasts. EMBO J., 10:2921-2930 (1991).

Gibbs, J. B.: Ras C-terminal processing enzymes - new drug targets? Cell, 65:1-4 (1991).

Gibbs, J. B., M. S. Marshall, E. M. Scolnick, R. A. F. Dixon, and U.S. Vogel: Modulation of guanine nucleotides 
bound to ras in NIH3T3 cells by oncogenes, growth factors, and the GTPase activating protein (GAP). $J$. Biol. Chem., 265:20,437-20,442 (1990).

Gibbs, J. B., M. D. Schaber, W. J. Allard, I. S. Sigal, and E. M. Scolnick: Purification of ras GTPase activating protein from bovine brain. Proc. Natl. Acad. Sci. U.S.A., 85:5026-5030 (1988).

Gibbs, J. B., M. D. Schaber, T. L. Schofield, and E. M. Scolnick: Xenopus oocyte germinal-vesicle breakdown induced by [ $\left.\mathrm{Val}^{12}\right]$ Ras is inhibited by a cytosol-localized Ras mutant. Proc. Natl. Acad. Sci. U.S.A., 86:6630-6634 (1989).

Gille, H., A. D. Sharrocks, and P. E. Shaw: Phosphorylation of transcription factor p62TCF by MAP kinase stimulates ternary complex formation at c-fos promoter. Nature, 358:414-417 (1992).

Glenney, J. R., W. S. Chen, C. S. Lazar, G. M. Walton, L. M. Zokas, M. G. Rosenfeld, and G. N. Gill: Ligand-induced endocytosis of the EGF receptor is blocked by mutational inactivation and by microinjection of antiphosphotyrosine antibodies. Cell, 52:675-684 (1988),

Goldschmidt-Clermont, P. J. and P. A. Janmey: Profilin, a weak CAP for actin and RAS. Cell, 66:419-421 (1991).

Goldschmidt-Clermont, P. J., J. W. Kim, L. M. Machesky, S. G. Rhee, and T. D. Pollard: Regulation of phospholipase $\mathrm{C}-\gamma 1$ by profilin and tyrosine phosphorylation. Science, 251:1231-1233 (1991).

Goldschmidt-Clermont, P. J., L. M. Machesky, J. J. Baldassare, and T. D. Pollard: The actin-binding protein profilin binds to $\mathrm{PIP}_{2}$ and inhibits its hydrolysis by phospholipase C. Science, 247:1575-1578 (1990).

Goldstein, J. L. and M. S. Brown: Regulation of the mevalonate pathway. Nature, 343:425-430 (1990).

Goldstein, J. L., M. S. Brown, S. J. Stradley, Y. Reiss, and L. M. Gierasch: Nonfarnesylated tetrapeptide inhibitors of protein farnesyltransferase. J. Biol. Chem., 266:15,575-15,578 (1991).

Golubic, M., K. Tanaka, S. Dobrowolski, D. Wood, M. H. Tsai, M. Marshall, F. Tamanoi, and D. W. Stacey: The GTPase stimulatory activities of the neurofibromatosis type 1 and the yeast IRA2 proteins are inhibited by arachidionic acid. EMBO J., 10:2897-2903 (1991).

Gómez, N. and P. Cohen: Dissection of the protein kinase cascade by which nerve growth factor activates MAP kinases. Nature, 353:170-173 (1991).

Graves, J. D., J. Downward, S. Rayter, P. Warne, A. L. Tutt, M. Glennie, and D. A. Cantrell: CD2 antigen mediated activation of the guanine nucleotide binding proteins $\mathrm{p} 21^{\text {ras }}$ in human $\mathrm{T}$ lymphocytes. J. Immunol, 146:3709-3712 (1991).

Greenwald, I. and G. M. Rubin: Making a difference: the role of cell-cell interactions in establishing separate identities for equivalent cells. Cell, 68:271-281 (1992).

Gross, E., D. Goldberg, and A. Levitzki: Phosphorylation of the $S$. cerevisiae $\mathrm{Cdc} 25$ in response to glucose results in its dissociation from Ras. Nature, 360:762-765 (1992a).

Gross, E., I. Marbach, D. Engelberg, M. Segal, G. Simchen, A. Levitzki: Anti-Cdc25 antibodies inhibit guanyl nucleotide-dependent adenylyl cyclase of Saccharomyces cerevisiae and cross-react with a 150-kilodalton mammalian protein. Mol. Cell. Biol., 12:2653-2661 (1992b).

Gutierrez, L., A. I. Magee, C. J. Marshall, and J. F. Hancock: Post-translational processing of $\mathrm{p} 21$ ras is two-step and involves carboxyl-methylation and carboxy-terminal proteolysis. EMBO J., 8:1093-1098 (1989).

Gutman, A. and B. Wasylyk: The collagenase gene promoter contains a TPA and oncogene-responsive unit encompassing the PEA3 and AP-1 binding sites. EMBO J., 9:2241-2246 (1990).

Hafen, E., K. Basler, J. E. Edstroem, and G. M. Rubin: sevenless, a cell-specific homeotic gene of Drosophila, encodes a putative transmembrane receptor with a tyrosine kinase domain. Science, 236:55-63 (1987).

Hagag, N., S. Halegoua, and M. Viola: Inhibition of growth factor-induced differentiation of $\mathrm{PC} 12$ cells by microinjection of antibody to ras p21. Nature, 319:680-682 (1986).

Hall, A., C. J. Marshall, N. K. Spurr, and R. A. Weiss: Identification of transforming gene in two human sarcoma cell lines as a new member of the ras gene family located on chromosome 1. Nature, 303:396400 (1983).

Han, M. and P. W. Sternberg: let-60, a gene that specifies cell fates during $\mathrm{C}$. elegans vulval induction, encodes a ras protein. Cell, 60:921-931 (1990).

Hancock, J. F., K. Cadwallader, and C. J. Marshall: Methylation and proteolysis are essential for efficient membrane binding of prenylated $\mathrm{p} 21^{K-\operatorname{ras}(B)} . E M B O \mathrm{~J}$, 10:641-646 (1991a).

Hancock, J. F., K. Cadwallader, H. Paterson, and C. J. Marshall: A CAAX or a CAAL motif and a second signal are sufficient for plasma membrane targeting of ras proteins. EMBO J., 10:4033-4039 (1991b).

Hancock, J. F., A. I. Magee, J. E. Childs, and C. J. Marshall: All ras proteins are polyisoprenylated but only some are palmitoylated. Cell, 57:1167-1177 (1989).

Handler, J. A., R. M. Danilowicz, and T. E. Eling: Mitogenic signaling by epidermal growth factor (EGF), but not platelet-derived growth factor, requires arachidonic acid metabolism in BALB/c 3T3 cells. J. Biol. Chem., 265:3669-3673 (1990).

Hanks, S. K., A. M. Quinn, and T. Hunter: The protein kinase family: conserved features and deduced phylogeny of the catalytic domains. Science, 241:42-52 (1988).

Hariharan, I. and J. M. Adams: cDNA sequence for human $b c r$, the gene that translocates to the $a b l$ oncogene in chronic leukaemia. EMBO J., 6: 115-119 (1987).

Hariharan, I. K., R. W. Carthew, and G. M. Rubin: The Drosophila roughened mutation: activation of a rap homolog disrupts eye development and interferes with cell determination. Cell, 67:717-722 (1991).

Hart, M. J., A. Eva, T. Evans, S. A. Aaronson, and R. A. Cerione: Catalysis of guanine nucleotide exchange on the $\mathrm{CDC} 42 \mathrm{Hs}$ protein by the $d b l$ oncogene product. Nature, 354:311-314 (1991).

Harvey, J. J.: An unidentified virus which causes the rapid production of tumors in mice. Nature, 204: 1 104-1105 (1964). 
Heideran, M. A., J. H. Pierce, D. Lombardi, M. Ruggiero, J. S. Gutkind, T. Matsui, and S. A. Aaronson: Deletion or substitution within the $\alpha$ platelet-derived growth factor receptor kinase insert domain: effects on functional coupling with intracellular signaling pathways. Mol. Cell. Biol., 11:134-142 (1991).

Hiles, I. D., M. Otsu, S. Volinia, M. J. Fry, I. Gout, R. Dhand, G. Panayotou, F. Ruiz-Larrea, A. Thompson, N. F. Totty, J. J. Hsuan, S. A. Courtneidge, P. J. Parker, and M. D. Waterfield: Phosphatidylinositol 3-kinase: structure and expression of the $110 \mathrm{kd}$ catalytic subunit. Cell, 70:419-429 (1992).

Hirai, $H$. and H. E. Varmus: Site-directed mutagenesis of the SH2- and SH3-coding domains of c-src produces varied phenotypes, including oncogenic activation of p60'ssrc. Mol. Cell. Biol., 10:1307-1318 (1990).

Honegger, A. M., D. Szapary, A. Schmidt, R. Lyall, E. van Obberghen, T. J. Dull, A. Ullrich, and J. Schlessinger: A mutant epidermal growth factor receptor with defective protein tyrosine kinase is unable to stimulate proto-oncogene expression and DNA synthesis. Mol. Cell. Biol., 7:4568-4571 (1987).

Housey, G. M., M. D. Johnson, W. L. W. Hsiao, C. A. O'Brian, J. P. Murphy, P. Kirschmeier, and I. B. Weinstein: Overproduction of protein kinase $C$ causes disordered growth control in rat fibroblasts. Cell, 52:343-354 (1988).

Howe, L. R., S. J. Leevers, N. Gómez, S. Nakielny, P. Cohen, and C. J. Marshall: Activation of the MAP kinase pathway by the protein kinase raf. Cell, 71:335342 (1992).

Hu, P., B. Margolis, E. Y., Skolnik, R. Lammers, A. Ullrich, and J. Schlessinger: Interaction of phosphatidylinositol 3-kinase-associated p85 with epidermal growth factor and platelet-derived growth factor receptors. Mol. Cell. Biol., 12:981-990 (1992).

Huang, Y. K., H.-F. Kung, and T. Kamata: Purification of a factor capable of stimulating the guanine nucleotide exchange reaction of ras proteins and its effect on rasrelated small molecular mass $\mathrm{G}$ proteins. Proc. Natl. Acad. Sci. U.S.A., 87:8008-8012 (1990).

Hughes, D. A., Y. Fukui, and M. Yamamoto: Homologous activators of ras in fission and budding yeast. Nature, 344:355-357 (1990).

Imler, J., C. Schatz, C. Wasylyk, B. Chatton, and B. Wasylyk: A Harvey-ras responsive transcription element is also responsive to a tumor promoter and to serum. Nature, 332:275-278 (1988).

Isakov, N., P. McMahon, and A. Altman: Selective posttranscriptional down-regulation of protein kinase $C$ isoenzymes in leukemic T-cells chronically treated with phorbol ester. J. Biol. Chem., 265:2091-2097 (1990).

Izquierdo, M., J. Downward, J. D. Graves, and D. A. Cantrell: Role of protein kinase $C$ in $T$-cell antigen receptor regulation of $\mathrm{p} 21^{\text {ras}}$ : evidence that two $\mathrm{p} 21^{\text {ras }}$ regulatory pathways coexist in T cells. Mol. Cell. Biol., 12:3305-3312 (1992).

Izquierdo, M., J. Downward, W. J. Leonard, H. Otani, and D. A. Cantrell: IL-2 activation of $\mathrm{p} 21^{\mathrm{ras}}$ in murine myeloid cells transfected with human IL--2 receptor beta chain. Eur. J. Immunol., 22:817-821 (1991).

Jackson, P. and D. Baltimore: N-terminal mutations activate the leukemogenic potential of the myristoylated form of c-abl. EMBO J., 8:449-456 (1989).

Jacquet, E., M. Vanoni, C. Ferrari, L. Alberghina, E. Martegani, and A. Parmeggiani: A mouse CDC25like product enhances the formation of the active GTP complex of human ras $\mathrm{p} 21$ and Saccharomyces cerevisiae RAS2 proteins. J. Biol. Chem., 267:2418124183 (1992).

Jones, S., M.-L. Vignias, and J. R. Broach: The $C D C 25$ protein of Saccharomyces cerevisiae promotes exchange of guanine nucleotides bound to ras. $\mathrm{Mol}$. Cell. Biol., 11:2641-2646 (1991).

Jurnak, F: Structure of the GDP domain of EF-Tu and location of the amino acids homologous to ras oncogene proteins. Science, 230:32-36 (1985).

Kaibuchi, K., T. Mizuno, H. Fujioka, T. Yamamoto, K. Kishi, Y. Fukumoto, Y. Hori, and Y. Takai: Molecular cloning of the cDNA for stimulatory GDP/GTP exchange protein for sing p21s (ras p21-like small GTP.binding proteins) and characterization of stimulatory GDP/GTP exchange protein. Mol. Cell. Biol., 11:2873-2880 (1991).

Kaplan, D. R., D. K. Morrison, G. Wong, F. McCormick, and $\mathrm{L} T$. Williams: PDGF $\beta$-receptor stimulates tyrosine phosphorylation of GAP and association of GAP with a signaling complex. Cell, 61:125-133 (1990).

Kaplan, D. R., M. Whitman, B. Schaffhausen, D. C. Pallas, M. White, L. Cantley, and T. M. Roberts: Common elements in growth factor stimulation and oncogenic transformation: $85 \mathrm{kd}$ phosphoprotein and phosphatidylinositol kinase activity. Cell, 50:1021-1029 (1987).

Kashishian, A., A. Kazlauskas, and J. A. Cooper: Phosphorylation sites in the PDGF receptor with different specificities for binding GAP and PI3 kinase in vivo. EMBO J., 11:1373-1382 (1992).

Kataoka, T, D. Broek, and M. Wigler: DNA sequence and characterization of the $S$. cervisiae gene encoding adenylate cyclase. Cell, 43:493-505 (1985).

Kato, J.-Y., T. Takeya, C. Grandori, H. Iba, J. B. Levy, and H. Hanafusa: Amino acid substitutions sufficient to convert the nontransforming $\mathrm{p} 60^{c-s r c}$ protein to a transforming protein. Mol.Cell. Biol., 6:4155-4160 (1986).

Katzay, S., D. Martin-Zanca, and M. Barbacid: vav, a novel human oncogene derived from a locus ubiquitously expressed in hematopoietic cells. EMBO J., 8: 22832290 (1989).

Kazlauskas, A. and J. A. Cooper: Autophosphorylation of the PDGF receptor in the kinase insert region regulates interaction with cell proteins. Cell, 58:11211133 (1989).

Kazlauskas, A., C. Ellis, T. Pawson, and J. A. Cooper: Binding of GAP to activated PDGF receptors. Science, 247:1578-1581 (1990).

Kazlauskas, A., A. Kashishian, J. A. Cooper, and M. Valius: GTPase-activating protein and phosphatidylinositol 
3-kinase bind to distinct regions of the platelet-derived growth factor receptor $\beta$ subunit. Mol. Cell. Biol., 12:2534-2544 (1992).

Kim, H. K., J. W. Kim, A. Zilberstein, B. Margolis, J. G. Kim, J. Schlessinger, and S. G. Rhee: PDGF stimulation of inositol phospholipid hydrolysis requires PLC$\gamma 1$ phosphorylation on tyrosine residues 783 and 1254 . Cell, 65:435-441 (1991).

Kirsten, W. H. and L. A. Mayer: Morphologic responses to a murine erythroblastosis virus. I. Natl. Cancer Inst., 39:311-319 (1967).

Kitayama, H., Y. Sugimoto, T. Matsuzaki, Y. Ikawa, and M. Noda: A ras-related gene with transformation suppressor activity. Cell, 56:77-84 (1989).

Kizaka-Kondoh, S., K. Sato, K. Tamura, H. Nojima, and H. Okayama: Raf-1 protein kinase is an integral component of the oncogenic signal cascade shared by epidermal growth factor and platelet-derived growth factor. Mol. Cell. Biol., 12:5078-5086 (1992).

Klarlund, J. K, and M. P. Czech: Insulin-like growth factor $I$ and insulin rapidly increse casein kinase II activity in BALB/c 3T3 fibroblasts. J. Biol. Chem., 263:15,872-15,875 (1988).

Klausner, R. D. and L. E. Samelson: T cell antigen receplor activation pathways: the tyrosine kinase connection. Cell, 64:875-878 (1991).

Klingler, M., M. Erdélyi, J, Szabad, and C. Nüsslein-Volhard: Function of torso in determining the terminal anlagen of the Drosophila embryo. Nature, 335:275-277 (1988).

Koch, C. A., D. Anderson, M. F. Moran, C. Ellis, and T. Pawson: SH2 and SH3 domains: Elements that control interactions of cytoplasmic signaling proteins. Science, 252:668-674 (1991).

Koide, H., K. Ogita, U. Kikkawa, and Y. Nishizuka: Isolation and characterization of the $\varepsilon$ subspecies of protein kinase C from rat brain. Proc. Natl. Acad. Sci. U.S.A., 89:1149-1153 (1992).

Kolch, W., G. Heidecker, P. Lloyd, and U. R. Rapp: Raf-1 protein kinase is required for growth of induced NIH/ 3T3 cells. Nature, 349:426-428 (1991).

Korn, L. J., C. W. Siebel, F. McCormick, and R. A. Roth: Ras $\mathrm{p} 21$ as a potential mediator of insulin action in Xenopus oocytes. Science, 236:840-843 (1987).

Kosako, H., Y. Gotoh, S. Matsuda, M. Ishikawa, and E. Nishida: Xenopus MAP kinase activator is a serine/ threonine/tyrosine kinase activated by threonine phosphorylation. EMBO J, 11:2903-2908 (1992).

Kovacina, K. S., K. Yonezawa, D. L. Brautigan, N. K. Tonks, U. R. Rapp, and R. A. Roth: Insulin activates the kinase activity of the Raf-1 proto-oncogene by increasing its serine phosphorylation. J, Biol. Chem., 265:12,115-12,118 (1990).

Krämer, H., R. L. Cagan, and S. L. Zipursky: Interaction of bride of sevenless membrane-bound ligand and the sevenless tyrosine-kinase receptor. Nature, 352:207212 (1991).
Krauss, R. S., G. M. Housey, M. D. Johnson, and I. B. Weinstein: Disturbances in growth control and gene expression in a $\mathrm{C} 3 \mathrm{H} / 10 \mathrm{~T}_{1 / 2}$ cell line that stably overproduces protein kinase C. Oncogene, 4:991-998 (1989).

Krengel, U., I. Schlichting, A. Scherer, R. Schumann, M. Frech, J. John, W. Kabsch, E. F. Pai, and A. Wittinghofer: Three-dimensional structures of $\mathrm{H}$-ras p21 mutants: molecular basis for their inability to function as signal switch molecules. Cell, 62:539-548 (1990).

Kypta, R. M., Y. Goldberg, E. T. Ulug, and S. A. Courtneidge: Association between the PDGF receptor and members of the src family of tyrosine kinases. Cell, 62:481492 (1990)

Kyriakis, J. M., H. App, X. Zhang, P. Banerjee, D. L. Brautigan, U. R. Rapp, and J. Avruch: Raf-1 activates MAP kinase-kinase. Nature, 358:417-421 (1992).

L'Allemain, G., J-H. Her, J. Wu, T. W. Sturgill, and M. J. Weber: Growth factor-induced activation of a kinase activity which causes regulatory phosphorylation of p42/microtubule-associated protein kinase. Mol. Cell. Biol., 12:2222-2229 (1992).

Lacal, J. C.: Diacylglycerol production in Xenopus laevis oocytes after microinjection of $\mathrm{p} 21^{\text {rus }}$ proteins is a consequence of activation of phosphatidylcholine metabolism. Mol. Cell. Biol., 10:333-340 (1990).

Lacal, J. C., P. De la Pena, J. Moscat, P. Garcia-Barreno, P. Anderson, and S. A. Aaronson: Rapid stimulation of diacylglycerol production in Xenopus oocytes by microinjection of H-ras p21. Science, 238:533-536 (1987a).

Lacal, J. C., P. de la Pena, J. Moscat, P. Garcia-Barreno, P. S. Anderson, and S. A. Aaronson: Rapid stimulation of diacylglycerol production in Xenopus oocytes by microinjection of H-ras p21. Science, 238:533-536 (1987b).

Lacal, J. C., T. P. Fleming, B. S, Warren, P. M. Blumberg, and $\mathrm{S}$. A. Aaronson: Involvement of functional protein kianse $\mathrm{C}$ in the mitogenic response to the H-ras oncogene product. Mol. Cell. Biol., 7:4146-4149 $(1987 \mathrm{c})$

Lacal, J. C., J. Moscat, and S. A. Aaronson: Novel source of 1,2-diacylglycerol elevated in cells transformed by Ha-ras oncogene. Nature, 330:269-272 (1987d).

Langer, S. J., D. M. Bortner, M. F. Roussel, C. J. Sherr, and M. C. Ostrowski: Mitogenic signaling by colony-stimulating factor 1 and ras is suppressed by the ets-2 DNAbinding domain and restored by myc overexpression. Mol. Cell, Biol., 12:5355-5362 (1992).

Larrodera, P., M. E. Cornet, M. T. Diaz-Meco, M. LopezBarahona, I. Diaz-Laviada, P. H. Guddal, T. Johansen, and J. Moscat: Phospholipase C-mediated hydrolysis of phosphatidylcholine is an important step in PDGFstimulated DNA synthesis. Cell, 61:1113-1120(1990).

Lavan, B. E., M. R. Kuhné, C. W. Garner, D. Anderson, M. Reedijk, T. Pawson, and G. E. Lienhard: The associa- 
tion of insulin-elicited phosphotyrosine proteins with sic homology 2 domains. J. Biol. Chem., 267:11,63111,636 (1992).

Lee, R., M. H. Cobb, and P. J. Blackshear: Evidence that extracellular signal-regulated kinases are the insulinactivated Raf- 1 kinase kinases. J. Biol. Chem., 267:1088-1092 (1992).

Leevers, S. J. and C. J. Marshall: Activation of extracellular signal-regulated kinase, ERK2, by p21ras oncoprotein. EMBO J., 11:569-574 (1992).

Lehman, J. M., G. Riethmüller, and J. P. Johnson: Nck, a melanoma cDNA encoding a cytoplasmic protein consisting of the src homology units $\mathrm{SH} 2$ and $\mathrm{SH} 3$. Nucleic Acids Res., 18:1048 (1990).

Li, B.-Q., D. Kaplan, H.-F. Kung, and T. Kamata: Nerve growth factor stimulation of the Ras-guanine nucleotide exchange factor and GAP activities. Science, 256: 1456-1459 (1992a).

Li, P., K. Wood, H. Mamon, W. Haser, and T. Roberts: Raf1: a kinase currently without a cause but not lacking in effects. Cell, 64:479-482 (1991).

Li, W., P. Hu, E. Y. Skolnik, A. Ullich, and J. Schlessinger: The $\mathrm{SH} 2$ and $\mathrm{SH} 3$ domain-containing Nck protein is oncogenic and a common target for phosphorylation by different surface receptors. Mol. Cell. Biol., 12:5824-5833 (1992b).

Lin, A., J. Frost, T. Deng, T. Smeal, N. Al-Alawi, U. Kikkawa, T. Hunter, D. Brenner, and M. Karin: Casein kinase II is a negative regulator of c-Jun DNA binding and AP-1 activity. Cell, 70:777-789 (1992).

Lips, D. L., P. W. Majerus, F. R. Gorga, A. L. Young, and T. L. Benjamin: Phosphatidylinositol 3-phosphate is present in normal and transformed fibroblasts and is resistant to hydrolysis by bovine brain phospholipase C II, J. Biol. Chem., 264;8759-8763 (1989).

Lloyd, A., N. Yancheva, and B. Wasylyk: Transformation suppressor activity of a Jun transcription factor lacking its activation domain. Nature, 352:635-638 (1991).

Lloyd, A. C., H. F. Paterson, J. D. H. Morris, A. Hall, and C. J. Marshall: P21 $1^{\mathrm{H}-\text { ras }}$ induced morphological transformation and increases in c- $m y c$ expression are dependent on functional protein kinase C. EMBO $J$, 8:1099-1104 (1989).

Lowenstein, E. J., R. J. Daly, A. G. Batzer, W. Li, B. Margolis, R. Lammers, A. Ullrich, E. Y. Skolnik, D. Bar-Sagi, and J. Schlessinger: The SH2 and SH3 domain-containing protein GRB2 links receptor tyrosine kinases to ras signaling. Cell, 70:431-442 (1992).

Macara, 1. G.: Elevated phosphocholine concentration in rastransformed NIH 3 T3 cells arises from increased choline kinase activity, not from phosphatidylcholine breakdown. Mol. Cell. Biol., 9:325-328 (1989).

Macara, I. G., G. V. Marinetti, and P. C. Balduzzi: Transforming protein of avian sarcoma virus UR2 is associated with phosphatidylinositol kinase activity: possible role in tumorigenesis. Proc. Natl. Acad. Sci. U.S.A., 81:2728-2732 (1984).
Magee, A. I., L. Gutierrez, I. A. McKay, C. J. Marshall, and A. Hall: Dynamic fatty acylation of $\mathrm{p} 21^{\mathrm{N} \text {-ras }}$. EMBO J., 6:3353-3357 (1987).

Manak, J. R., N. de Bisschop, R. M. Kris, and R. Prywes: Casein kinase II enhances the DNA binding activity of serum response factor. Genes Dev., 4:955-967 (1990).

Margolis, B., P. Hu, S. Katzav, W. Li, J. M. Oliver, A. Ullrich, A. Weiss, and J. Schlessinger: Tyrosine phosphorylation of vav proto-oncogene product containing SH2 domain and transcription factor motifs. $\mathrm{Na}$ ture, 356:71-74 (1992).

Margolis, B., N. Li, A. Koch, M. Mohammadi, D. R. Hurwitz, A. Zilberstein, A. Ullrich, T, Pawson, and J. Schlessinger: The tyrosine phosphorylated carboxyterminus of the EGF receptor is a binding site for GAP and PLC- $\gamma$ EMBO J., 9:4375-4380 (1990a).

Margolis, B., S. G. Rhee, S. Felder, M. Mervic, R. Lyall, A. Levitzki, A. Ullrich, A. Zilberstein, and J. Schlessinger: EGF induces tyrosine phosphorylation of phospholipase C-II: a potential mechanism for EGF receptor signaling. Cell, 57:1101-1107 (1989).

Margolis, B., A. Zilberstein, C. Franks, S. Felder, S. Kremer, A. Ullrich, S. G. Rhee, K. Skorecki, and J. Schlessinger: Effect of phospholipase C- $\gamma$ overexpression on PDGFinduced second messengers and mitogenesis. Science, 248:607-610 (1990b).

Mark, G. E., R. J. MacIntyre, M. E. Digan, L. Ambrosio, and N. Perrimon: Drosophila melanogaster homologs of the raf oncogene. Mol. Cell. Biol., 7:2134-2140 (1987).

Marshall, M. S., W. S. Hill, S. N. Assunta, U. S. Vogel, M. D. Schaber, E. M. Scolnick, R. A. F. Dixon, I. S. Sigal, and J. B. Gibbs: A c-terminal domain of GAP is sufficient to stimulate ras p21 GTPase activity. EMBO J., 8:1105-1110 (1989).

Martegani, E., M. Vanoni, R. Zippel, P. Coccetti, R. Brambilla, C. Ferrari, E. Sturani, and L. Alberghina: Cloning by functional complementation of a mouse cDNA encoding a homologue of CDC25, a Saccharomyces cerevisiae RAS activator. EMBO J., 11:21512157 (1992).

Martin, G. A., D. Viskochil, G. Bollag, P. C. McCabe, W. J. Crosier, H. Haubruck, L. Conroy, R. Clark, P. O'Connell, R. M. Cawthon, M. A. Innes, and F. McCormick: the GAP-related domain of the neurofibromatosis type 1 gene product interacts with ras $\mathrm{p} 21$. Cell, 63 843-849 (1990).

Martin, G. A., A. Yatani, R. Clark, L. Conroy, P. Polakis, A. M. Brown, and F. McCormick: GAP domains responsible for ras p21-dependent inhibition of muscarinic atrial $\mathrm{K}^{+}$channel currents. Science, 255:192-194 (1992).

Matrisian, L. M., P. Leroy, C. Ruhlmann, M.-C. Gesnel, and $R$. Breathnach: Isolation of the oncogene and epidermal growth factor-induced transin gene: complex control in rat fibroblasts. Mol. Cell. Biol., 6:1679-1686 (1986). 
Matsuda, M., B. J. Mayer, Y. Fukui, and H. Hanafusa: Binding of transforming protein, $\mathrm{p} 47^{\mathrm{gag}-\mathrm{crk}}$, to a broad range of phosphotyrosine-containing proteins. Science, 248:1537-1539 (1990).

Matsuda, S., H. Kosako, K. Takenaka, K. Moriyama, H. Sakai, T. Akiyama, Y. Gotoh, and E. Nishida: Xenopus MAP kinase activator: identification and function as a key intermediate in the phosphorylation cascade. EMBO J., 11:973-982 (1992).

Mayer, B. J., M. Hamaguchi, and H. Hanafusa: A novel viral oncogene with structural similarity to phospholipase C. Nature, 332:272-275 (1988).

Mayer, B. J. and H. Hanafusa: Association of the v-crk oncogene product with phosphotyrosine-containing proteins and protein kinase activity. Proc. Natl. Acad. Sci. U.S.A., 87:2638-2642 (1990).

Mayer, B. J., P. K. Jackson, and D. Baltimore: The noncatalytic $\operatorname{sic}$ homology region 2 segment of $a b l$ tyrosine kinase binds to tyrosine-phosphorylated cellular proteins with high affinity. Proc. Natl. Acad. Sci. U.S.A., 88:627-631 (1991).

McClain, D. A., H. Maegawa, J. Lee, T. J. Dull, A. Ullrich, and J. M. Olefsky: A mutant insulin receptor with defective tyrosine kinase displays no biologic activity and does not undergo endocytosis. J. Biol. Chem., 262:14,663-14,671 (1987).

McCormick, F.: ras GTPase activating protein: signal transmitter and signal terminator. Cell, 56:5-8 (1989).

McGlade, J., A. Cheng, G. Pelicci, P. G. Pelicci, and T. Pawson: She proteins are phosphorylated and regulated by the v-src and v-fps protein tyrosine kinases. Proc. Natl. Acad, Sci. U.S.A., 89:8869-8873 (1992).

McGrath, J. P., D. J. Capon, D. V. Goddel, and A. D. Levinson: Comparative biochemical properties of normal and activated human ras p21 protein. Nature, 310:644-649 (1984).

Medema, R. H., B. M. T. Burgering, and J. L. Bos: Insulininduced p21ras activation does not require protein kinase $\mathrm{C}$, but a protein sensitive to phenylarsine oxide. J. Biol. Chem., 266:21,186-21,189 (1991a).

Medema, R. H., W. L. de Laat, G. A. Martin, F. McCormick, and J. L. Bos: GTPase-activating protein $\mathrm{SH} 2-\mathrm{SH} 3$ domains induce gene expression in a ras-dependent fashion. Mol. Cell. Biol., 12:3425-3430 (1992).

Medema, R. H., A, M. M. de Vries-Smits, G. C. M. van der Zon, J. A. Maassen, and J. L. Box: Ras activation by insulin and epidermal growth factor through enhanced exchange of guanine nucleotides on $221^{\text {ras }}$. Mol. Cell. Biol., 13:155-162 (1993).

Medema, R. H., R. Wubbolts, and J. L. Bos: Two dominant inhibitory mutants of p21 ras interfere with insulininduced gene expression. Mol. Cell. Biol., 11:59635967 (1991b).

Megidish, T. and N. Mazurek: A mutant protein kinase $\mathrm{C}$ that can transform fibroblasts. Nature, 342:807-811 (1989).

Meisenhelder, J. and T. Hunter: The SH2/SH3 domaincontaining protein Nck is recognized by certain anti-phospholipase $\mathrm{C}-\gamma 1$ monoclonal antibodies, and its phosphorylation on tyrosine is stimulated by platelet-derived growth factor and epidermal growth factor treatment. Mol. Cell. Biol., 12:5843-5856 (1992).

Meisenhelder, J., P.-G. Suh, S. G. Rhee, and T. Hunter: Phospholipase C- $\gamma$ is a substrate for the PDGF and the EGF receptor protein-tyrosine kinases in vivo and in vitro. Cell, 57:1109-1122 (1989).

Mendola, C. E. and J. M. Backer: Lovastatin blocks N-ras oncogene-induced neuronal differentiation. Cell. Growth Differ., 1:499-502 (1990).

Michaelj, T, J. Field, R. Ballester, K. O. O'Niel, and M. Wigler: Mutants of H-ras that interfere with RAS effector function in Saccharomyces cerevisiae. EMBO J., 8:3039-3044 (1989)

Milburn, M. V., L. Tong, A. M. deVos, A. Brünger, Z. Yamaizumi, S. Nishimura, and S.-H. Kim: Molecular switch for signal transduction: structural differences between active and inactive forms of protooncogenic ras proteins. Science, 247:939-945 (1990).

Mizuno, T., K. Kaibuchi, T. Yamamoto, M. Kawamura, T. Sakoda, H. Fujioka, Y. Matsuura, and Y. Takai: A stimulatory GDP/GTP exchange protein for smg p21 is active on the post-translationally processed form of c-Ki-ras p21 and thoA p21. Proc. Natl. Acad. Sci. U.S.A., 88:6442-6446 (1991).

Mohammadi, M., C. A. Dionne, W. Li, N. Li, T. Spivak, A. M. Honegger, M. Jaye, and J. Schlessinger: Point mutation in FGF receptor eliminates phosphatidylinositol hydrolysis without affecting mitogenesis. Nature, 358:681-684 (1992).

Mohammadi, M., M. Honegger, D. Rotin, R. Fischer, F. Bellot, W. Li, C. A. Dionne, M. Jaye, M. Rubinstein, and J. Schlessinger: A tyrosine-phosphorylated carboxy-terminal peptide of the fibroblast growth factor receptor (Flg) is a binding site for the $\mathrm{SH} 2$ domain of phospholipase C- $\gamma 1$. Mol. Cell. Biol., 11:50685078 (1991).

Molloy, C. J., D. P. Bottaro, T, P. Fleming, M. S. Marshall, J. B. Gibbs, and S. A. Aaronson: PDGF induction of tyrosine phosphorylation of GTPase activating protein. Nature, 342:711-714 (1989).

Molloy, C. J., T. P. Fleming, D. P. Bottaro, A. Cuadrado, and S. A. Aaronson: Platelet-derived growth factor stimulation of GTPase-activating protein tyrosine phosphorylation in control and $\mathrm{c}-\mathrm{H}$-ras-expressing $\mathrm{NIH} 3 \mathrm{T3}$ cells correlates with p21ras activation. Mol. Cell. Biol., 12:3903-3909 (1992).

Moolenaar, W. H., A. J. Bierman, B. C. Tilly, I. Verlaan, L. H. K. Defize, A. M. Honegger, A. Ullrich, and J. Schlessinger: A point mutation at the ATP-binding site of the EGF-receptor abolishes signal transduction. EMBO J., 7: 707-710 (1988).

Moolenaar, W. H., W. Kruijer, B. C. Tilly, I. Verlaan, A. J. Bierman, and S. W. deLaat: Growth factor-like action of phosphatidic acid. Nature, 323:171-173 (1986).

Moran, M. F., C. A. Koch, D. Anderson, C. Ellis, L. England, G. S. Martin, and T. Pawson: Src homology region 2 domains direct protein-protein interactions in signal transduction. Proc. Natl. Acad. Sci. U.S.A., 87:8622-8626 (1990). 
Moran, M. F., P. Polakis, F. McCormick, T. Pawson, and C. Ellis: Protein-tyrosine kinases regulate the phosphorylation, protein interactions, subcellular distribution, and activity of $221^{\text {ras }}$ GTPase-activating protein. Mol. Cell. Biol., 11:1804-1812 (1991).

Morris, J. D. H., B. Price, A. C. Lloyd, A. J. Self, C. J. Marshall, and A. Hall: Scrape-loading of Swiss 3T3 cells with ras protein rapidly activates protein kinase $\mathrm{C}$ in the absence of phosphoinositide hydrolysis. Oncogene, 4:27-31 (1989).

Morrison, D. K., D. R. Kaplan, J. A. Escobedo, U. R. Rapp, T. M. Roberts, and L. T. Williams: Direct activation of the serine/threonine kinase activity of raf-1 through tyrosine phosphorylation by the PDGF $b$-receptor. Cell, 58:649-657 (1989).

Morrison, D. K., D. R. Kaplan, U. Rapp, and T. M. Roberts: Signal transduction from membrane to cytoplasm: growth factors and membrane-bound oncogene products increase raf-1 kinase phosphorylation and associated protein kinase activity. Proc. Natl. Acad. Sci. U.S.A., 85:8855-8859 (1988).

Mulcahy, L. S., M. R. Smith, and D. W. Stacey: Requirements for ras proto-oncogene function during serumstimulated growth of NIH 3T3 cells. Nature, 313:241243 (1985).

Mulder, K. M. and S. L. Morris: Activation of p2 $1^{\text {ras }}$ by transforming growth factor $\mathrm{b}$ in epithelial cells. $J$. Biol. Chem., 267:5029-5031 (1992).

Munemitsu, S., M. A. Innis, R. Clark, F. McCormick, A. Ullrich, and P. Polakis: Molecular cloning and expression of a G25K cDNA, the human homolog of the yeast cell cycle gene CDC42. Mol. Cell. Biol., 10:5977-5982 (1990).

Nadin-Davis, S. A. and A. Nasim: A gene which encodes a predicted protein kinase can restore some functions of the ras gene in fission yeast. EMBO J., 7:985-993 (1988).

Nadin-Davis, S. A. and A. Nasim: Schizosaccharomyces pombe ras 1 and byrl are functionally related genes of the ste family that affect starvation-induced transcription of mating-type genes. Mol. Cell. Biol., 10:549560 (1990).

Nadin-Davis, S. A., A. Nasim, and D. Beach: Involvement of ras in sexual differentiation but not in growth control in fission yeast Schizosaccharomyce pombe. EMBO J., 5:2963-2972 (1986).

Nakafuku, M., T. Satoh, and Y. Kaziro: Differentiation factors, including nerve growth factor, fibroblast growth factor, and interleukin-6, induce an accumulation of an active Ras-GTP complex in rat pheochromocytoma PC12 cells. J. Biol. Chem., 267:19,448-19,454 (1992).

Nakagawa, T., M. Mabry, A. de Bustros, J. N. Ihle, B. D. Nelkin, and S. B. Baylin: Introduction of v-Harras oncogene induces differentiation of cultured human medullary thyroid carcinoma cells. Proc. Natl, Acad. Sci. U.S.A., 84:5923-5927 (1987).

Nakielny, S., D. G. Campbell, and P. Cohen: MAP kinase kinase from rabbit skeletal muscle. FEBS Lett., 308: 183-189 (1992a).
Nakielny, S., P. Cohen, J. Wu, and T. Sturgill: MAP kinase activator from insulin-stimulated skeletal muscle is a protein threonine/tyrosine kinase. EMBO J., 11:21232129 (1992b).

Nielsen, $O_{\text {, }}$ J. Davey, and R. Egel: The rasl function of Schizosaccharomyces pombe mediates pheromoneinduced transcription. EMBO J., 11:1391-1395 (1992).

Nishizuka, Y: Turnover of inositol phospholipids and signal transduction, Science, 225:1365-1370 (1984).

Nishizuka, Y.: The molecular heterogeneity of protein kinase $C$ and its implications for cellular regulation. Nature, 334:661-665 (1988).

Noda, M., M. Ko, A. Ogura, D. Liu, A. Amano, T. Takano, and Y. Ikawa: Sarcoma viruses carrying ras oncogenes induce differentiation-associated properties in a neural cell line. Nature, 318:73-75 (1985).

Nori, M., U. S. Vogel, J. B. Gibbs, and M. J. Weber: Inhibition of v-src-induced transformation by a GTPaseactivating protein. Mol. Cell. Biol., 11:2812-2818 (1991).

Ogita, K., S.-I. Miyamoto, K. Yamaguchi, H. Koide, N. Fujisawa, U. Kikkawa, S. Sahara, Y. Fukami, and Y. Nishizuka: Isolation and characterization of $\delta$-subspecies of protein kianse C from rat brain. Proc. Natl. Acad. Sci. U.S.A., 89:1592-1596 (1992).

Olson, E. N., G. Spizz, and M. A. Tainsky: The oncogenic forms of N-ras or H-ras prevent skeletal myoblast differentiation. Mol. Cell. Biol., 7:2104-2111 (1987).

Ono, Y., T, Fujii, K. Ogita, U. Kikkawa, K. Igarashi, and Y. Nishizuka: Protein kinase $\mathrm{C} \zeta$ subspecies from rat brain: its structure, expression, and properties. Proc. Natl. Acad. Sci. U.S.A., 86:3099-3103 (1989).

Osterop, A. P. R. M., R. H. Medema, G. C. M. van der Zon, J. L. Bos, W. Möller, and J. A. Maassen: Epidermal growth factor receptors generate Ras-GTP more efficiently than insulin receptors, Eur. J. Biochem., 212:477-482 (1993).

Otsu, M., I. Hiles, I. Gout, M. J. Fry, F. Ruiz-Larrea, G. Panayotou, A. Thompson, R. Dhand, J. Hsuan, N. Totty, A. D. Smith, S. J, Morgan, S. A. Courtneidge, P. J. Parker, and M. D. Waterfield: Characterization of two $85 \mathrm{kD}$ proteins that associate with receptor tyrosine kinases, middle- $T / \mathrm{pp} 60^{c-s \mathrm{sr}}$ complexes, and PI3-kinase. Cell, 65:91-104 (1991).

Owen, R. D., D. M. Bortner, and M. C. Ostrowski: ras oncogene activation of a VL30 transcriptional element is linked to transformation. Mol. Cell. Biol., 10:1-9 (1990).

Owen, R. D. and M. C. Ostrowski: Transcriptional activation of a conserved sequence element by ras requires a nuclear factor distinct from c-fos or c-jun. Proc. Natl. Acad. Sci, U.S.A., 87:3866-3870 (1990).

Pai, E. F., U. Krengel, G. A. Petsko, R. S. Goody, W. Kabsch, and A. Wittinghofer: Refined crystal structure of the triphosphate conformation of $\mathrm{H}$-ras $\mathrm{p} 21$ at $1.35 \AA$ resolution: implications for the mechanism of GTP hydrolysis. EMBO J., 9:2351-2359 (1990).

Parada, L. F., C. J. Tabin, C. Shih, and R. A. Weinberg: Human EJ bladder carcinoma oncogene is homologue 
of Harvey sarcoma virus ras gene. Nature, 297:474478 (1982).

Park, D. and S. G. Rhee: Phosphorylation of Nck in response to a variety of receptors, phorbol myristate acetate, and cyclic AMP. Mol. Cell. Biol., 12:5816-5823 (1992).

Payne, D. M., A. J. Rossomando, P. Martino, A. K. Erickson, J.-H. Her, J. Shabanowitz, D. F. Hunt, M. J. Weber, and T. W. Sturgill: Identification of the regulatory phosphorylation sites in pp42/mitogen-activated protein kinase (MAP kinase). EMBO $J ., 10: 885-892$ (199) ).

Pelicci, G., L. Lanfrancone, F. Grignani, J, McGlade, F. Cavallo, G. Forni, I. Nicoletti, F. Grignani, T. Pawson, and P. G. Pelicci: A novel transforming protein (SHC) with an $\mathrm{SH} 2$ domain is implicated in mitogenic signal transduction. Cell, 70:93-104 (1992).

Perkins, L. A., I. Larsen, and N. Perrimon: corkscrew encodes a putative protein tyrosine phosphatase that functions to transduce the terminal signal from the receptor tyrosine kinase torso. Cell, 70:225-236 (1992).

Persons, D. A., W. O. Wilkison, R. M. Bell, and O. J. Finn: Altered growth regulation and enhanced tumorigenicity of NIH 3T3 fibroblasts transfected with protein kinase C-1 cDNA. Cell, 52:447-458 (1988),

Pessin, M. S., J. J. Baldassare, and D. M. Raben: Molecular species analysis of mitogen-stimulated 1,2-diglycerides in fibroblasts. J. Biol. Chem., 265:7959-7966 (1990).

Peters, K. G., J. Marie, E. Wilson, H. E. Ives, J. Escobedo, M. Del Rosario, D. Mirda, and L. T. Williams: Point mutation of an FGF receptor abolishes phosphatidylinositol turnover and $\mathrm{Ca}^{2+}$ flux but not mitogenesis. Nature, 358:678-681 (1992).

Porras, A., A. R. Nebreda, M. Benito, and E. Santos: Activation of ras by insulin in $3 \mathrm{~T} 3 \mathrm{~L} 1$ cells does not involve GTPase-activating protein phosphorylation. J. Biol. Chem., 267:21,124-21,131 (1992).

Posada, J. and J. A. Cooper: Requirements for phosphorylation of MAP kinase during meiosis in Xenopus oocytes. Science, 255:212-215 (1992).

Powers, S., E. Gonzales, T. Christensen, J. Cubert, and D. Broek: Functional cloning of $B U D 5$, a $C D C 25$-related gene from $S$. cerevisiae that can suppress a dominantnegative RAS2 mutant. Cell, 65:1225-1231 (1991).

Powers, S., T. Kataoka, O. Fasano, M. Goldfarb, J. Strathern, J. Broach, and M. Wigler: Genes in Saccharomyces cerevisiae encoding proteins with domains homologous to the mammalian ras proteins. Cell, 36:607612 (1984).

Price, B. D., J. D. H. Morris, C. J. Marshall, and A. Hall: Stimulation of phosphatidylcholine, diacylglycerol release, and arachidonic acid production by oncogenic ras is a consequence of protein kinase $C$ activation. J. Biol. Chem., 264:16,638-16,643 (1989).

Privé, G. G., M. V. Milburn, L. Tong, A. M. de Vos, Z. Yamaizumi, S. Nishimura, and S.-H. Kim: X-ray crystal structures of transforming $\mathrm{p} 21$ ras mutants suggest a transition-state stabilization mechanism for GTP hydrolysis. Proc. Natl. Acad. Sci. U.S.A., 89:36493653 (1992).

Pronk, G. J., J. McGlade, G. Pelicci, T. Pawson, and J. L. Bos: Insulin-induced phosphorylation of the 46 and $52 \mathrm{kDa}$ She proteins. J. Biol. Chem., 268:5748-5753 (1993).

Pronk, G. J., R. H. Medema, B. M. T. Burgering, R. Clark, F. McCormick, and J. L. Bos: Interaction between the p21 $1^{\text {ras }}$ GTPase activating protein and the insulin receptor. J. Biol. Chem., 267:24,058-24,063 (1992).

Pulverer, B. J., J. M. Kyriakis, J. Avruch, E. Nikolakaki, and J. R. Woodgett: Phosphorylation of c-jun mediated by MAP kinases. Nature, 353:670-674 (1991).

Qiu, M.-S. and S. H. Green: NGF and EGF rapidly activate p $21^{\text {ras }}$ in $\mathrm{PC} 12$ cells by distinct, convergent pathways involving tyrosine phosphorylation. Neuron, 7:937946 (1991).

Qiu, M.-S. and S. H. Green: PC12 cell neuronal differentiation is associated with prolonged $\mathrm{p} 21^{\text {ras }}$ activity and consequent prolonged ERK activity. Neuron, 9:705717 (1992).

Rapp, U. R.: Role of Raf-1 serine/threonine protein kinase in growth factor signal transduction. Oncogene, 6:495500 (1991),

Rayter, S. I., M. Woodrow, S. C. Lucas, D. A. Cantrell, and J. Downward: p2 $1^{\text {ras }}$ mediates control of $I L-2$ gene promoter function in $\mathrm{T}$ cell activation. EMBO J., 11:4549-4556 (1992).

Reddy, E. P., R. K. Reynolds, E. Santos, and M. Barbacid: A point mutation is responsible for the acquisition of transforming properties by the T24 human bladder carcinoma oncogene. Nature, 300:149-152 (1982).

Reedijk, M., X. Liu, and T. Pawson: Interactions of phosphatidyl kinase, GTPase activating protein (GAP) and GAP-associated proteins with the colony-stimulating factor 1 receptor. Mol. Cell. Biol., 10:5601-5608 (1990).

Reedijk, M., X. Liu, P. van der Geer, K. Letwin, M. D. Waterfield, T. Hunter, and T. Pawson: Tyr 721 regulates specific binding of the CSF-1 receptor kinase insert to PI 3'-kinase SH2 domains: a model for SH2mediated receptor-target interactions. EMBO J., 11:1365-1372 (1992).

Reiss, Y., J. L. Goldstein, M. C. Seabra, P. J. Casey, and M. S. Brown: Inhibition of purified $\mathrm{p} 21^{\text {ras }}$ farnesyl: protein transferase by Cys-AAX tetrapeptides. Cell, 62:81-88 (1990).

Ren, R., B. J. Mayer, P. Cicchetti, and D. Baltimore: Identification of a ten-amino acid proline-rich $\mathrm{SH} 3$ binding site. Science, 259:1157-1161 (1993).

Rey, I., P. Soubigou, L. Debussche, C. David, A. Morgat, P. E. Bost, J. F. Mayaux, and B. Tocque: Antibodies to synthetic peptide from the residue 33 to 42 domain of c-Ha-ras p21 block reconstitution of the protein with different effectors. Mol. Cell. Biol, 9:3904-3910 (1989).

Ridley, A. J. and A. Hall: The small GTP-binding protein rho regulates the assembly of focal adhesions and actin stress fibers in response to growth factors. Cell, 70:389399 (1992). 
Ridley, A. J., H. F. Paterson, C. L. Johnston, D. Diekmann, and A. Hall: The small GTP-binding protein rac regulates growth factor-induced membrane ruffling. Cell, 70:401-410 (1992).

Ridley, A. J., H. F. Paterson, M. Noble, and H. Land: rasmediated cell cycle arrest is altered by nuclear oncogenes to induce Schwann cell transformation. EMBO $J ., 7: 1635-1645$ (1988).

Roberts, T. M.: A signal chain of events. Nature, 360:534 535 (1992).

Rodaway, A. R. F., M. J. E. Sternberg, and D. L. Bentley: Similarity in membrane proteins. Nature, 342:624 (1989).

Rogge, R. D., C. A. Karlovich, and U. Banerjee: Genetic dissection of a neurodevelopmental pathway: Son of sevenless functions downstream of the sevenless and EGF receptor tyrosine kinase. Cell, 64:39-48 (1991).

Ron, D., S. R. Tronick, S. A. Aaronson, and A. Eva: Molecular cloning and characterization of the human $d b l$ proto-oncogene: evidence that its overexpression is sufficient to transform $\mathrm{NIH} / 3 \mathrm{~T} 3$ cells. EMBO $J$., 7:2465-2473 (1988).

Rossomando, A., J. Wu, M. J. Weber, and T. W. Sturgill: The phorbol ester-dependent activator of the mitogen-activated protein kinase $42^{\text {mapk }}$ is a kinase with specificity for the threonine and tyrosine regulatory sites. Proc. Natl. Acad. Sci. U.S.A., 89:5221-5225 (1992).

Rottapel, R., M. Reedijk, D. E. Williams, S. D. Lyman, D. M. Anderson, T. Pawson, and A. Bernstein: The Steel/W transduction pathway: Kit autophosphorylation and its association with a unique subset of cytoplasmic signaling proteins is induced by the Steel factor. Mol. Cell. Biol., 11:3043-3051 (1991).

Rozakis-Adcock, M., J. McGlade, G. Mbamalu, G. Pelicci, R. Daly, W. Li, A. Batzer, S. Thomas, J. Brugge, P. G. Pelicci, J. Schlessinger, and T. Pawson: Association of the Shc and Grb2/Sem5 SH2-containing proteins is implicated in activation of the Ras pathway by tyrosine kinases. Nature, 360:689-692 (1992).

Rubin, G. M.: Development of the Drosophila retina: inductive events studied at single cell resolution, Cell, 57:519-520 (1989).

Rubin, G. M.: Signal transduction and the fate of the R7 photoreceptor in Drosophila. Trends Genet., 7:372377 (1991).

Ruderman, N. B., R. Kapeller, M. F. White, and L. C. Cantley: Activation of phosphatidylinositol 3-kinase by insulin. Proc. Natl. Acad. Sci. U.S.A., 87:14111415 (1990).

Russell, D. S., R. Gherzi, E. L. Johnson, C.-K. Chou, and O. M. Rosen: The protein-tyrosine kinase activity of the insulin receptor is necessary for insulin-mediated receptor down-regulation. J. Biol. Chem., 262:11,83311,840 (1987).

Sadowski, I., J. C. Stone, and T. Pawson: A non-catalytic domain conserved among cytoplasmic protein-tyrosine kinases modifies the kinase function and transforming activity of Fujinami sarcoma virus pl30gus.fps. $\mathrm{Mol}$. Cell. Biol., 6:4396-4408 (1986).
Satoh, T., M. Endo, M. Nakafuku, T. Akiyama, T. Yamamoto, and Y. Kaziro: Accumulation of $\mathrm{p} 21^{\text {ras }}$. GTP in response to stimulation with epidermal growth factor and oncogene products with tyrosine kinase activity. Proc. Natl.Acad. Sci. U.S,A., 87:7926-7929 (1990a).

Satoh, T., M. Endo, M. Nakafuku, S. Nakamura, and Y. Kaziro: Platelet-derived growth factor stimulates formation of active $\mathrm{p} 2 \mathrm{l}^{\text {ras }}$-GTP complex in Swiss mouse 3 T3 cells. Proc. Natl. Acad. Sci. U.S.A., 87:59935997 (1990b).

Satoh, T., M. Nakafuku, A. Miyajima, and Y. Kaziro: Involvement of ras p2l protein in signal-transduction pathways from interleukin 2 , interleukin 3 , and granulocyte/macrophage colony-stimulating factor, but not from interleukin 4. Proc. Natl. Acad. Sci. U.S.A., 88:3314-3318 (1991).

Satoh, T., S. Nakamura, and Y. Kaziro: Induction of neurite formation in PC12 cells by microinjection of protooncogenic $\mathrm{Ha}$-ras protein preincubated with guanine5'-O-(3-thiotriphosphate). Mol. Cell. Biol., 7:45534556 (1987).

Schafer, W. R., R. Kim, R. Sterne, J. Thomer, S.-H. Kim, and J. Rine: Genetic and pharmacological suppression of oncogenic mutations in $R A S$ genes of yeast and humans. Science, 245:379-385 (1989).

Schlessinger, J.: Signal transduction by allosteric receptor oligomerization. Trends Biochem. Sci., 13:443-447 (1988).

Schlichting, I., S. C. Almo, G. Rapp, K. Wilson, K. Petratos, A. Lentfer, A. Wittinghofer, W. Kabsch, E. F. Pai, G. A. Petsko, and R. S. Goody: Time-resolved X-ray crystallographic study of the conformational change in Ha-Ras p21 protein on GTP hydrolysis. Nature, 345:309-315 (1990).

Schönthal, A.: Requirement for fos gene expression in the transcriptional activation of collagenase by other oncogenes and phorbol esters. Cell, 54:325-334 (1988).

Schweighoffer, F., I. Barlat, M. Chevallier-Multon, and B. Tocque: Implication of GAP in ras-dependent transactivation of a polyoma enhancer sequence. Science, 256:82.5-827 (1992).

Scolnick, E. M., A. G. Papageorge, and T. Y. Shih: Guanine nucleotide-binding activity as an assay for src protein of rat-derived murine sarcoma viruses. Proc. Natl. Acad. Sci. U.S.A., 76:5355-5359 (1979).

Seidel-Dugan, C., B. E. Meyer, S. M. Thomas, and J. S. Brugge: Effects of SH2 and $\mathrm{SH} 3$ deletions on the functional activities of wild-type and transforming variants of c-Src. Mol. Cell. Biol., 12:1835-1845 (1992).

Serth, J., A. Lautwein, M. Frech, A. Wittinghofer, and A. Pingoud: The inhibition of the GTPase activating protein-Ha-ras interaction by acidic lipids is due to physical association of the C-terminal domain of the GTPase activating protein with micellar structures. $E M B O J$., 10:1325-1330 (1991).

Serth, J., W. Weber, M. Frech, A. Wittinghofer, and A. Pingoud: Binding of the H-ras GTPase activating pro- 
tein by the activated epidermal growth factor receptor leads to inhibition of the GTPase activity in vitro. Biochemistry, 31:6361-6365 (1992).

Serunian, L. A., M. T. Haber, T. Fukui, J. W. Kim, S. G. Rhee, J. M. Lowenstein, and L. C. Cantley: Polyphosphoinositides produced by phosphatidylinositol 3-kinase are poor substrates for phospholipases $\mathrm{C}$ from rat liver and bovine brain. J. Biol. Chem., 264:17,80917,815 (1989).

Seth, A., E. Alvarez, S. Gupta, and R. J. Davis: A phosphorylation site localed in the $\mathrm{NH}_{2}$-terminal domain of $c$-myc increases transactivation of gene expression. $J$. Biol. Chem., 266:23,521-23,524 (1991).

Settleman, J., C. F. Albright, L. C. Foster, and R. A. Weinberg: Association between GTPase activators for Rho and Ras families. Nature, 359:153-154 (1992a).

Settleman, J., V. Narasimhan, L. C. Foster, and R. A. Weinberg: Molecular cloning of cDNAs encoding the GAP-associated protein p190: implications for a signaling pathway from ras to the nucleus. Cell, 69:539549 (1992b).

Seuwen, K., A. Lagarde, and J. Pouysségur: Deregulation of hamster fibroblast proliferation by mutated ras oncogenes is not mediated by constitutive activation of phosphoinositide-specific phospholipase C. EMBO J, 7:161-168 (1988).

Severinsson, L., B. Ek, K. Mellström, L. Claesson-Welsh, and C.-H. Heldin: Deletion of the kinase insert sequence of the platelet-derived growth factor $\beta$-receptor affects kinase activity and signal transduction. Mol. Cell. Biol., 10:801-809 (1990).

Shen, S.-H,, L. Bastien, B. I. Posner, and P. Chrétien: A protein-tyrosine phosphatase with sequence similarity to the SH2 domain of the protein-tyrosine kinases. Nature, 352:736-739 (1991).

Shih, C. and R. A. Weinberg: Isolation of a transforming sequence from a human bladder sarcoma cell line. Cell, 29:161-169 (1982).

Shih, T. Y., A. G. Papageorge, P. E., Stokes, M. O. Weeks, and E. M. Scolnick: Guanine nucleotide-binding and autophosphorylating activities associated with the p21 src protein of Harvey murine sarcoma virus. $\mathrm{Na}$ ture, 287:686-691 (1980).

Shimizu, K., M. Goldfarb, M. Perucho, and M. Wigler: Isolation and preliminary characterization of the transforming gene of a human neuroblastoma cell line. Proc. Natl. Acad. Sci. U.S.A., 80:383-387 (1983).

Shou, C., C. L. Farnsworth, B. G. Neel, and L. A. Feig: Molecular cloning of cDNAs encoding a guaninereleasing factor for ras p21. Nature, 358:351-354 (1992).

Siegel, J. N., R. D. Klausner, U. R. Rapp, and L. E. Samelson: $T$ cell antigen receptor engagement stimulates $c$-ras phosphorylation and induces c-raf-associated kinase activity via a protein kinase $C$-dependent pathway. $J$. Biol. Chem., 265:18,472-18,480 (1990).

Sigal, I. S., J. B. Gibbs, J. S. D'Alonzo, and E. M. Scolnick: Identification of effector residues and a neutralizing epitope of Ha-ras-encoded p21. Proc. Natl. Acad. Sci. U.S.A., 83:4725-4729 (1986a).

Sigal, I. S., J. B. Gibbs, J. S. D'Alonzo, G. L. Temeles, B. S. Wolanski, S. H. Socher, and E. M. Scolnick: Mutant ras-encoded proteins with altered nucleotide binding exert dominant biological effects. Proc. Natl. Acad. Sci. U.S.A., 83:952-956 (1986b),

Simon, M. A., D. D. L. Bowtell, G. S. Dodson, T. R. Laverty, and G. M. Rubin: Ras 1 and a putative guanine nucleotide exchange factor perform crucial steps in signaling by the sevenless protein tyrosine kinase. Cell, 67:701-716 (1991).

Sjölander, A., K. Yamamoto, B. E. Huber, and E. G. Lapetina: Association of $\mathrm{p} 21^{\text {ras }}$ with phosphatidylinositol 3-kinase. Proc. Natl. Acad. Sci. U.S.A., 88:7908-7912 (1991).

Skolnik, E. Y., B. Margolis, M. Mohammadi, E. Lowenstein, R. Fischer, A. Drepps, A. Ulirich, and J. Schlessinger: Cloning of PI3 kinase-associated p85 utilizing a novel method for expression/cloning of target proteins for receptor tyrosine kinases. Cell, 65:83-90 (1991).

Smeal, T., B. Binétruy, D. A. Mercola, M. Birrer, and M. Karin: Oncogenic and transcriptional cooperation with Ha-Ras requires phosphorylation of c-Jun on serines 63 and 73. Nature, 354:494-496 (1991).

Smeal, T., B. Binétruy, D. A. Mercola, A. Grover-Bardwick, G. Heidecker, U. R. Rapp, and M. Karin: Oncoprotein-mediated signalling cascade stimulates c-Jun activity by phosphorylation of serines 63 and 73. $\mathrm{Mol}$. Cell. Biol., 12:3507-3513 (1992).

Smith, M. R., S. J. DeGudicibus, and D. W. Stacey: Requirement for c-ras proteins during viral oncogene transformation. Nature, 320:540-543 (1986).

Smith, M. R., Y.-L. Liu, H. Kim, S. G. Rhee, and H.F. Kung: Inhibition of serum- and ras-stimulated DNA synthesis by antibodies to phospholipase C. Science, 247:1074-1077 (1990).

Sommercorn, J., J. A. Mulligan, F. J. Lozeman, and E. G. Krebs: Activation of casein kinase II in response to insulin and to epidermal growth factor. Proc. Natl. Acad. Sci, U.S.A., 84:8834-8838 (1987).

Sprenger, F., L. M. Stevens, and C. Nüsslein-Volhard: The Drosophila gene torso encodes a putative receptor tyrosine kinase. Nature, 338:478-483 (1989).

St. Johnston, D. and C. Nüsslein-Volhard: The origin of pattern and polarity in the Drosophila embryo. Cell, 68:201-219 (1992).

Stacey, D. W., L. A. Feig, and G. B. Gibbs: Dominant inhibitory ras mutants selectively inhibit the activity of either cellular or oncogenic ras. Mol. Cell. Biol., 11:4053-4064 (1991).

Stacey, D. W. and H.-F. Kung: Transformation of NIH 3T3 cells by microinjection of Ha-ras p21 protein. Nature, 310:508-511 (1984).

Stacey, D. W., T. Watson, H.-F. Kung, and T. Curran: Microinjection of transforming ras protein induces $\mathrm{c}-\mathrm{fos}$ expression. Mol. Cell. Biol., 7:523-527 (1987).

Stanton, V. P., D. W. Nichols, A. P. Laudano, and G. M. Cooper: Definition of the human raf amino-terminal 
regulatory region by deletion mutagenesis. $\mathrm{Mol}$. Cell. Biol., 9:639-647 (1989).

Sternberg, P. W. and H. R. Horvitz: Signal transduction during $C$. elegans vulval induction. Trends Genet., 7:366-371 (1991).

Stevenson, B. J., N. Rhodes, B. Errede, and G. F. Sprague, $\mathrm{J}_{\mathrm{r}}$ : Constitutive mutants of the protein kinase STE 11 activate the yeast pheromone response pathway in the absence of the G protein. Genes Dev., 6:1293-1304 (1992).

Stokoe, D., D. G. Campbell, S. Nakielny, H. Hidaka, S. J. Leevers, C. J. Marshall, and P. Cohen: MAPKAP kinase-2: a novel protein kinase activated by mitogenactivated protein kinase. EMBO J., 11:3985-3994 (1992).

Strulovici, B., S. Daniel-Issakani, G. Baxter, J. Knopf, L. Sultzman, H. Cherwinski, J. Nestor, D. R. Webb, and J. Ransom: Distinct mechanisms of regulation of protein kinase $\mathrm{C} \varepsilon$ by hormones and phorbol diesters. $J$. Biol. Chem., 266:168-173 (1991).

Sturgill, T. W., L. B. Ray, E. Erikson, and J. L. Maller: Insulin-stimulated MAP-2 kinase phosphorylates and activates ribosomal protein S6 kinase II. Nature, 334:715-718 (1988).

Sugimoto, Y., M. Whitman, L. C. Cantley, and R. L. Erikson: Evidence that Rous sarcoma virus transforming gene product phosphorylates phosphatidylinositol and diacylglycerol. Proc. Natl. Acad. Sci. U.S.A., 81:21172121 (1984).

Sultzman, L., C. Ellis, L.-H. Lin, T. Pawson, and J. Knopf: Platelet-derived growth factor increases the in vivo activity of phospholipase $\mathrm{C}-\gamma_{1}$ and phospholipase $\mathrm{C}-\gamma_{2}$. Mol. Cell. Biol., 11:2018-2025 (1991).

Sun, X. J., P. Rothenberg, C. R. Kahn, J. M. Backer, E. Araki, P. A. Wilden, D. A. Cahill, B. J. Goldstein, and M. F. White: Structure of the insulin receptor substrate IRS-1 defines a unique signal transduction protein. Nature, 352:73-77 (1991).

Sweet, R. W., S. Yokoyama, T. Kamata, J. R. Feramisco, M. Rosenberg, and $\mathrm{M}$. Gross: The product of ras is a GTPase and the T24 oncogenic mutant is deficient in this activity. Nature, 311:273-275 (1984).

Szeberényi, J., H. Cai, and G. M. Cooper: Effect of a dominant inhibitory Ha-ras mutation on neuronal differentiation of PC12 cells. Mol. Cell. Biol, 10:53245332 (1990).

Tabin, C. J., S. M. Bradley, C. I. Bargmann, R. A. Weinberg, A. G. Papageorge, E. M. Scolnick, R. Dhar, D. R. Lowy, and E. H. Chang: Mechanism of activation of a human oncogene. Nature, 300:143-149 (1982).

Tanaka, K., K. Matsumoto, and A. Toh-e: IRAI, an inhibitory regulator of the RAS-cyclic AMP pathway in Saccharomyces cerevisiae. Mol. Cell. Biol., 9:757768 (1989).

Tanaka, K., M. Nakafuku, T. Satoh, M. S. Marshall, J. B, Gibbs, K. Matsumoto, Y. Kaziro, and A. Toh-e: $S$. Cerevisiae genes IRAI and IRA2 encode proteins that may be functionally equivalent to mammalian ras GTPase activating protein. Cell, 60:803-807 (1990).
Thomas, S. M., M. DeMarco, G. D'Arcangelo, S. Halegoua, and J. S. Brugge: Ras is essential for nerve growth factor- and phorbol ester-induced tyrosine phosphorylation of MAP kinases. Cell, 68:1031-1040 (1992).

Toda, T., M. Shimanuki, and M. Yanagida: Fission yeast genes that confer resistance to staurosporine encode an AP-1-like transcription factor and a protein kianse related to the mammalian ERK1/MAP2 and budding yeast FUS3 and KSSI kinases. Genes Dev., 5:60-73 (1991).

Toda, T., I. Uno, T. Ishikawa, S. Powers, T. Kataoka, D. Broek, S. Camerom, J. Broach, K. Matsumoto, and M. Wigler: In yeast, RAS proteins are controlling elements of adenylate cyclase. Cell, 40:27-36 (1985).

Torti, M., K. B. Marti, D. Altschuler, K. Yamamoto, and E. G. Lapetina: Erythropoietin induces $\mathrm{p} 21$ ras activation and p120GAP tyrosine phosphorylation in human erythroleukemia cells. I. Biol. Chem., 267:82938298 (1992).

Trahey, M. and F. McCormick: A cytoplasmic protein stimulates normal N-ras p21 GTPase, but does not affect oncogenic mutants. Science, 238:542-545 (1987).

Trahey, M., G. Wong, R. Halenbeck, B. Rubinfeld, G. A. Martin, M. Ladner, C. M. Long, W. J. Crosier, K. Watt, K. Koths, and F. McCormick: Molecular cloning of two types of GAP complementary DNA from human placenta. Science, 242:1697-1700 (1988).

Traverse, S., N. Gomez, H. Paterson, C. J. Marshall, and P. Cohen: Sustained activation of the mitogen-activated protein (MAP) kinase cascade may be required for differentiation of PC12 cells - comparison of the effects of the nerve growth factor and the epidermal growth factor. Biochem. J., 288:351-357 (1992).

Troppmair, J., J. T. Bruder, H. App, H. Cai, L. Liptak, J. Szeberényi, G. M. Cooper, and U. R. Rapp: Ras controls coupling of growth factor receptors and protein kinase $\mathrm{C}$ in the membrane to Raf-1 and B-Raf protein serine kinases in the cytosol. Oncogene, 7:1867-1873 (1992).

Tsai, M.-H., M. Roudebush, S. Dobrowolski, C.-L. Yu, J. B. Gibbs, and D. W. Stacey: Ras GTPase-activating protein physically associates with mitogenically active phospholipids. Mol. Cell. Biol., 11:2785-2793 (1991).

Tsai, M.-H., C.-L. Yu, and D. W. Stacey: A cytoplasmic protein inhibits the GTPase activity of $\mathrm{H}$-ras in a phospholipid dependent manner. Science, 250:982985 (1990).

Tsai, M.-H., C.-L. Yu, F.-S. Wei, and D. W. Stacey: The effect of GTPase activating protein upon ras is inhibited by mitogenically responsive lipids. Science, 243:522-526 (1989).

Turner, B., U. R. Rapp, H. App, M. Greene, K. Dobashi, and J. Reed: Interleukin 2 induces tyrosine phosphorylation and activation of p72-74 Raf-1 kinase in a T-cell line. Proc. Natl. Acad. Sci. U.S.A., 88:1227-1231. (1991).

Ullich, A. and J. Schlessinger: Signal transduction by receptors with tyrosine kinase activity. Cell, 61:203-212 (1990). 
van Corven, E. J., A. Groenink, K. Jalink, T. Eichholtz, and W. H. Moolenaar: Lysophosphatidate-induced cell proliferation: identification and dissection of signalling pathways mediated by G proteins. Cell, 59:45-54 (1989).

van Corven, E. J., P. L. Hordijk, R. H. Medema, J. L. Bos, and W. H. Moolenaar: Pertussis toxin-sensitive activation of $\mathrm{p} 2 \mathrm{i}^{\mathrm{ras}}$ by $\mathrm{G}$ protein-coupled receptor agonists, Proc. Natl. Acad. Sci. U.S.A., 90:1257-1261 (1993).

Varticovski, L., B. Druker, D. Morrison, L. Cantley, and T. Roberts: The colony stimulating factor-1 receptor associates with and activates phosphatidylinositol-3 kinase. Nature, 342:699-702 (1989).

Viskochil, D., A. M. Buchberg, G. Xu, R. M. Cawthon, J. Stevens, R. K. Wolff, M. Culver, J. C. Carey, N. G. Copeland, N. A. Jenkins, R. White, and P. O'Connell: Deletions and a translocation interrupt a cloned gene at the neurofibromatosis type 1 locus. Cell, 62:187$192(1990)$.

Vogel, U. S., R. A. F. Dixon, M. D. Schaber, R. E. Diehl, M. S. Marshall, E. M. Scolnick, I. S. Sigal, and J. B. Gibbs: Cloning of bovine GAP and its interaction with oncogenic ras p21. Nature, 335:90-93 (1988).

Vogt, P. K. and T. J. Bos: Jun: oncogene and transcription factor. Cancer Res., 55:1-35 (1990).

Wallace, M. R., D. A. Marchuk, L. B. Andersen, R. Letcher, H. M. Odeh, A. M. Saulino, J. W. Fountain, A. Brereton, J. Nicholson, A. L. Mitchell, B. H. Brownstein, and F. S. Collins: Type 1 neurofibromatosis gene: identification of a large transcript disrupted in three NF1 patients. Science, 249:181-186 (1990).

Wang, Y., H.-P. Xu, M. Riggs, L. Rodgers, and M. Wigler: byr 2 , a Schizosaccharomyces pombe gene encoding a protein kinase capable of partial suppression of the rasl mutant phenotype. Mol. Cell. Biol., 11:35543563 (1991).

Warden, C. H. and M. Friedkin: Regulation of choline kinase activity and phosphatidylcholine biosynthesis by mitogenic growth factors in 3T3 fibroblasts. J. Biol. Chem., 260:6006-6011 (1985).

Wasylyk, B., C. Wasylyk, P. Flores, A. Begue, D. Leprince, and D. Stehelin: The $c$-ets proto-oncogenes encode transcription factors that cooperate with c-Fos and c-Jun for transcriptional activation. Nature, 346:191193 (1990).

Wasylyk, C., P. Flores, A. Gutman, and B. Wasylyk: PEA3 is a nuclear target for transcription activation by nonnuclear oncogenes. EMBO J,, 8:3371-3378 (1989).

Watanabe, T., Y. Ono, Y. Taniyama, K. Hazama, K. Igarashi, K. Ogita, U. Kikkawa, and Y. Nishizuka: Cell division arrest induced by phorbol ester in $\mathrm{CHO}$ cells overexpressing protein kinase $\mathrm{C}-\gamma$ subspecies. Proc. Natl. Acad. Sci. U.S.A., 89:10,159-10,163 (1992).

Ways, D. K., P. P. Cook, C. Webster, and P. J. Parker: Effect

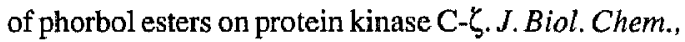
267:4799-4805 (1992).

Weissman, B. E. and S. A. Aaronson: BALB and Kirsten murine sarcoma viruses alter growth and differentiation of EGF-dependent BALB/c mouse epidermal keratinocyte lines. Cell, 32:599-606 (1983).
West, M., H. Kung, and T. Kamata: A novel membrane factor stimulates guanine nucleotide exchange reaction of ras proteins. FEBS Lett., 259:245-248 (1990).

Westermark, B., A. Siegbahn, C.-H. Heldin, and L. ClaessonWelsh: B-type receptor for platelet-derived growth factor mediates a chemotactic response by means of ligand-induced activation of the receptor protein-tyrosine kinase. Proc. Nall. Acad. Sci. U.S.A., 87:128132 (1990).

Whitman, M., C. P. Downes, M. Keeler, T. Keller, and L. Cantley: Type 1 phosphatidylinositol kinase makes a novel inositol phospholipid, phosphatidylinositol-3phosphate. Nature, 332:644-646 (1988).

Whitman, M., D. R. Kaplan, B. Schaffhausen, L. Cantley, and T. M. Roberts: Association of phosphatidylinositol kinase activity with polyoma middle-T competent for transformation. Nature, 315:239-242 (1985).

William, F., F. Wagner, M. Karin, and A. S. Kraft: Multiple doses of diacylglycerol and calcium ionophore are necessary to activate AP-1 enhancer activity and induce markers of macrophage differentiation. J. Biol. Chem,, 265:18,166-18,171 (1990).

Williams, L. T.: Signal transduction by the platelet-derived growth factor receptor. Science, 243:1564-1570 (1989).

Williams, N. G., T. M. Roberts, and P. Li: Both $\mathrm{p} 21^{\text {ras }}$ and pp60 ${ }^{\text {-ssc }}$ are required, but neither alone is sufficient, to activate the Raf-1 kinase. Proc. Natl.Acad.Sci.U.S.A., 89:2922-2926 (1992).

Willumsen, B. M., A. Christensen, H. L. Hubbert, A. G. Papageorge, and D. R. Lowy: The p21 ras c-terminus is required for transformation and membrane association. Nature, 310:583-586 (1984).

Willumsen, B. M., A. G. Papageorge, H. Kung, E. Bekesi, T. Robins, M. Johnson, W. C. Vass, and D. R. Lowy: Mutational analysis of a ras catalytic domain. Mol. Cell. Biol., 6:2646-2654 (1986).

Wolfman, A. and I. G. Macara: Elevated levels of diacylglycerol and decreased phorbol ester sensitivity in rastransformed fibroblasts. Nature, 325:359-361 (1987).

Wolfman, A. and I. G. Macara: A cytosolic protein catalyzes the release of GDP from p21 ras. Science, 248:67-69 (1990).

Wong, G., O. Müller, R. Clark, L. Conroy, M. F. Moran, P. Polakis, and F. McCormick: Molecular cloning and nucleic acid binding properties of the GAP-associated tyrosine phosphoprotein p62. Cell, 69:551-558 (1992).

Wood, K. W., C. Sarnecki, T. M. Roberts, and J. Blenis: ras mediates nerve growth factor receptor modulation of three signal-transducing protein kinases: MAP kinase, Raf-1 and RSK. Cell, 68:1041-1050 (1992).

Woodgett, J. R.: A common denominator linking glycogen metabolism, nuclear oncogenes and development. Trends Biochem. Sci., 16:177-181 (1991).

Xu, G., B. Lin, K. Tanaka, D. Dunn, D. Wood, R. Gesteland, R. White, R. Weiss, and F. Tamaonoi: The catalytic domain of the neurofibromatosis type 1 gene product stimulates ras GTPase and complements ira mutants of $S$. cerevisiae. Cell, 63:835-841 (1990a). 
Xu, G., P. O'Connell, D, Viskochil, R. Cawthon, M. Robertson, M. Culver, D. Dunn, J. Stevens, R. Gesteland, R. White, and R. Weiss: The neurofibromatosis type 1 gene encodes a protein related to GAP. Cell, 62:599-608 (1990b).

Yamaguchi-Iwai, Y., M. Satake, Y. Murakami, M. Sakai, M. Muramatsu, and $Y$. Ito: Differentiation of F9 embryonal carcinoma cells induced by the $c-j u n$ and activated c-Ha-ras oncogenes. Proc. Natl. Acad. Sci. U.S.A., 87:8670-8674 (1990).

Yarden, Y. and A. Ullrich: Growth factor receptor tyrosine kinases. Annu. Rev. Biochem., 57:443-478 (1988).

Yatani, A., K. Okabe, P. Polakis, R. Halenbeck, F. McCormick, and A. M. Brown: Ras $\mathrm{p} 21$ and GAP inhibit coupling of muscarinic receptors to atrial $\mathrm{K}^{+}$ channels. Cell, 61:769-776 (1990).

Yu, C.-L., M.-H. Tsai, and D. W. Stacey: Cellular ras activity and phospholipid metabolism. Cell, 52:63-71 (1988).
Yu, C.-L., M. H. Tsai, and D. W. Stacey: Serum stimulation of NIH 3T3 cells induces the production of lipids able to inhibit GTPase-activating protein activity. Mol. Cell. Biol., 10:6683-6689 (1990).

Yu, J.-C., M. A. Heideran, J. H. Pierce, J. S. Gutkind, D. Lombardi, M. Ruggiero, and S. A. Aaronson: Tyrosine mutations within the $\alpha$ platelet-derived growth factor receptor kinase insert domain abrogate receptorassociated phosphatidylinositol-3 kinase activity without affecting mitogenic or chemotactic signal transduction. Mol. Cell. Biol., 11:3780-3785 (1991).

Zhang, K., J. E. DeClue, W. C. Vass, A. G. Papageorge, F. McCormick, and D. R. Lowy: Suppression of crras transformation by GTPase-activating protein. Nature, 346:754-756 (1990).

Zhang, K., A. G. Papageorge, and D. R. Lowy: Mechanistic aspects of signaling through ras in NIH $3 \mathrm{~T} 3$ cells. Science, 257:671-674 (1992). 